\title{
Long term complications following elbow-based autogenous haemodialysis access
}

Citation for published version (APA):

Vaes, R. H. D. (2016). Long term complications following elbow-based autogenous haemodialysis access: studies on high flow and hand ischemia. [Doctoral Thesis, Maastricht University]. Maastricht University. https://doi.org/10.26481/dis.20160420rv

Document status and date:

Published: 01/01/2016

DOI:

10.26481/dis.20160420rv

Document Version:

Publisher's PDF, also known as Version of record

\section{Please check the document version of this publication:}

- A submitted manuscript is the version of the article upon submission and before peer-review. There can be important differences between the submitted version and the official published version of record. People interested in the research are advised to contact the author for the final version of the publication, or visit the DOI to the publisher's website.

- The final author version and the galley proof are versions of the publication after peer review.

- The final published version features the final layout of the paper including the volume, issue and page numbers.

Link to publication

\footnotetext{
General rights rights.

- You may freely distribute the URL identifying the publication in the public portal. please follow below link for the End User Agreement:

www.umlib.nl/taverne-license

Take down policy

If you believe that this document breaches copyright please contact us at:

repository@maastrichtuniversity.nl

providing details and we will investigate your claim.
}

Copyright and moral rights for the publications made accessible in the public portal are retained by the authors and/or other copyright owners and it is a condition of accessing publications that users recognise and abide by the legal requirements associated with these

- Users may download and print one copy of any publication from the public portal for the purpose of private study or research.

- You may not further distribute the material or use it for any profit-making activity or commercial gain

If the publication is distributed under the terms of Article $25 \mathrm{fa}$ of the Dutch Copyright Act, indicated by the "Taverne" license above, 


\title{
Long term complications following elbow-based autogenous haemodialysis access: studies on high flow and hand ischemia
}

\author{
Roel Henk Dorine Vaes
}


Publication of this thesis was financially sponsored by:

Máxima Medisch Centrum - Catharina ziekenhuis - Maastricht Universitair Medisch Centrum -

Stichting Fonds voor het Hart - Econtent en Zo - Zelma Consulting - van den Bogaert en partners - ERBE -

Krijnen Medical - Chipsoft - Rabobank - Transonic - Vascutek - W.L. Gore \& associates - ABN AMRO
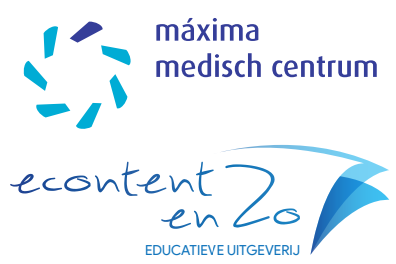

VDB\&P

VAN DEN BOGAERT EN PARTNERS

FINANCIFEL. ADVIESBUREAU VOOR MEDICI
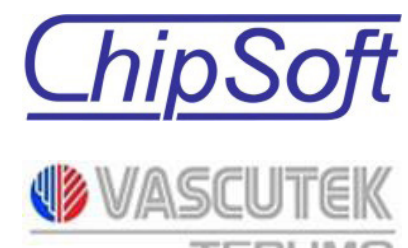
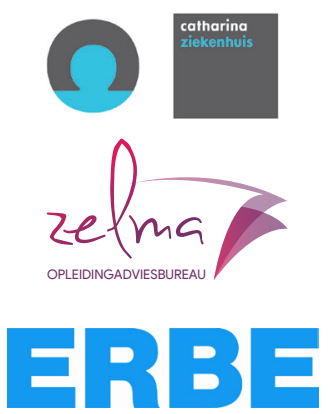

tronș

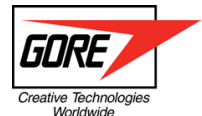

Financial support by the Dutch Kidney Foundation for the publication of this thesis is gratefully acknowledged. Financial support by the Dutch Heart Foundation for the publication of this thesis is gratefully acknowledged.

\section{Colofon}

Author:

Cover design:

Lay-out:

Printing:

ISBN:
Roel Henk Dorine Vaes

Simone van den Boom, www.simi.nl

Marlies van Hoof, www.madebymarlies.nl

Supreme Graphic Solutions

978-94-92272-OI-O

(C) R.H.D Vaes, 2016

All rights reserved. No part of this publication may be reproduced or transmitted in any form by any means, without permission of the author. 


\title{
Long term complications following elbow-based autogenous haemodialysis access: studies on high flow and hand ischemia
}

\author{
PROEFSCHRIFT
}

ter verkrijging van de graad van doctor

aan de Universiteit Maastricht,

op gezag van Rector Magnificus, prof. dr. L.L.G. Soete

volgens het besluit van het College van Decanen,

in het openbaar te verdedigen

op woensdag 20 april 2016 om I6.0o uur

door

Roel Henk Dorine Vaes

geboren te Nijmegen op 4 juli I986 


\section{Promotor}

Prof. dr. J.A.W. Teijink

\section{Copromotoren}

Dr. M.R.M. Scheltinga (Máxima Medisch Centrum, Veldhoven)

Dr. J.H.M. Tordoir

\section{Beoordelingscommissie}

Prof. dr. J.P. Kooman (voorzitter)

Prof. dr. M.W. de Haan

Dr. J.I. Rotmans (Leids Universitair Medisch Centrum)

Prof. dr. C.J.A.M. Zeebregts (Universitair Medisch Centrum Groningen) 


\section{Table of contents}

Chapter I Introduction, aims and outline of thesis 7

Chapter 2 Blood flow dynamics in patients with haemodialysis access induced 2I hand ischaemia

Journal of vascular surgery 20I3;58(2):446-45I

Chapter 3 Side brand ligation for haemodialysis access induced distal ischaemia

European Journal of Vascular and Endovascular Surgery

$2012 ; 44(4): 45^{2-}-456$

Chapter 4 Venous side branch ligation as a first step treatment for haemodialysis access induced hand ischaemia: effects on access flow volume and digital perfusion

European Journal of Vascular and Endovascular Surgery 2015;50(6):810-8I4

Chapter 5 Resolution of severe haemodialysis access induced distal ischaemia using a femoro-axillary bypass graft

European Journal of Vascular and Endovascular Surgery Extra 20Ir;

22: e6r-e63

Chapter 6 Systemic effects of a high-flow arteriovenous fistula for hemodialysis Journal of Vascular Access 20I4;I5(3):I63-I68

Chapter 7 High flow access and cardiac failure in haemodialysis patients. An overview on pathophysiology, diagnostics and treatment options.

Submitted

Chapter 8 Effectiveness of surgical banding for high flow in brachial arterybased hemodialysis vascular access

Journal of Vascular Surgery 2015; 6I(3): 762-766

Chapter 9 One-year efficacy of the RUDI technique for flow reduction in high-

flow autologous brachial artery-based hemodialysis vascular access Journal of Vascular Access 2015; I6(9):96-IoI

Chapter ro Summarizing discussion, conclusions and future perspectives

Chapter 11 Valorisation

Chapter 12 Samenvatting (Dutch summary)

Dankwoord

Curriculum Vitae 



\section{CHAPTER - I}

\section{Introduction,}

\section{aims and outline of thesis}




\section{Introduction}

\section{An optimal vascular access for haemodialysis treatment}

Most patients with end stage renal disease (ERSD) choose to undergo intermittent haemodialysis (HD) rather than peritoneal dialysis (PD) (I). Although central venous catheters (CVC) or arteriovenous grafts (AVG) may provide an excellent mode for HD treatment, an arterialized superficial arm vein after an arteriovenous anastomosis (arteriovenous fistula, AVF) is the primary choice for vascular access (VA) creation. When adequately matured, an autologous AVF may function for a long term period with a low complication rate (2).

Since its introduction in I966, the forearm radiocephalic arteriovenous fistula (RC-AVF) as proposed by Brescia, Cimino and Appel has been the method of choice for VA and recommended by Dutch and international guidelines $(3,4)$. As a second choice autologous VA, the construction of an elbow or upper arm AVF by anastomosing an elbow vein or basilic vein to the brachial artery (brachiocephalic and brachiobasilic arteriovenous fistula, BC /BB-AVF) is advocated. The community of vascular surgeon's thoughts on the preferred technique have not changed over the years. However, patient demographics did change considerably. HD populations are currently older with multiple comorbidities such as arteriosclerosis, diabetes and cardiac disease. Due to these changing population characteristics, specific demands and modifications of the standard surgical VA practice in contemporary and future HD patients are necessary.

\section{Changes in populations requiring haemodialysis}

In the year of 20I4, 1969 Dutch patients developed ESRD requiring renal replacement therapy (RRT) (I). Currently (2015), a total of 5588 patients receive intermittent HD in the Netherlands (I). In 20I4, more than half of these patients (55\%) were older than 65 years, compared to $44 \%$ in the year of 2000 . It is anticipated that increasing numbers of patients with diabetes, hypertension, arteriosclerosis and other cardiovascular comorbidities will develop ERSD and require HD (4). At present, hypertension and diabetes are the two most common causes for the development of ESRD in the USA (5). As a consequence of these multimorbid patient populations with usually inadequate forearm vessels, a functional RC-AVF as first choice VA will be increasingly difficult to perform $(6,7)$.

\section{Contemporary shift from a primary $\mathrm{RC}-\mathrm{AVF}$ to a primary $\mathrm{BC}-\mathrm{AVF}$}

The choice of preferred type of AVF is thus greatly influenced by a changing patient population (8). Vascular surgeons are nowadays forced to create a BC-AVF rather than a RC-AVF in increasing number of patients (9). This paradigm shift has advantages as well as disadvantages. 
A BC-AVF probably stands a higher chance of successful maturation. The downside of a higher chance on a well-functioning AVF however is an increased risk on the development of long term complications such as haemodialysis access-induced distal ischaemia (HAIDI) and high flow (high flow access, HFA) with or without cardiac failure (9-I2).

\section{HAIDI, a long term consequence of a BC-AVF}

HAIDI tends to develop in about $5 \%$ of patients with a RC-AVF and up to $9 \%$ in patients with a brachial artery based AVF (I3, I4). Symptoms usually occur within 2 years after AVF creation. Almost half of the HAIDI patients also suffer from diabetes ( 13 ). In essence, HAIDI is caused by a decreased perfusion pressure in the hand (I2). Patients complain of pain or coldness, cramps, paraesthesia or loss of strength (II). Symptoms may be continuous (at rest, at night), or just apparent during HD or while using the hand (15). At physical examination, signs of diminished hand perfusion such as a pale or cyanotic colour, absent or diminished arterial pulsations or diminished capillary refill may be found. Symptoms and signs may improve after manually compressing the AVF's venous outflow tract. Returning of arterial pulsations following such a compression test predicts outcome after AVF revision (II). In severe HAIDI, rest pain and ulcerations or necrotic lesions may be present (I4).

\section{Pathophysiology of HAIDI}

Several factors contribute to the pathophysiology of HAIDI. Although steal (a reversal of arterial blood flow in arteries distal to the VA anastomosis) is often thought to contribute to hand ischaemia, steal is considered a physiological phenomenon (I6-I9). Conversely, HAIDI is probably due to generalized arterial stiffness and atherosclerosis in HD patients harbouring a VA (I4). Diminished arterial remodelling due to uraemia, diabetes, increased age and atherosclerosis limits the patient's ability to properly adapt to changing local vascular hemodynamics after VA creation $(6,20-22)$. This arterial stiffness and generalized atherosclerosis induce a gradient pressure drop between heart and hand (23). By creating a VA, an additional pressure drop is induced due to turbulent flow around the anastomosis (23). Ongoing peripheral atherosclerosis further decreases perfusion pressure. If a stenosis somewhere in the inflow arterial tree becomes hemodynamically significant, distal blood pressure is even lower (I4). Open venous sidebranches close to the AVF anastomosis are found to contribute to this pressure loss (I4). HAIDI may become symptomatic once digital pressures drops below the ischemic threshold level of $40 \mathrm{~mm} \mathrm{Hg}$ (digital pressure), or if the digital brachial index is <0.6 (I4). 


\section{Treatment of HAIDI}

Treatment of HAIDI should be initiated when patients consistently complain of typical symptoms combined with a decreased finger pressure. Following early treatment, symptoms are likely to disappear and detoriation may be prevented. However, a thorough understanding of the pathophysiology of hand ischemia is necessary to decide on the appropriate treatment. Diagnosis should focus on the identification of the source of blood pressure loss. Angiography or duplex may reveal an arterial inflow stenosis that possibly contributes to this pressure loss. When hemodynamically significant, this lesion requires endovascular treatment by means of a percutaneous transluminal angioplasty (PTA). If unresponsive, one should initially focus on identifying the AVF's venous sides branches (SB). Ligation of these SB's may attenuate pressure loss and diminish symptoms of HAIDI. If again insufficient, surgical options focus on reducing the pressure drop around the anastomosis by diminishing total access flow. Surely, drops in access flow resulted in immediate increases in finger pressures ( 15 ). Decisions on type of surgical technique are dictated by preference of the vascular surgeon as comparative studies or randomized controlled trials are lacking. A patient with HAIDI and a low access flow (300-1000 $\mathrm{ml} / \mathrm{min}$ ) may undergo a distal revascularization and interval ligation procedure (DRIL), or a proximalization of the arterial inflow (PAI) (I4, 24-29). The DRIL procedure consists of a venous or PTFE bypass that connects an inflow artery proximal from the AVF anastomosis to a distal outflow artery. The artery between AVF anastomosis and the bypass' distal landing is ligated (figure I) (24). Hand perfusion is claimed to improve by bypassing the AVF anastomosis and by prohibiting reversal of arterial flow in the outflow artery.

In a PAI procedure, the original AVF is disconnected, and the venous outflow tract is revascularized using an interponate that is connected to a more proximal portion of the arterial inflow tract (such as the subclavian/axillar artery, figure $2 \mathrm{a}-\mathrm{b}$ ). The arterial pressure drop around this novel anastomosis is usually limited $(28,29)$.

If the access flow is between I0o0-2000 $\mathrm{ml} / \mathrm{min}$, HAIDI patients are advised to either undergo banding of the venous outflow tract or a revision using distal inflow (RUDI, figure $3 \mathrm{a}-\mathrm{c}$ ) under access flow guidance (IO, I4, 30). Several studies have shown that banding effectively attenuates ischemic symptoms although long-term patency rates are unknown (Io, 30). The effectiveness of a RUDI for HAIDI has not been studied.

Surgical AVF ligation should only be performed as a last resort when all other treatment options have failed. 


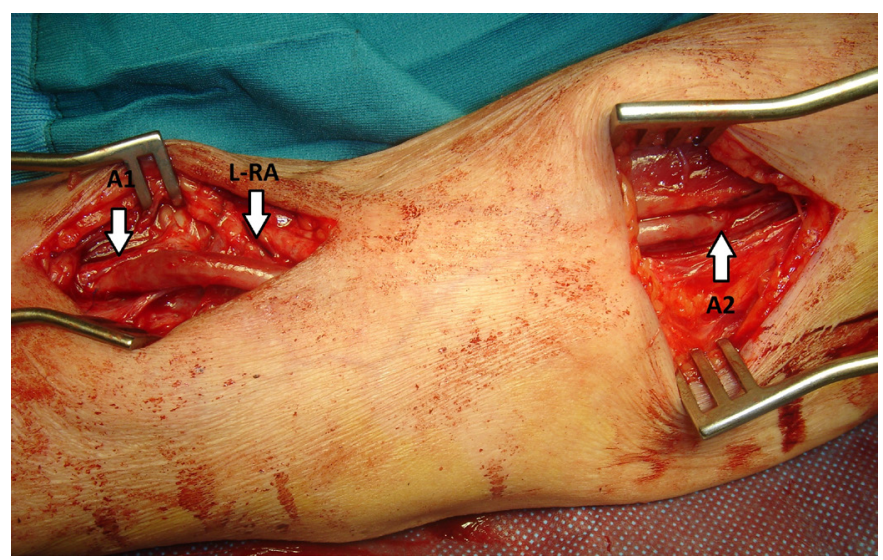

Figure 1. DRIL procedure. A part of the great saphenous vein is used to create a bypass from the brachial artery (A2) proximal from the arteriovenous anastomosis to the radial artery (A1). The proximal radial artery is ligated (L-RA).

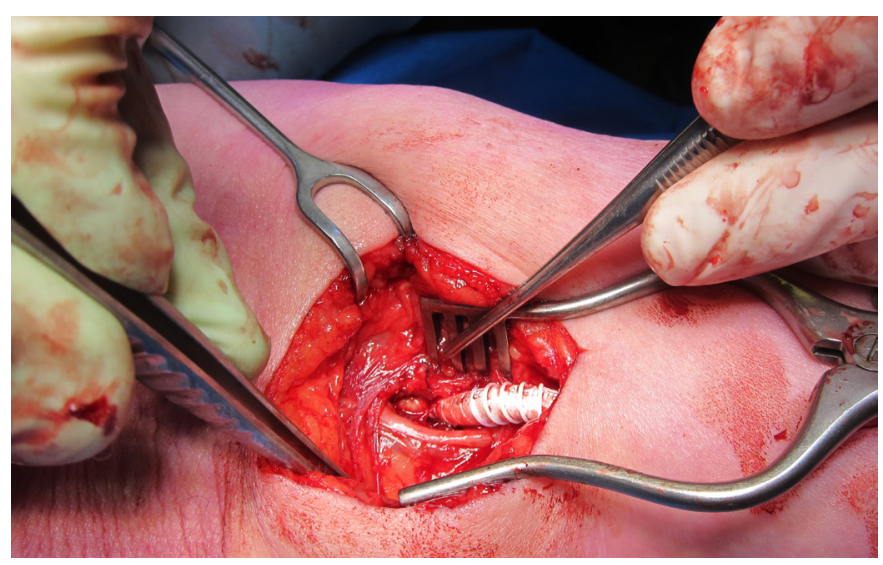

Figure 2a. PAI procedure.

The arterial inflow of the BC$\mathrm{AVF}$ is proximalized using an interponate that is anastomosed to the axillary artery.

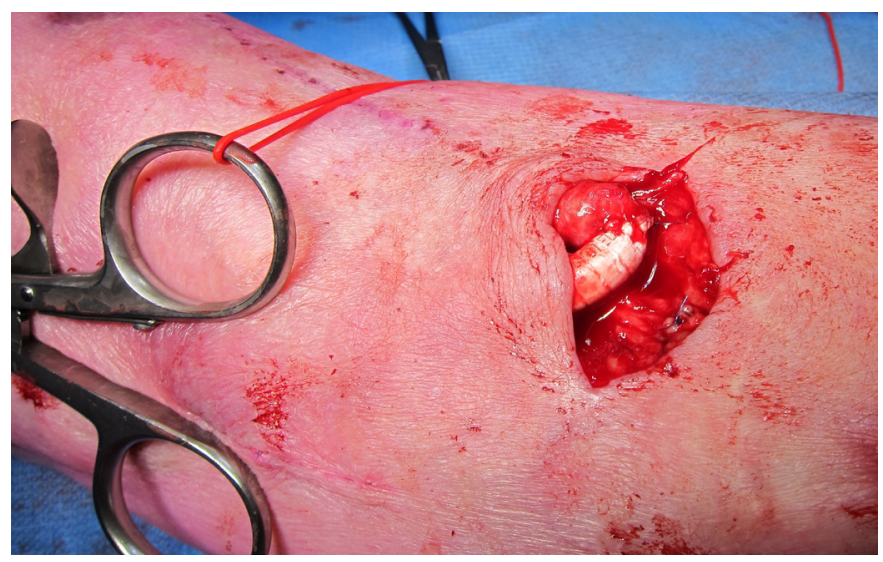

Figure 2b. PAI procedure. Subsequently the interponate is anastomosed with the cephalic vein, the outflow vein of the original AVF. 


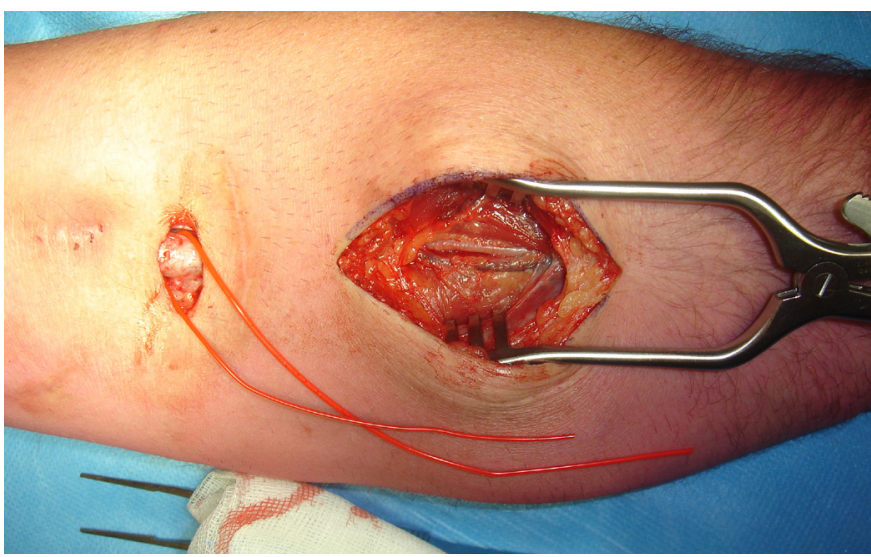

Figure 3a. RUDI procedure. Surgical technique of inflow reduction in patients undergoing RUDI for a HFA (> $2 \mathrm{~L} / \mathrm{min}$ ). A vessel loop is around the venous outflow tract of a brachiocephalic AVF. A portion of the proximal radial artery is dissected.

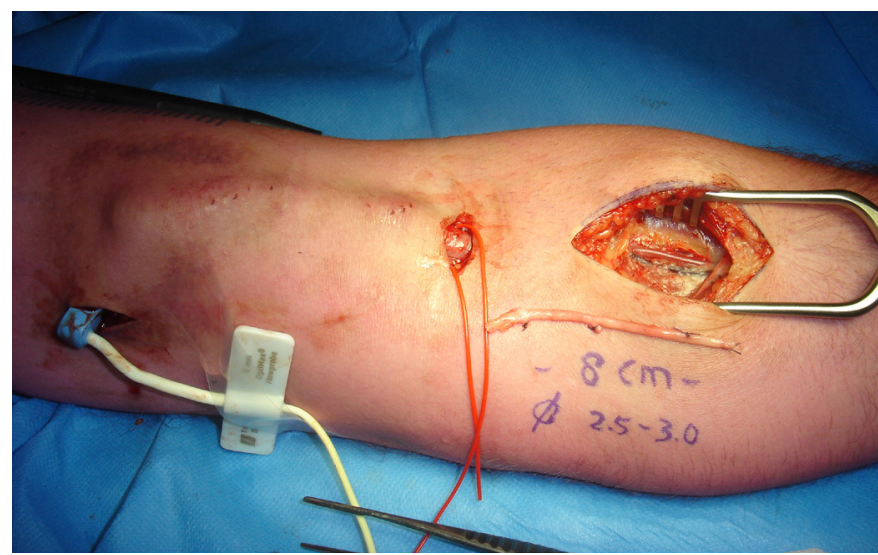

Figure $3 b$. RUDI procedure. Access flow is measured downstream using an ultrasonic transit time technique. An $8 \mathrm{~cm}$ portion of greater saphenous vein is used as an interposition graft.

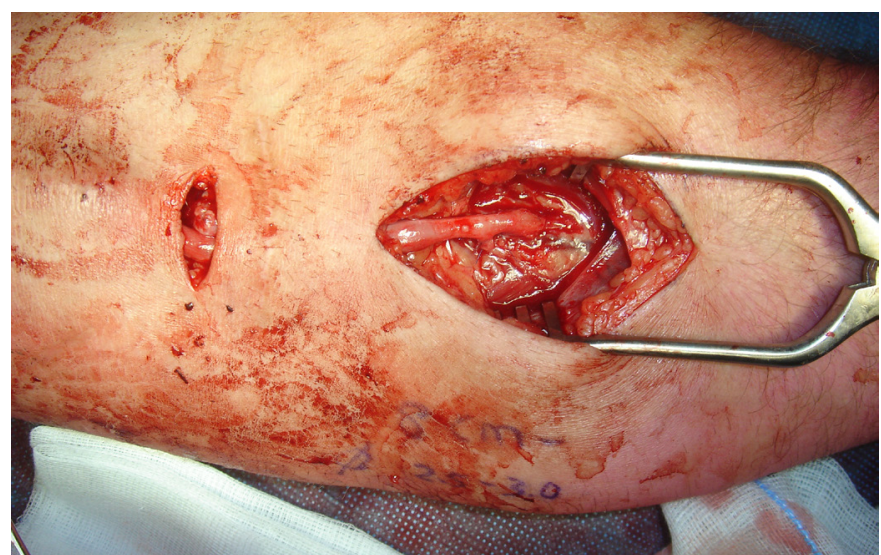

Figure 3c. RUDI procedure. The AVF some $5-7 \mathrm{~cm}$ downstream from the anastomosis with the brachial artery is transsected. The venous stump on the brachial artery's side is truncated and ligated using 5.0 Prolene. The GSV is used as a graft between the radial artery (end-to-side, 6.0 or 7.0 Prolene) and to the stump of the access (end-to-end or end-to-sinde, 5.0 Prolene). 


\section{High flow access, a long term consequence of BC-AVF}

An AVF is considered a high flow access (HFA) when access flow is $>2 \mathrm{~L} / \mathrm{min}$, measured on repetitive occasions (3I). This cut-off point is identified by studies in both HD and transplant patients demonstrating that cardiac failure was more prominent when access flow was $>2 \mathrm{~L} / \mathrm{min}$ $(32,33)$. It is assumed that a patient with a chronic HFA may eventually develop cardiac overload (and often also HAIDI) although the vast majority is asymptomatic (Io, 25).

Risk factors for a HFA are young age (25-40 years) with a BC-AVF or BB-AVF (rather than a RC-AVF), and absence of other comorbidities (such as diabetes). Most patients suffer from hypertension. In contrast, the majority is non-smoker. These patient characteristics are advantageous for proper and effective maturation of a newly constructed AVF as earlier discussed (5, I8-20). However, uncontrolled maturation and remodelling of inflow artery and outflow veins may eventually lead to inappropriately high access flows.

\section{Cardiac burden of an AVF and a HFA}

AVF creation induces several hemodynamic and cardiac changes that may increase the cardiac burden. Immediately after AVF creation, the average cardiac output $(\mathrm{CO})$ increases Io-20 percent and may stay 25 percent higher at 6 months postoperatively compared to preoperatively $(34,35)$. This increased $\mathrm{CO}$ is achieved by increasing left and right end diastolic volumes, augmenting ventricular contractility and by a higher heart rate $(34,35)$. In contrast, cardiac oxygen supply is considerably decreased due to the AVF while a higher supply is needed (36). Strikingly, HD patients are particularly at risk for cardiovascular death during the first two months after HD initiation, possibly due to an inappropriate adaptation (5). Moreover, an AVF in itself poses an increased cardiac burden. For instance, left ventricular hypertrophy (LVH) is more prominent in HD patients compared to PD patients (37). Additionally, signs of $\mathrm{LVH}$ are reversible after AVF closure in transplanted patients $(38,39)$. Patients having access flows exceeding $2 \mathrm{1} / \mathrm{min}$ indeed sustained a greater risk on cardiac failure when compared to individuals with lower access flows $(32,33)$. Therefore, it is intuitive to assume that an AVF with a high flow will exert an additional burden on heart functioning in a HD patient.

\section{Indications for HFA treatment}

There are several indications for HFA treatment per se. For instance, the presence of HAIDI in patients with a HFA may contribute to a decision of surgically reducing access flow (ro). HAIDI will benefit from this measure as an finger pressure increase is found that is proportional to the decrease in access flow (Io). 
The most important indication for HFA correction is cardiac failure. Some HD patients may have symptoms and signs of cardiac failure, even if access flows are below the $21 /$ min cut off point $(32,33)$. A first therapeutic step is conservative. Hypertension must be adequately treated with medication. In case of volume overload, extra ultrafiltration may be required. Anaemia must be corrected. If these conservative options are to no avail, more invasive treatment should be initiated aimed at decreasing access flow.

An asymptomatic HD patient demonstrating three (or more) consecutive, bimonthly performed, access flow measurements $>2 \mathrm{l} / \mathrm{min}$ should undergo a cardiac analysis consisting of a full history of hidden symptoms of cardiac failure such as orthopnoea, tachypnoea, or tachycardia. Physical examination often reveals a fully matured AVF with grossly dilated arm veins and an intense thrill (40). The hemodynamic response (drop in heart rate, increase in systemic blood pressure) to temporary manual AVF compression may allow for an estimation of the systemic effect of HFA although its clinical use is questioned (4I). An echocardiographic analysis may unveil deleterious cardiac effects of the chronic high flow AVF (left ventricular hypertrophy, enlarged right ventricular volume dimensions, increased left ventricular mass) (39). Eventually, a decision on access flow reduction should be discussed in a multidisciplinary meeting consisting of a nephrologist, cardiologist, dialysis nurse, radiologist and vascular surgeon. Its main goal, at all times, is to limit the cardiac damage sustained by the chronic HFA by a timely access flow reduction (39).

\section{Surgical HFA treatment}

Aim of any surgical treatment of a HFA is to achieve flow reduction while an effective VA is maintained. Several surgical techniques have been proposed over time although there are no comparative studies or randomized controlled trials (Io, $42^{-46}$ ).

Surgical plication or banding of the venous outflow tract is an effective approach. It is a popular and a frequently used technique with a $95 \%$ short-term success rate (Io, 25, 47, 48). The chance on success increases when access flow is monitored during the operation and thereby preventing access thrombosis (30). HFA recurrence rates after banding are by many vascular surgeons considered high. However, the effectiveness of banding on the long term is unknown. In anticipation of a presumed high recurrence rate following banding, alternative surgical treatment options for brachial artery based HFA's are proposed. In the RUDI technique (revision using distal inflow), the arteriovenous anastomosis is disconnected and reanastomosed to a radial artery in the proximal forearm (figure $3 \mathrm{a}-\mathrm{c}$ ). Preferably, a venous or a PTFE interponate is used $(44,46)$. Once an AVF 
is revascularised using a smaller flow artery, AVF access flow will drop in suit. A surgical variant for flow reduction is to vascularize the venous outflow tract using a transposed radial artery (figure 4) (42). Preliminary results are hopeful although the long term effectiveness of the technique remains to be proven. An alternative technique termed proximal radial artery ligation (PRAL) is available for radial artery based HFA's (43). The radial artery just proximal to the arteriovenous anastomosis is ligated (figure 5). $\mathrm{RC}-\mathrm{AVF}$ inflow is maintained via the ulnar artery, through the palmar arch and the distal radial artery.

HFA ligation is only considered if all conservative and surgical options have failed.

Figure 4. Radial artery transposition. The venous outflow tract is vascularized using a transposed radial artery (42). (printed with permission of P. Bourquelot)

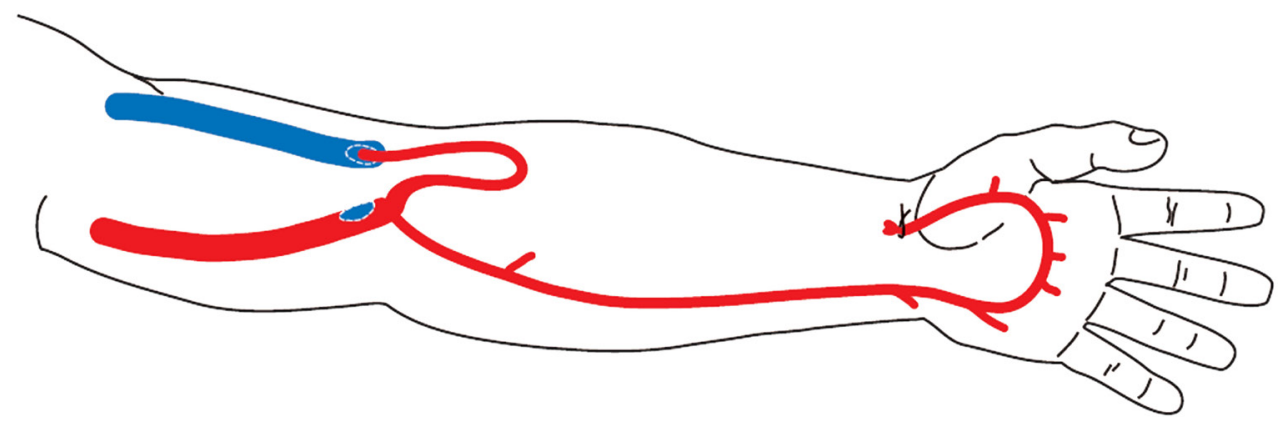

Figure 5. Proximal radial artery ligation. The radial artery just proximal to the arteriovenous anastomosis is ligated (43). (printed with permission of P. Bourquelot)

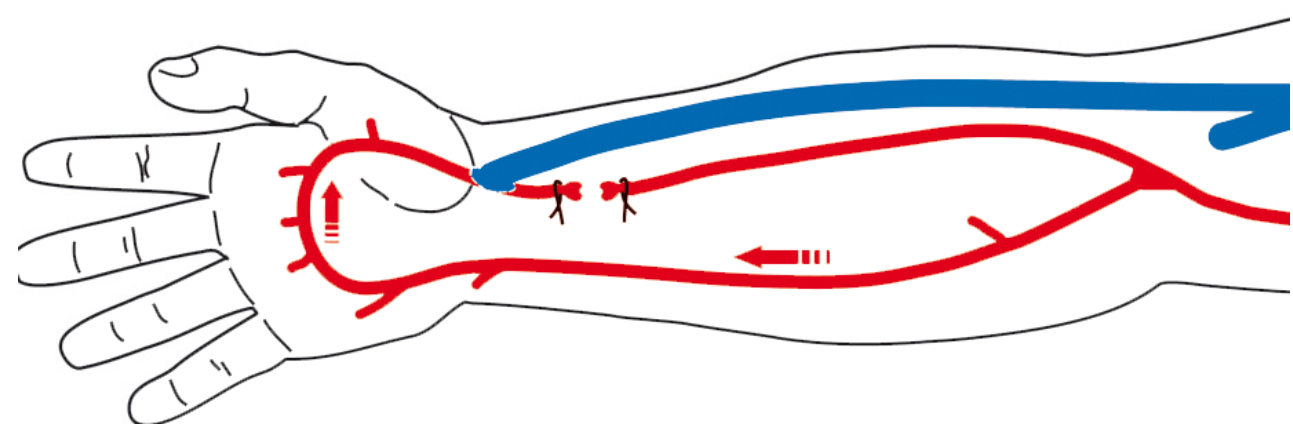




\section{General aim of thesis}

To study several aspects of pathophysiology and treatment of hand ischemia and high blood flow associated with the presence of a brachial artery-based AVF in haemodialysis patients.

\section{Specific aims}

I. To study forearm arm arterial blood flow direction and hemodynamics in HD patients with HAIDI.

2. To study immediate and long-term effects of BC-AVF venous side branch ligation on hand ischaemia, access flow and AVF patency in patients with HAIDI.

3. To study the haemodynamic consequences of access clamping in HD patients having a HFA.

4. To perform a literature study on the consequences of a HFA on cardiovascular performance in HD patients.

5. To describe the long-term efficacy of a surgical technique termed banding in patients with a HFA.

6. To describe the efficacy of a flow reducing surgical technique termed RUDI in HFA patients.

\section{Outline of thesis}

There is an ongoing debate in the literature on the use of the term steal as the proper term to describe hand ischemia that may develop in the presence of a BC-AVF. By definition, steal is reversal of flow in an artery (directed towards the heart rather than to the periphery). It is assumed by many that reversal of arterial flow in the lower arm's arteries distal to a BC-AVF contributes to hand ischemia. We have previously coined the term 'HAIDI' to describe the phenomenon of hand ischemia that is induced by the presence of an AVF (haemodialysis access-induced distal ischaemia, HAIDI). To study whether reversal of flow in fore arm arteries may be observed in patients having a $\mathrm{BC}-\mathrm{AVF}$ and hand ischemia, we compared arterial flow direction and flow dynamics in HD patients with and without hand ischemia (chapter two).

HAIDI is thought to occur due to a loss of blood pressure in the arm's arterial vasculature. Open venous side branches $(\mathrm{SB})$ of a $\mathrm{BC}-\mathrm{AVF}$ theoretically contribute to blood pressure loss and may induce ischemic symptoms. However, this hypothesis was never put to the test in patients with HAIDI. The effects of surgical ligation of non-functional venous SB's (side branch ligation, SBL) on HAIDI symptoms and finger pressures are studied in chapter three. As long-term effects of SBL are also unknown, we additionally studied the effect of SBL on access flow, access patency, ischemic symptoms and finger pressure after one year in chapter four. 
HAIDI is occasionally due to an impaired arterial inflow. A HD patient with severe ischemia due to occluded subclavian arteries was successfully treated by the use of a femoral-axillary arterial bypass graft as reported in chapter five.

Some patients with a BC-AVF will develop a high flow access (HFA, >2 1/min). Theoretically, a chronic HFA may pose a cardiovascular burden over time, even if seemingly asymptomatic. Whether flow reducing surgery is required is questioned. Studying hemodynamics in a HFA patient group may provide important clues on necessity of flow reductive treatment. The systemic effects of perioperative clamping of a BC-AVF were studied in patients undergoing surgery for HFA in chapter six.

Chapter seven reports on a literature study regarding the cardiovascular effects of HD in general, and high flow AVF's in particular. There are some early reports favouring a banding procedure as an effective flow reducing surgical technique for HFA's. In chapter eight, one year efficacies of banded HFA's on access flow, high flow recurrence and complication rates in three hospitals are reported.

The revision using distal inflow (RUDI) technique is an alternative flow reducing technique for HFA. One year results on access flow, HFA recurrence and complications are reported in chapter nine.

In chapter Io, a summarizing discussion, conclusions and future perspectives are described. The valorisation of this thesis is outlined in chapter Ir. A Dutch summary is reported in chapter I2. Finally, acknowledgements and curriculum vitae of the author are provided. 


\section{References}

I. Nefrovisie/Renine, website: www.renine.nl.

2. Murad MH, Elamin MB, Sidawy AN, Malaga G, Rizvi AZ, Flynn DN, et al. Autogenous versus prosthetic vascular access for hemodialysis: a systematic review and meta-analysis. J Vasc Surg. 2008 Nov;48(5 Suppl):34S$47 \mathrm{~S}$.

3. K/DOQI clinical practice guidelines for cardiovascular disease in dialysis patients. Am J Kidney Dis. 2005 Apr;45(4 Suppl 3):SI-I53.

4. Betjes MGH, Hoogeveen EK. Richtlijn Vaattoegang. 2009.

5. Saran RL, Y.; Robinson, B.;. US Renal Data System 2014 annual data report: epidemiology of kidney disease in the United States. Am J Kidney Dis. 2015;66(I):30I-6.

6. Georgiadis GS, Georgakarakos EI, Antoniou GA, Panagoutsos S, Argyriou C, Mourvati E, et al. Correlation of pre-existing radial artery macrocalcifications with late patency of primary radiocephalic fistulas in diabetic hemodialysis patients. J Vasc Surg. 20I4 Aug;6o(2):462-70.

7. Lazarides MK, Georgiadis GS, Antoniou GA, Staramos DN. A meta-analysis of dialysis access outcome in elderly patients. J Vasc Surg. 2007 Feb;45(2):420-6.

8. Tordoir JH, Bode AS, van Loon MM. Preferred strategy for hemodialysis access creation in elderly patients. Eur J Vasc Endovasc Surg. 2015 Jun;49(6):738-43.

9. Kimball TA, Barz K, Dimond KR, Edwards JM, Nehler MR. Efficiency of the kidney disease outcomes quality initiative guidelines for preemptive vascular access in an academic setting. J Vasc Surg. 20II Sep;54(3):760-5; discussion $5^{-6}$.

Io. van Hoek F, Scheltinga M, Luirink M, Pasmans H, Beerenhout C. Banding of hemodialysis access to treat hand ischemia or cardiac overload. Semin Dial. 2009 Mar-Apr;22(2):204-8.

II. van Hoek F, Scheltinga MR, Kouwenberg I, Moret KE, Beerenhout CH, Tordoir JH. Steal in hemodialysis patients depends on type of vascular access. Eur J Vasc Endovasc Surg. 2006 Dec;32(6):710-7.

I2. Scheltinga MR, van Hoek F, Bruijninckx CM. Time of onset in haemodialysis access-induced distal ischaemia (HAIDI) is related to the access type. Nephrol Dial Transplant. 2009 Oct;24(Io):3198-204.

13. Padberg FT,Jr., Calligaro KD, Sidawy AN. Complications of arteriovenous hemodialysis access: recognition and management. J Vasc Surg. 2008 Nov;48(5 Suppl):55 S-8oS.

I4. Scheltinga MR, Bruijninckx CM. Haemodialysis access-induced distal ischaemia (HAIDI) is caused by loco-regional hypotension but not by steal. Eur J Vasc Endovasc Surg. 20I2 Feb;43(2):218-23.

I5. van Hoek F, Scheltinga MR, Luirink M, Raaymakers LC, van Pul C, Beerenhout CH. Access flow, venous saturation, and digital pressures in hemodialysis. J Vasc Surg. 2007 May;45(5):968-73.

16. Anaya-Ayala JE, Pettigrew CD, Ismail N, Diez-De Sollano AL, Syed FA, Ahmed FG, et al. Management of dialysis access-associated "steal" syndrome with DRIL procedure: challenges and clinical outcomes. J Vasc Access. 20I2 Jul;13(3):299-304.

17. Odland MD, Kelly PH, Ney AL, Andersen RC, Bubrick MP.Management of dialysis-associated steal syndrome complicating upper extremity arteriovenous fistulas: use of intraoperative digital photoplethysmography. Surgery. I99I Oct;IIO(4):664-9; discussion 9-70.

I8. Tynan-Cuisinier GS, Berman SS. Strategies for predicting and treating access induced ischemic steal syndrome. Eur J Vasc Endovasc Surg. 2006 Sep;32(3):309-15.

19. Goldfeld M, Koifman B, Loberant N, Krowll I, Haj M. Distal arterial flow in patients undergoing upper extremity dialysis shunting: a prospective study using doppler sonography. AJR Am J Roentgenol. 2000 Aug; $175(2): 513-6$.

20. Achneck HE, Sileshi B, Li M, Partington EJ, Peterson DA, Lawson JH. Surgical aspects and biological considerations of arteriovenous fistula placement. Semin Dial. 20Io Jan-Feb;23(I):25-33.

21. Aitken E, Jackson A, Kong C, Coats P, Kingsmore D. Renal function, uraemia and early arteriovenous fistula failure. BMC nephrology. 20I4;15:I79.

22. van Golde JM, Ruiter MS, Schaper NC, Voo S, Waltenberger J, Backes WH, et al. Impaired collateral recruitment and outward remodeling in experimental diabetes. Diabetes. 2008 Oct;57(IO):28I8-23.

23. Reifsnyder T, Arnaoutakis GJ. Arterial pressure gradient of upper extremity arteriovenous access steal syndrome: treatment implications. Vasc Endovascular Surg. 20Io Nov;44(8):650-3.

24. Berman SS, Gentile AT, Glickman MH, Mills JL, Hurwitz RL, Westerband A, et al. Distal revascularizationinterval ligation for limb salvage and maintenance of dialysis access in ischemic steal syndrome. J Vasc Surg. I997 Sep;26(3):393-402; discussion -4. 
25. Zanow J, Petzold K, Petzold M, Krueger U, Scholz H. Flow reduction in high-flow arteriovenous access using intraoperative flow monitoring. J Vasc Surg. 2006 Dec;44(6):I273-8.

26. Huber TS, Brown MP, Seeger JM, Lee WA. Midterm outcome after the distal revascularization and interval ligation (DRIL) procedure. J Vasc Surg. 2008 Oct;48(4):926-32; discussion 32-3.

27. Schanzer H, Schwartz M, Harrington E, Haimov M. Treatment of ischemia due to "steal" by arteriovenous fistula with distal artery ligation and revascularization. J Vasc Surg. 1988 Jun;7 (6):770-3.

28. Thermann F, Wollert U. Proximalization of the arterial inflow: new treatment of choice in patients with advanced dialysis shunt-associated steal syndrome? Ann Vasc Surg. 2009 Jul-Aug;23(4):485-90.

29. Zanow J, Kruger U, Scholz H. Proximalization of the arterial inflow: a new technique to treat access-related ischemia. J Vasc Surg. 2006 Jun;43(6):I2I6-2I; discussion 2I.

30. Scheltinga MR, Van Hoek F, Bruyninckx CM. Surgical banding for refractory hemodialysis access-induced distal ischemia (HAIDI). J Vasc Access. 2009 Jan-Mar;Io(I):43-9.

31. NVvH. Richtlijn shuntchirurgie. 2010.

32. Basile C, Lomonte C, Vernaglione L, Casucci F, Antonelli M, Losurdo N. The relationship between the flow of arteriovenous fistula and cardiac output in haemodialysis patients. Nephrol Dial Transplant. 2008 Jan;23(I):282-7.

33. Schier T, Gobel G, Bosmuller C, Gruber I, Tiefenthaler M. Incidence of arteriovenous fistula closure due to high-output cardiac failure in kidney-transplanted patients. Clinical transplantation. 20I3 Nov$\operatorname{Dec} ; 27(6): 85^{8-65}$.

34. Dundon BK, Torpey K, Nelson AJ, Wong DT, Duncan RF, Meredith IT, et al. The deleterious effects of arteriovenous fistula-creation on the cardiovascular system: a longitudinal magnetic resonance imaging study. International journal of nephrology and renovascular disease. 20I4;7:337-45.

35. MacRae JM, Levin A, Belenkie I. The cardiovascular effects of arteriovenous fistulas in chronic kidney disease: a cause for concern? Semin Dial. 2006 Sep-Oct;19(5):349-52.

36. Bos WJ, Zietse R, Wesseling KH, Westerhof N. Effects of arteriovenous fistulas on cardiac oxygen supply and demand. Kidney Int. I999 May;55(5):2049-53.

37. Tian JP, Wang T, Wang H, Cheng LT, Tian XK, Lindholm B, et al. The prevalence of left ventricular hypertrophy in Chinese hemodialysis patients is higher than that in peritoneal dialysis patients. Ren Fail. 2008;30(4):39I-400.

38. Unger P, Velez-Roa S, Wissing KM, Hoang AD, van de Borne P. Regression of left ventricular hypertrophy after arteriovenous fistula closure in renal transplant recipients: a long-term follow-up. Am J Transplant. 2004 Dec;4(12):2038-44.

39. van Duijnhoven EC, Cheriex EC, Tordoir JH, Kooman JP, van HooffJP. Effect of closure of the arteriovenous fistula on left ventricular dimensions in renal transplant patients. Nephrol Dial Transplant. 200I Feb;16(2):36872.

40. Scheltinga M, Hoek van F. Banding for high flow hemodialysis access. J Tordoir: Vascular access. Turino: Edizione Minverva Medica; 2009. p. I4I-50.

4I. Dikow R, Schwenger V, Zeier M, Ritz E. Do AV fistulas contribute to cardiac mortality in hemodialysis patients? Semin Dial. 2002 Jan-Feb;I5(I):I4-7.

42. Bourquelot P, Gaudric J, Turmel-Rodrigues L, Franco G, Van Laere O, Raynaud A. Transposition of radial artery for reduction of excessive high-flow in autogenous arm accesses for hemodialysis. J Vasc Surg. 2009 Feb;49(2):424-8, 8 er.

43. Bourquelot P, Gaudric J, Turmel-Rodrigues L, Franco G, Van Laere O, Raynaud A. Proximal radial artery ligation (PRAL) for reduction of flow in autogenous radial cephalic accesses for haemodialysis. Eur J Vasc Endovasc Surg. 2010 Jul;40(I):94-9.

44. Minion DJ, Moore E, Endean E. Revision using distal inflow: a novel approach to dialysis-associated steal syndrome. Ann Vasc Surg. 2005 Sep;r9(5):625-8.

45. Murray BM, Rajczak S, Herman A, Leary D. Effect of surgical banding of a high-flow fistula on access flow and cardiac output: intraoperative and long-term measurements. Am J Kidney Dis. 2004 Dec;44(6):1o9o-6.

46. Parmar CD, Chieng G, Abraham KA, Kumar S, Torella F. Revision using distal inflow for treatment of heart failure secondary to arteriovenous fistula for hemodialysis. J Vasc Access. 2009 Jan-Mar;Io(I):62-3.

47. Schneider CG, Gawad KA, Strate T, Pfalzer B, Izbicki JR. T-banding: a technique for flow reduction of a hyperfunctioning arteriovenous fistula. J Vasc Surg. 2006 Feb;43(2):402-5.

48. Tellioglu G, Berber I, Kilicoglu G, Seymen P, Kara M, Titiz I. Doppler ultrasonography-guided surgery for high-flow hemodialysis vascular access: preliminary results. Transplant Proc. 2008 Jan-Feb;40(I):87-9. 



\section{CHAPTER - II}

\section{Blood flow dynamics in patients with haemodialysis access induced hand ischaemia}

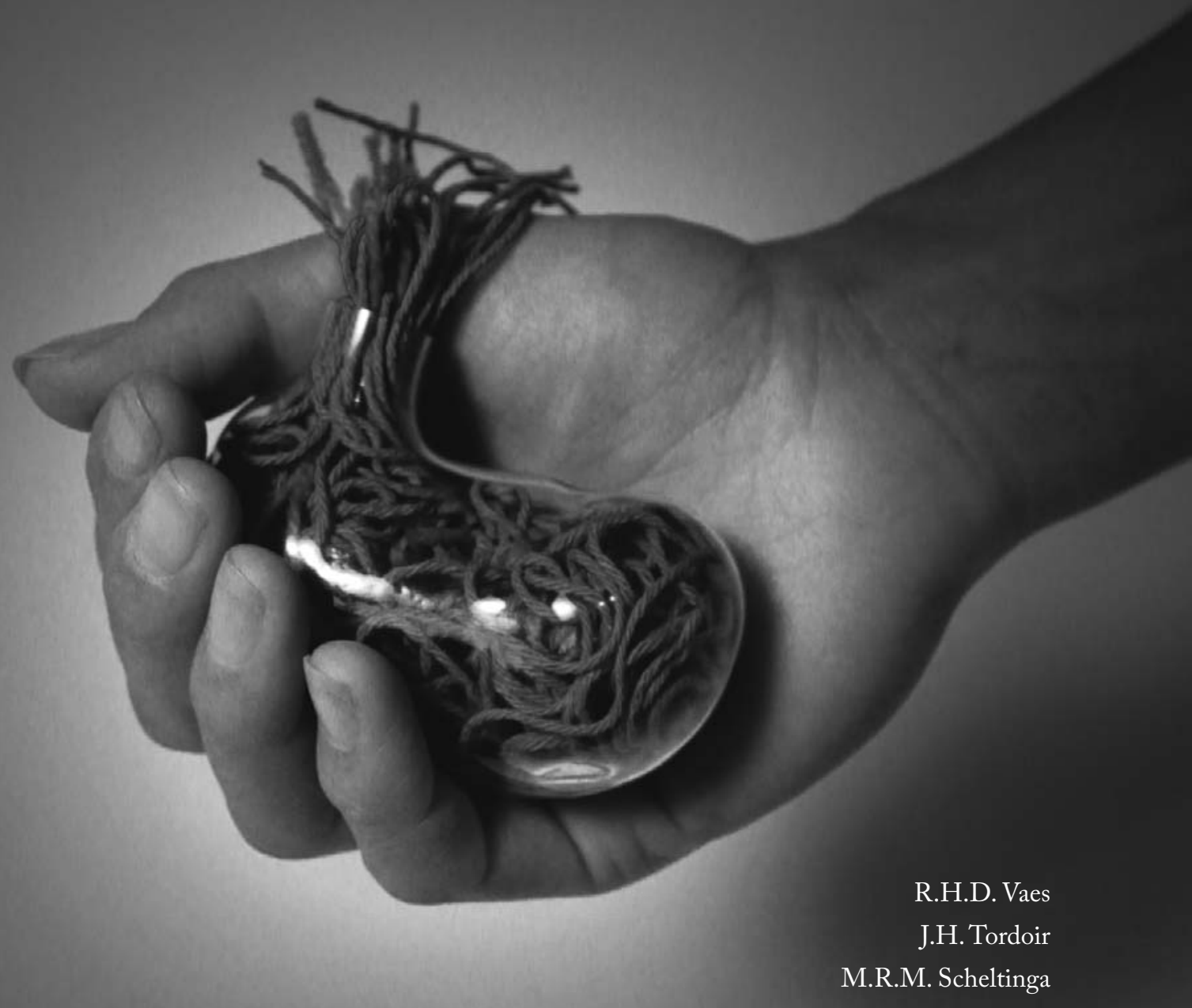

J Vasc Surg. 20I3 Aug;58(2):446-5 


\section{Abstract}

\section{Objective}

Hand ischaemia may occur in the presence of a haemodialysis arteriovenous fistula (AVF) but its pathophysiology is partly unclear. The aim of this observational study was to investigate flow characteristics of forearm arteries in patients with a brachial artery based AVF suffering from haemodialysis access induced distal ischemia (HAIDI).

\section{Design of study}

A questionnaire scored hand ischemia in HAIDI patients scheduled for revisional surgery (no symptoms of ischemia, o points; maximal ischemia, 500 points). Systolic index finger pressures (Pdig) and digital brachial index (DBI) were determined with open and compressed AVF. Blood flow direction and peak systolic velocity (PSV) were measured in radial and ulnar arteries using Doppler ultrasonography. Age and gender matched haemodialysis patients without HAIDI served as controls ('CONT').

\section{Results}

Questionnaire scores were 275 (200-3II) in HAIDI patients ( $\mathrm{n}=\mathrm{IO})$ compared to I4 $(\mathrm{o}-42)$ in CONT ( $\mathrm{n}=\mathrm{Io}, \mathrm{P}<. \mathrm{oI})$. Pdig and DBI with open AVF were lower in the HAIDI group than CONT group (Pdig o (o-44) vs IO2 (7I-II6) mm Hg; DBI o (o-0.36) vs o.69 (o.62-0.78), both $\mathrm{P}<$.oI). Ulnar artery PSV was lower in HAIDI compared to CONT patients $43\left(3 \mathrm{I}^{-} 45\right)$ vs $64\left(5^{8-}\right.$ 68) $\mathrm{cm} / \mathrm{s}, \mathrm{P}<$.oI). Mean ulnar artery PSV was significantly correlated to Pdig ( $\mathrm{r}=0.87, \mathrm{P}=0 . \mathrm{oI})$ in contrast to mean radial artery PSV $(r=0.06, p=0.8 \mathrm{I})$. Ulnar artery blood flow direction was always towards the ischemic hand $(n=20)$. However, blood flow was reversed in just a short segment of the proximal radial artery in one HAIDI patient but also in two CONT patients.

\section{Conclusion}

Hand ischaemia in haemodialysis patients with a brachial artery based arteriovenous fistula is not caused by a reversed blood flow direction in forearm arteries. However, forearm blood flow is diminished in these patients leading to critically reduced arterial pressures in the hand. 


\section{Introduction}

Haemodialysis access induced distal ischemia (HAIDI) is a disabling complication in hemodialysis (HD) patients. Up to five percent of dialysis patients require invasive treatment for severe HAIDI, usually one to two years after AVF creation (I). The typical risk patient is an elderly diabetic female patient with a history of previous access surgery presently having an autogenous brachial artery based ('elbow') fistula $(2,3)$. HAIDI is probably caused by the combined effect of progressively atherosclerotic arm arteries, reduced remodelling of the AVF's inflow artery and loss of blood pressure at the anastomosis (4-8). Some are convinced that 'steal', a reversal of blood flow direction in distal arteries, is crucial in the pathophysiology of hand ischaemia $(9$, ro). Steal phenomena may occasionally be detected in forearm arteries but not necessarily in concert with hand ischaemia (4-6).Patients with HAIDI consistently demonstrate signs of reduced hand perfusion as reflected by lowered digital pressures $(7, \mathrm{II})$.

The role of radial and ulnar arterial blood flow characteristics in relation to severe hand ischemia in the presence of a BC-AVF is largely unknown. Aim of this observational study was to determine forearm artery blood flow dynamics in patients with a BC-AVF scheduled for an invasive procedure because of type $2 \mathrm{~b}-4$ HAIDI (I). It was hypothesized that forearm blood flow was reduced in patients with hand ischemia compared to HD patients not suffering from ischemia.

\section{Patients and Methods}

\section{Patient selection}

The study was performed between July 2010 and January 2012 in Maxima Medical Center (MMC) in Veldhoven, the Netherlands. Access flow was determined every two months in each HD patient using a two-needle dilution technique as suggested by K-DOQI (HDor, Transonic Systems Inc, New York, USA). Patients were eligible for study if they harboured a BC-AVF and if they were suffering from HAIDI grade $2 \mathrm{~b}-4 \mathrm{~b}$ requiring invasive revision ('HAIDI'-group) $(3, \mathrm{I} 2)$. Subjects were not eligible if they were referred from another hospital or if mental capacity or Dutch language skills were limited. Patients with a BC-AVF but not reporting hand ischaemia were matched on the basis of gender and age and served as controls ('CONT'-group). The selection and matching process was performed by one investigator (RV) who was blinded to previous haemodynamic studies. The study was performed according to the declaration of Helsinki. The MMC Medical Ethics Committee judged that study approval was not required as the burden of a non-invasive Doppler analysis in CONT was considered negligible. Doppler analysis in HD 
patients is considered standard of care. Informed oral and written consent was obtained from all participants.

\section{Study protocol}

If patients reported symptoms possibly associated with hand ischaemia (pain, coldness, loss of strength), they underwent a standard history and physical examination. Hands were inspected for signs of diminished perfusion, prolonged capillary refill or wounds. An AVF compression test supported the diagnosis HAIDI if patients experienced improved skin perfusion or if absent radial artery pulsations returned (3). Patients were asked to respond to a published questionnaire that quantifies hand ischaemia (HIQ, hand ischemic questionnaire, see appendix I) (3, II, I3, I4). A HIQ score reflects severity and frequency of five cardinal symptoms associated with hand ischaemia (pain, cramps, coldness, loss of strength and diminished sensibility). HIQ scores range from o (no symptoms associated with ischaemia) to 500 (maximal symptoms). HIQ scores in a dialysis population not suffering from hand ischaemia were found to range from 35 to 50 (3). Successful AVF revision in HAIDI patients reduced mean HIQ scores from $I_{53}$ to 42 (I3).

Systolic blood pressure (SBP) was obtained from the contralateral arm using a standard oscillatory technique (Aisys, GE Medical, Hoevelaken, The Netherlands), whereas plethysmography of the index finger of the dialysis hand was performed with and without AVF compression using a Doppler scanner (Vasoguard Nicolet $8 \mathrm{MHz}$, Scimet, Bristol, UK). A <50 mmHg systolic pressure (Pdig, in $\mathrm{mmHg}$ ) and a < 0.6 digital brachial index (DBI, Pdig divided by the contralateral SBP) are accepted cut-off points for hand ischaemia in the presence of an AVF (I4, I5). Patients were graded according to a published I-4 scale analogous to the Fontaine classification for peripheral arterial obstructive disease (Table I, see appendix 2 for HAIDI classification) (I, II).

All study patients underwent peak systolic velocity and flow direction measurements in 3 portions of ulnar and radial arteries (PSV, in cm/s; Nicolet Vasoguard, VIASYS Healthcare, USA). Measurements were obtained approximately $2 \mathrm{~cm}$ distal to the AVF anastomosis (PSVulna, rad I), halfway down the lower arm (PSVulna, $\operatorname{rad} 2)$, and some $2 \mathrm{~cm}$ proximal to the palmar arch (PSVulna, rad 3). Mean PSVulna, rad was calculated as the average PSV over all three segments. Mean PSVtotal was calculated as the average PSV over all six segments in both arteries. If history, physical examination, HIQ scores and Pdig strongly suggested HAIDI, a Seldinger angiography through the femoral artery was advised to exclude stenotic disease of the subclavian, axillary and brachial arteries. HAIDI patients underwent the set of measurements in the weeks prior to the invasive procedure whereas the CONT group was studied in April and May 2012. 


\section{Statistical analysis}

The I7.0 SPSS software version was used for data collection and statistical analyses (SPSS Inc., Chicago, IL, USA). Data was expressed as median (interquartile range, IQR). Differences between groups were determined using the Mann-Whitney $U$ test, Fisher-exact test and one way ANOVA with a post-hoc Bonferroni as indicated. Differences within groups were calculated with the Wilcoxon test. A Spearman correlation test calculated correlations between Pdig and other variables. A $\mathrm{P}$ value of <.05 was considered significant.

\section{Results}

During the 18 months study period, I7 patients suspected of HAIDI were analyzed. As two patients did not meet inclusion critera (HAIDI type $2 \mathrm{a} n=\mathrm{I}$, high flow access without ischemia $\mathrm{n}=\mathrm{I}$ ), fifteen patients were eligible for the study. Five refused to participate (long distance referral $\mathrm{n}=3$, AVF ligation after successful kidney transplant $\mathrm{n}=\mathrm{I}$, no interest $\mathrm{n}=\mathrm{I}$ ). Therefore, the HAIDI group consisted of ten patients. The control group also contained ten patients. Demographics and most risk factors were similar between groups (Table I). However, PAOD was more frequently observed in the HAIDI group $(\mathrm{P}<.05)$.

The HAIDI group harboured a Gracz type brachiocephalic $\operatorname{AVF}(n=8)$, a basilic vein transposition $(\mathrm{n}=\mathrm{I})$ and a brachiocephalic fistula $(\mathrm{n}=\mathrm{I})$. The CONT group also had a Gracz type brachiocephalic AVF $(n=4)$, basilica vein transposition $(n=4)$ and a brachiocephalic fistula $(n=2)$. A Gracz type fistula is created by mobilizing the median cubital vein or deep perforating branch that is

Table I. Demographics of haemodialysis patients suffering from hand ischaemia (HAIDI, hemodialysis access induced distal ischemia) and controls (CONT) without ischaemia

\begin{tabular}{llll} 
& HAIDI & CONT & P \\
& $(\mathbf{n = 1 0 )}$ & $(\mathbf{n = 1 0 )}$ & 1.0 \\
\hline Male/female & $5 / 5$ & $5 / 5$ & 0.5 \\
Age & $78(74-82)$ & $74(69-83)$ & 10 \\
\hline Brachiocubital AVF & 10 & $29(12-54)$ & 0.15 \\
Time after AVF construction (months) & $13(4-46)$ & $785(685-1290)$ & 0.83 \\
\hline Access flow volume (ml/min) & $850(530-1450)$ & 0.01 \\
\hline Ischaemia questionnaire (score, 0-500) & $275(200-311)$ & $13.5(0-41.5)$ & 1.0 \\
\hline Diabetes Mellitus (yes/no) & $4 / 6$ & $5 / 5$ & 0.66 \\
\hline Hypertension (yes/no) & $6 / 4$ & $4 / 6$ & 0.02 \\
\hline Peripheral arterial obstructive disease (yes/no) & $8 / 2$ & $2 / 8$ & \\
\hline Grade of HAIDI (2b/3/4) & $5 / 3 / 2$ & & \\
\hline
\end{tabular}

AVF, arteriovenous fistula 
subsequently anastomosed to the brachial artery. Using this technique, outflow is usually via both the upper arm cephalic and basilic vein (I2). In the HAIDI group, five patients suffered from type $2 \mathrm{~b}$ HAIDI whereas three had type ${ }_{3}$ HAIDI and two suffered from type 4 HAIDI.

The invasive procedures for HAIDI were diverse. Two patients underwent angioplasty of the midportion of the brachial artery. A third patient with an occluded subclavian artery received a femoro-axillary bypass graft. Patient four underwent AVF ligation in the presence of a well functioning kidney transplant. Five additional patients underwent side branch ligation, two of them combined with a banding procedure. The tenth patient underwent a distal revascularization procedure. Cut-off values that were used for effective treatment were a digital pressure $>50 \mathrm{mmHg}$ and a digital brachial index >0.6 (II).

HIQ scores in the HAIDI group were higher compared to the CONT group (HAIDI: 275 (2003II) vs CONT: I4 (o-42), P<.oI). Access flows in both groups were not different (HAIDI: 850 (530-I450) $\mathrm{ml} / \mathrm{min}$ vs CONT: $\left.785\left(685^{-\mathrm{I} 290}\right) \mathrm{ml} / \mathrm{min}, \mathrm{P}=0.83\right)$ as were contralateral systolic arm blood pressures (HAIDI: I53 (I25-I62) $\mathrm{mmHg}$ vs CONT: I37 (II9-I53) mmHg, P=0.55).

Pdig of the dialysis hand was lower in the HAIDI group compared to CONT (HAIDI: Pdig o (o-44) vs CONT: Iо2 (7I-II6) mm Hg, P<.or; HAIDI: DBI o (o-o.36) vs o.69 (o.62-o.78), $\mathrm{P}<$.oI (Table II). AVF compression resulted in improved Pdig and DBI in both HAIDI (Pdig o (o-44) to 90 (I3-I47) $\mathrm{mmHg}, \mathrm{P}<.03$, DBI o (o-0.36) to o.57 (o.Io-r.o6), P<.03) and CONT (IO2 (7I-II6) to I26 (II2-I43) mmHg, P<.oI, DBI o.69 (o.62-0.78) to o.93 (o.83-I.05), P<.or, Table II).

Table II. Finger pressures before and after AVF compression in haemodialysis patients suffering from hand ischaemia (HAIDI) and controls (CONT) without ischaemia

\begin{tabular}{llll}
\hline & $\begin{array}{l}\text { HAIDI } \\
(\mathbf{n = 1 0})\end{array}$ & $\begin{array}{l}\text { CONT } \\
(\mathbf{n = 1 0})\end{array}$ & P \\
\hline Systolic blood pressures $(\mathrm{mm} \mathrm{Hg})$ & $153(125-162)$ & $137(119-153)$ & 0.55 \\
\hline Pdig, open AVF & $0(0-44)$ & $102(71-116)$ & 0.01 \\
\hline DBI, open AVF & $0(0-0.36)$ & $0.69(0.62-0.78)$ & 0.01 \\
Pdig, compressed AVF & $90(13-147)$ & $126(112-143)$ & 0.12 \\
DBI, compressed AVF & $0.57(0.10-1.06)$ & $0.93(0.83-1.05)$ & 0.16 \\
\hline
\end{tabular}


Ulnar artery PSV was significantly lower in HAIDI patients compared to values obtained in the CONT group (Table III and Figure I). PSV of the radial artery also showed lower values in HAIDI patients compared to CONT patients but these differences were not statistically different (Figure I and Table III). The mean total PSV was significantly higher in CONT patients compared to HAIDI patients $(55(48-67)$ vs $36(26-49) \mathrm{cm} / \mathrm{s}, \mathrm{P}<$.oI) (Table III). Pdig was significantly correlated to mean PSVulna ( $\mathrm{r}=0.87, \mathrm{P}=. \mathrm{oI})$ and PSVulna $3(\mathrm{r}=0.82, \mathrm{P}=. \mathrm{or})$ but not to mean PSVrad (r=0.06, p=0.8r) or PSVrad $3(r=0.29, P=0.26)$ (figure 2 and 3 ).

Table III. Peak systolic velocity $(\mathrm{cm} / \mathrm{s})$ in ulnar and radial artery in patients with hand ischaemia (HAIDI) and controls (CONT)

\begin{tabular}{lllll|lll} 
& Ulnar artery & & & Radial artery & & \\
& HAIDI & CONT & P & & HAIDI & CONT & P \\
\hline PSV $_{\text {proximal }}$ & $43(31-56)$ & $60(53-93)$ & 0.02 & $40(23-58)$ & $47(43-84)$ & 0.08 \\
PSV halfway & $39(20-44)$ & $69(52-83)$ & 0.01 & $35(24-57)$ & $43(36-51)$ & 0.53 \\
PSV $_{\text {distal }}$ & $43(20-45)$ & $66(45-78)$ & 0.01 & $35(11-50)$ & $49(40-64)$ & 0.11 \\
PSV $_{\text {mean }}$ & $43(31-45)$ & $64(58-68)$ & 0.01 & $31(14-55)$ & $49(35-57)$ & 0.29 \\
& & & & & & \\
\hline PSV $_{\text {mean total }}$ & $36(26-49)$ & $55(48-67)$ & 0.01 & & & \\
\hline
\end{tabular}

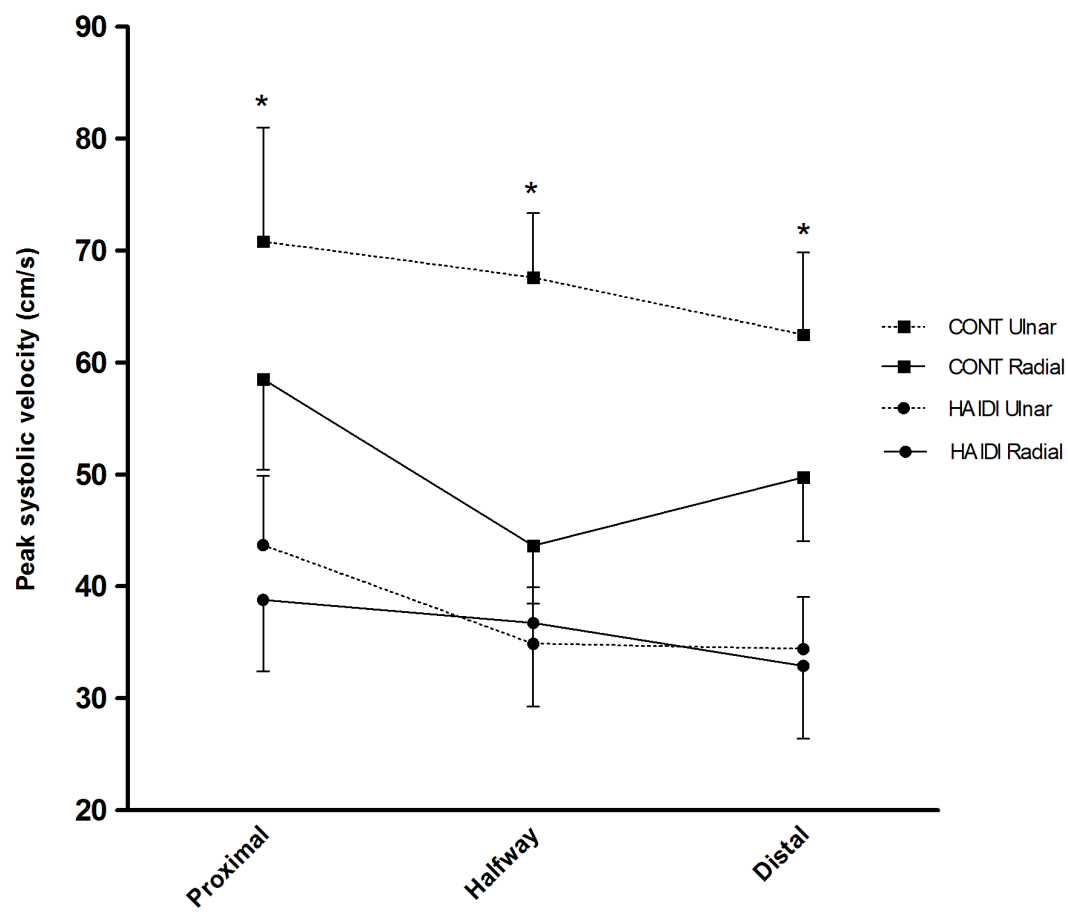

Figure 1. Peak systolic velocity in forearm arteries in dialysis patients with hand ischaemia and controls. 


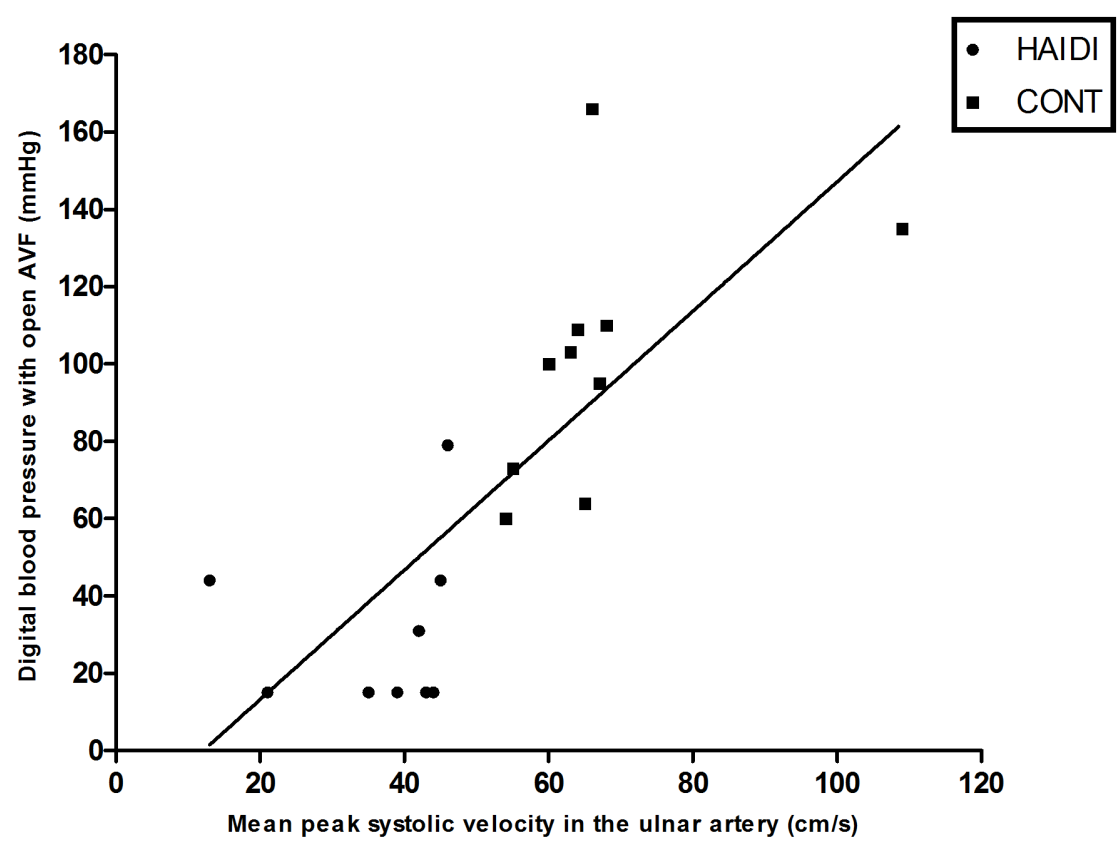

Figure 2. Correlation $(\mathrm{r}=0.87, \mathrm{p}=0.01)$ between mean ulnar artery PSV and Pdig of study patients (HAIDI, $\mathrm{n}=9$, CONT $\mathrm{n}=10$, data of one HAIDI patient was missing).

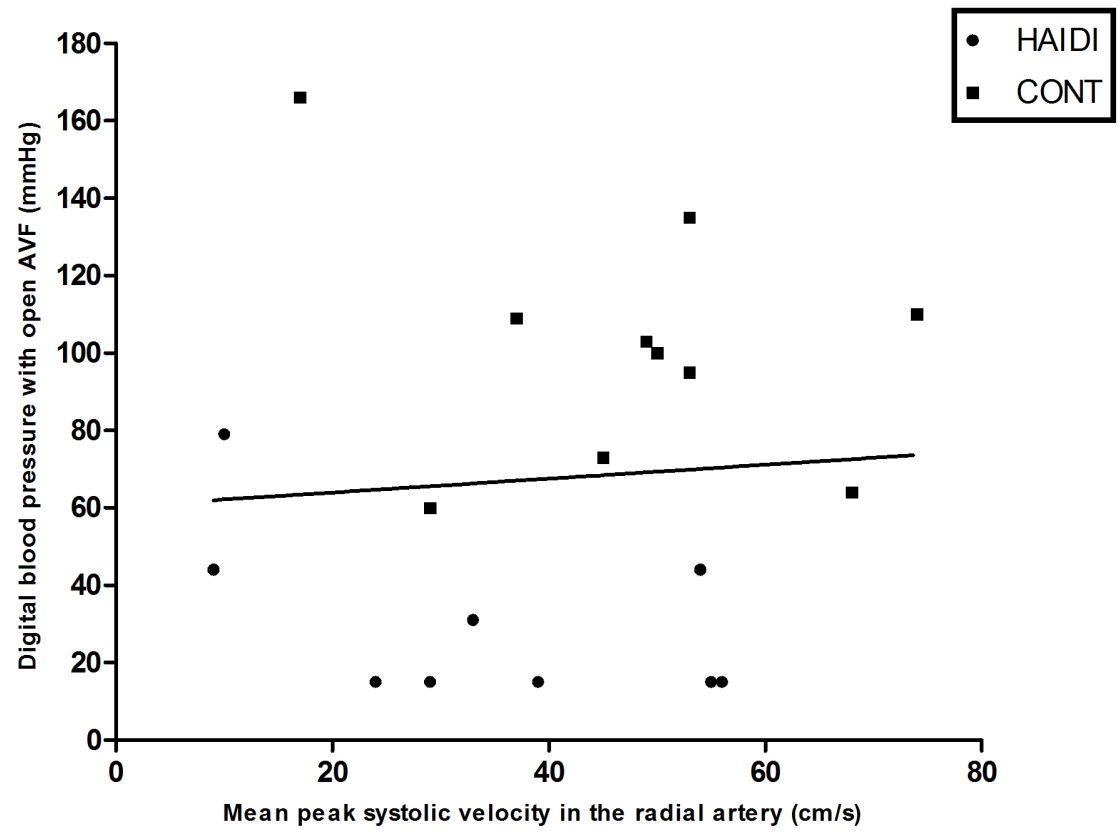

Figure 3. Correlation $(\mathrm{r}=0.06, \mathrm{p}=0.81$ ) between mean radial artery PSV and Pdig (HAIDI, $\mathrm{n}=8, \mathrm{CONT}$ $\mathrm{n}=10$, data of two HAIDI patient were missing). 
Angiographic results were available in 9 of ro HAIDI patients. Angiography was not performed in one patient who required AVF ligation after successful kidney transplantation. An arterial inflow obstruction was detected in three patients. Angioplasty of an occluded subclavian artery in the first patient was deemed hazardous and therefore he underwent a femoro-axillary bypass surgery. Stenotic midportions of proximal brachial arteries were successfully dilated in the second and third patient. Angiography was normal in the remaining six patients.

One HAIDI patient had several open collaterals bypassing the arteriovenous anastomosis (Figure 4). Interestingly, this was the only HAIDI patient demonstrating a steal phenomenon during both the systolic and diastolic phase in a $2-3 \mathrm{~cm}$ portion of the radial artery just distal to the anastomosis. Blood flow direction in the remaining part of this patient's radial artery was antegrade (towards the hand) during the entire cardiac cycle. Radial artery blood flow direction was antegrade in the remaining 9 HAIDI patients. However, a steal phenomenon in the proximal radial artery was also detected in 2 CONT patients. Ulnar blood flow direction was always antegrade in all 20 study patients.

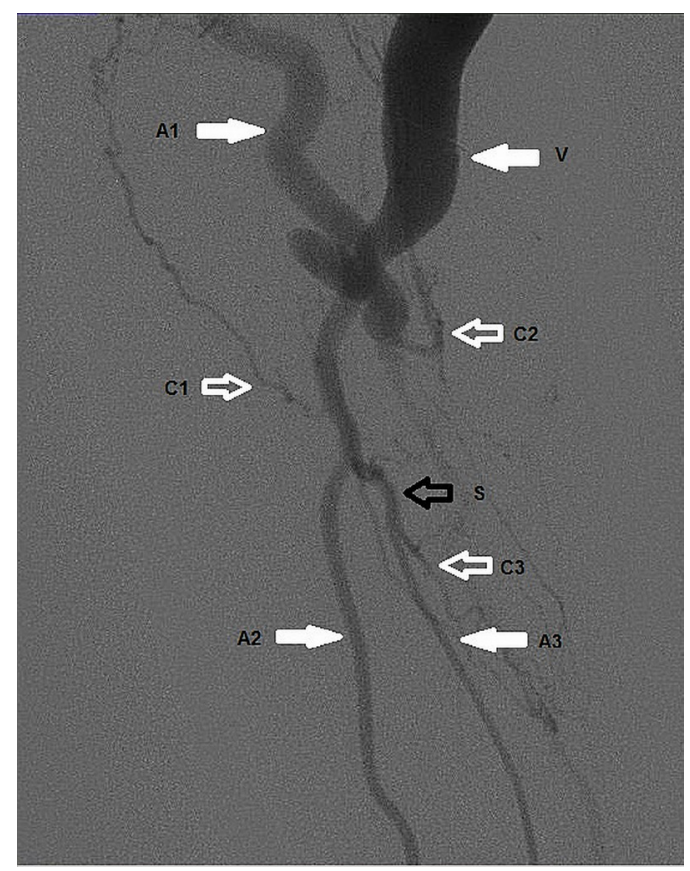

Figure 4. Static image of dynamic angiography showing a brachiocephalic fistula with inflow artery (brachial artery, A1), ulnar (A2) and radial artery (A3), distended cephalic outflow vein (V) and arterial collaterals bypassing the anastomosis (C1-3). A steal phenomenon was observed in the proximal portion of the radial artery $(\mathrm{S})$ reflecting proper collateral functioning. However, flow direction was antegrade in the remaining portion of the radial as well as in the ulnar artery. 


\section{Discussion}

Aim of the present observational investigation was to study forearm artery blood flow dynamics in $\mathrm{BC}-\mathrm{AVF}$ patients with severe hand ischemia scheduled for a revisional procedure. It was found that systolic velocity (a parameter reflecting flow volume) of ulnar arteries is diminished in HAIDI patients. These findings are in line with recent studies suggesting that ischemia is caused by locoregional hypotension resulting from pressure loss due to progressive arterial stiffening combined with turbulence at the arteriovenous anastomosis (6-8, II). Although previous studies implicated steal as the main cause for hand ischemia, the present study observed a reversal of blood flow direction just once in 20 forearm arteries of ten patients with severe HAIDI but also twice in ten control individuals not reporting hand ischemia (8, II). Therefore, retrograde flow in forearm arteries apparently does not play a role in the pathophysiology of HAIDI. Abbreviations proposed to describe hand ischaemia in the presence of an AVF such as DASS (dialysis access steal syndrome) and ISS (ischemic steal syndrome) therefore appear incorrect (II, I6).

The present study sought to determine associations between ultrasonographic and plethysmographic findings in HAIDI patients. The observation of a significant relationship between systolic blood pressures of the digits and ulnar peak systolic velocity (PSV) but not with radial PSV raises questions. Which of the two lower arm arteries (the interosseus artery is usually neglected) dominates hand perfusion in HD patients? Anatomical and physiological studies in normals suggest that both ulnar and radial arteries are important for hand perfusion but exceptions are numerous ( $\mathrm{I} 7$ ). A decreased blood flow in one artery usually induces a drop in digital perfusion pressure leading to compensatory increased flows in the other (I8). For example, radial artery harvesting for coronary surgery evokes a compensatory increase in ulnar artery flow and diameter ensuring adequate short and long term hand perfusion levels in most cases (19-23). Interestingly, patients with digital ulcers due to systemic sclerosis demonstrated reduced ulnar artery blood flows with normal radial artery flows (24). These data suggest that ulnar artery blood flow may be more important than radial artery blood flow with respect to hand perfusion in some patient populations. A significant correlation between ulnar PSV and digital pressure in the current HD patients suggests that ulnar arteries dictate hand perfusion. An explanation for this ulnar preponderance is currently lacking. One may hypothesize that the presence of a brachial artery based AVF has a differential effect on ulnar and radial artery blood flow. Variations in arterial anatomy may also offer a possible explanation as some patients demonstrate a mid upper arm radial artery take-off. Alternatively, collateralization may occur more easily in some vascular beds 
compared to others. Monitoring forearm artery flow volumes with an open and compressed AVF before and after revisional surgery may shed light on some of these issues.

Surgical construction of an AVF for HD normally induces physiologic adaptation mechanisms facilitating access maturation while adequate hand perfusion is maintained. After anastomosing, a decreased peripheral resistance will lead to increased arterial flow with subsequent augmented wall shear stress inducing endothelial nitric-oxide (NO) release. NO release is critical for vasodilatation, inflow artery remodeling and recruiting adjacent collaterals bypassing the anastomosis $(25)$. However, this response is impaired in diabetic and uraemic patients due to endothelial dysfunction and consequent lower NO levels (26). Aging and diabetes also reduce the formation of new collaterals as a response to ischemia (27). Not surprisingly, the present study found that Pdig (and DBI) with open AVF was significantly lower in the HAIDI group compared to CONT. Temporary access compression only partially restored digital perfusion in the HAIDI group compared to CONT patients. This group difference probably reflects the irreversible consequences of vascular stiffening and stenoses associated with peripheral arterial occlusive disease that was significantly more present in HAIDI patients. These data confirm findings of earlier studies reporting on the prominent role of diabetes, peripheral arterial occlusive disease and old age as the most important risk factors for HAIDI (28).

The present study has several limitations including small sample size and limited number of obtained Duplex parameters. For instance, measurement of end diastolic velocity, wall shear rate and vessel diameters may possibly have yielded additional information on the pathophysiological consequences of HAIDI. Future studies will focus on the short and long term effects of access revision on forearm blood flow dynamics in these patient populations.

In conclusion, lower arm blood flow is diminished in haemodialysis patients with hand ischaemia in the presence of a brachial artery based arteriovenous fistula leading to critically reduced arterial pressures in the hand. Hand ischaemia is not caused by a reversed blood flow direction in forearm arteries in these patients. 


\section{References}

I. Scheltinga MR, van Hoek F, Bruijninckx CM. Time of onset in haemodialysis access-induced distal ischaemia (HAIDI) is related to the access type. Nephrol Dial Transplant. 2009 Oct;24(Io):3198-204.

2. Wixon CL, Hughes JD, Mills JL. Understanding strategies for the treatment of ischemic steal syndrome after hemodialysis access. J Am Coll Surg. 2000 Sep;I9I(3):30I-Io.

3. van Hoek F, Scheltinga MR, Kouwenberg I, Moret KE, Beerenhout CH, Tordoir JH. Steal in hemodialysis patients depends on type of vascular access. Eur J Vasc Endovasc Surg. 2006 Dec;32(6):710-7.

4. Duncan H, Ferguson L, Faris I. Incidence of the radial steal syndrome in patients with Brescia fistula for hemodialysis: its clinical significance. J Vasc Surg. I986 Aug;4(2):I44-7.

5. Bussell JA, Abbott JA, Lim RC. A radial steal syndrome with arteriovenous fistula for hemodialysis. Studies in seven patients. Ann Intern Med. r97 Sep;75(3):387-94.

6. Zanow J, Krueger U, Reddemann P, Scholz H. Experimental study of hemodynamics in procedures to treat access-related ischemia. J Vasc Surg. 2008 Dec;48(6):I559-65.

7. Scheltinga MR, Bruijninckx CM. Haemodialysis access-induced distal ischaemia (HAIDI) is caused by loco-regional hypotension but not by steal. Eur J Vasc Endovasc Surg. 20I2 Feb;43(2):218-23.

8. Anaya-Ayala JE, Pettigrew CD, Ismail N, Diez-De Sollano AL, Syed FA, Ahmed FG, et al. Management of dialysis access-associated "steal" syndrome with DRIL procedure: challenges and clinical outcomes. J Vasc Access. 20I2 Jul;13(3):299-304.

9. Odland MD, Kelly PH, Ney AL, Andersen RC, Bubrick MP.Management of dialysis-associated steal syndrome complicating upper extremity arteriovenous fistulas: use of intraoperative digital photoplethysmography. Surgery. I99I Oct;IIO(4):664-9; discussion 9-70.

Io. Tynan-Cuisinier GS, Berman SS. Strategies for predicting and treating access induced ischemic steal syndrome. Eur J Vasc Endovasc Surg. 2006 Sep;32(3):309-I5.

II. Vaes RH, Scheltinga MR. Side Branch Ligation for Haemodialysis-access-induced Distal Ischaemia. Eur J Vasc Endovasc Surg. 2012 Oct;44(4):452-6.

I2. Gracz KC, Ing TS, Soung LS, Armbruster KF, Seim SK, Merkel FK. Proximal forearm fistula for maintenance hemodialysis. Kidney Int. I977 Jan;II(I):7I-5.

I3. van Hoek F, Scheltinga M, Luirink M, Pasmans H, Beerenhout C. Banding of hemodialysis access to treat hand ischemia or cardiac overload. Semin Dial. 2009 Mar-Apr;22(2):204-8.

I4. van Hoek F, Scheltinga MR, Luirink M, Raaymakers LC, van Pul C, Beerenhout CH. Access flow, venous saturation, and digital pressures in hemodialysis. J Vasc Surg. 2007 May;45(5):968-73.

I5. Goff CD, Sato DT, Bloch PH, DeMasi RJ, Gregory RT, Gayle RG, et al. Steal syndrome complicating hemodialysis access procedures: can it be predicted? Ann Vasc Surg. 2000 Mar;14(2):138-44.

16. Knox RC, Berman SS, Hughes JD, Gentile AT, Mills JL. Distal revascularization-interval ligation: a durable and effective treatment for ischemic steal syndrome after hemodialysis access. J Vasc Surg. 2002 Aug;36(2):250-5; discussion 6.

17. Coleman SS, Anson BJ. Arterial patterns in the hand based upon a study of 650 specimens. Surg Gynecol Obstet. 196I Oct;II3:409-24.

18. Dumanian GA, Segalman K, Buehner JW, Koontz CL, Hendrickson MF, Wilgis EF. Analysis of digital pulse-volume recordings with radial and ulnar artery compression. Plast Reconstr Surg. 1998 Nov;IO2(6):I9938.

I9. Pola P, Serricchio M, Flore R, Manasse E, Favuzzi A, Possati GF. Safe removal of the radial artery for myocardial revascularization: a Doppler study to prevent ischemic complications to the hand. J Thorac Cardiovasc Surg. I996 Sep;I12(3):737-44.

20. Schena S, Crabtree TD, Baker KA, Guthrie TJ, Curci J, Damiano RJ, et al. Absence of deterioration of vascular function of the donor limb at late follow-up after radial artery harvesting. J Thorac Cardiovasc Surg. 20II Aug;I42(2):298-30I.

2I. Brodman RF, Hirsh LE, Frame R. Effect of radial artery harvest on collateral forearm blood flow and digital perfusion. J Thorac Cardiovasc Surg. 2002 Mar;I23(3):512-6.

22. Brzezinski M, Luisetti T, London MJ. Radial artery cannulation: a comprehensive review of recent anatomic and physiologic investigations. Anesth Analg. 2009 Dec;109(6):I763-8I.

23. Vita JA, Holbrook M, Palmisano J, Shenouda SM, Chung WB, Hamburg NM, et al. Flow-induced arterial remodeling relates to endothelial function in the human forearm. Circulation. 2008 Jun I7;II7(24):3I26-33.

24. Frerix M, Stegbauer J, Dragun D, Kreuter A, Weiner SM. Ulnar artery occlusion is predictive of digital ulcers in SSc: a duplex sonography study. Rheumatology (Oxford). 2012 Apr;5I(4):735-42. 
25. Achneck HE, Sileshi B, Li M, Partington EJ, Peterson DA, Lawson JH. Surgical aspects and biological considerations of arteriovenous fistula placement. Semin Dial. 2010 Jan-Feb;23(I):25-33.

26. van Golde JM, Ruiter MS, Schaper NC, Voo S, Waltenberger J, Backes WH, et al. Impaired collateral recruitment and outward remodeling in experimental diabetes. Diabetes. 2008 Oct;57(Io):2818-23.

27. Semenza GL. Vascular responses to hypoxia and ischemia. Arterioscler Thromb Vasc Biol. 20Io Apr;30(4):64852.

28. Gupta N, Yuo TH, Konig Gt, Dillavou E, Leers SA, Chaer RA, et al. Treatment strategies of arterial steal after arteriovenous access. J Vasc Surg. 20II Jul;54(I):I62-7. 


\section{Appedix I}

\section{Hand Ischaemic Questionnaire}

A. General information

I. Name, age, sex

2. Type of fistula

3. Date of (last) operation

4. Side

5. Left or right dominance

B. Specific information

\section{Cold sensations}

I. Do you experience cold sensations in the fistula arm/hand (if not, go to question 6) ?

2. Which location (lower arm/wrist/hand/fingers) ?

3. Which finger (s) ?

4. Severity of cold sensation ( $\mathrm{o}=$ no cold sensation, $\mathrm{I}=$ = freezing cold) ?

5. Frequency of cold sensation $(\mathrm{o}=$ never, $\mathrm{Io}=$ always $)$ ?

Minimal $=0, \operatorname{Max}=$ Io $($ severity $) \times$ Io $($ frequency $)=$ Ioo points for cold sensation

\section{Pain}

6. Do you feel pain in the fistula arm/hand (if not, go to question II) ?

7. Which location (lower arm/wrist/hand/fingers) ?

8. Which finger(s) ?

9. Severity of pain $(\mathrm{o}=$ no pain, Io $=$ unbearable $)$ ?

Io. Frequency of pain (o = never, , o = always) ?

Minimal $=0, \operatorname{Max}=\mathrm{IO} \times \mathrm{IO}=\mathrm{IoO}$ points for pain

Sensibility

II. Is diminished or altered sensibility present in the fistula arm/hand (if not, go to question I4) ?

I2. Severity of diminished sensibility ( $\mathrm{o}=$ normal sensation, $\mathrm{IO}=$ total numbness) ?

I3. Frequency of diminished sensibility ( $\mathrm{o}=$ never, Io $=$ always $)$ ?

Minimal $=0$, Max $=$ Io $\times$ Io $=$ Ioo points for altered sensibility

Strength

I4. Do you experience diminished strength in the fistula arm/hand (if not, go to question I7) ?

I5. Severity of diminished strength ( $o=$ normal strength, Io $=$ total weakness) ?

I6. Frequency of diminished strength $(\mathrm{o}=$ never, $\mathrm{\text {Io }}=$ always $)$ ? 
Minimal $=0$, Max $=\mathrm{IO} \times \mathrm{IO}=\mathrm{IOO}$ points for strength

Cramps

I7. Do you suffer from cramps in the fistula arm/hand (if not, go to question 20)

18. Severity of cramps ( $\mathrm{o}=$ no cramps, Io $=$ spasms $)$ ?

I9. Frequency of cramps $(\mathrm{o}=$ never, $\mathrm{\text {IO }}=$ always $)$ ?

Minimal $=0, \operatorname{Max}=$ Io $\times$ Io $=$ Ioo points for cramps

Maximal Steal Score $=500$ points

20. Did you notice pallor in the fistula arm/hand: yes/no?

21. Did you observe changes in nail appearance in the fistula hand: yes/no ?

22. Do you have diminished growth of hair in the fistula $\mathrm{arm} / \mathrm{hand}$ : yes/no ?

23. Do you suffer from ulcers in the fistula arm/hand: yes/no?

\section{Appendix 2}

\section{HAIDI grade I}

No clear symptoms but discrete signs of mild ischaemia may be observed (slight cyanosis of nail beds, mild coldness of skin of hand, reduced arterial pulsations at the wrist, reduced systolic finger pressures). Conservative treatment may be indicated.

\section{HAIDI grade $2 a$}

Complaints during dialysis sessions or intense use of the hand: tolerable pain, cramps, paresthesias, numbness or disturbing coldness in fingers or hand. Conservative treatment is indicated.

\section{HAIDI grade $2 b$}

Complaints during dialysis sessions or use of the hand: intolerable pain, cramps, paresthesias, numbness or disturbing coldness in fingers or hand. A combined treatment including conservative and invasive treatment (endovascular or surgical) is indicated.

\section{HAIDI grade 3}

Rest pain or motoric dysfunction of fingers or hand. Urgent invasive treatment supported by conservative measures is indicated.

\section{HAIDI grade $4 a$}

Limited tissue loss (ulceration, necrosis). Clinically significant hand function is probably maintained if ischaemia is reversed. Urgent invasive treatment supported by conservative measures is indicated.

\section{HAIDI grade $4 b$}

Irreversible tissue loss of the hand or proximal parts of the extremity. Impossibility to preserve clinically significant hand function. Amputation is required. 



\section{CHAPTER - III}

\section{Side branch ligation for haemodialysis access induced distal ischaemia}

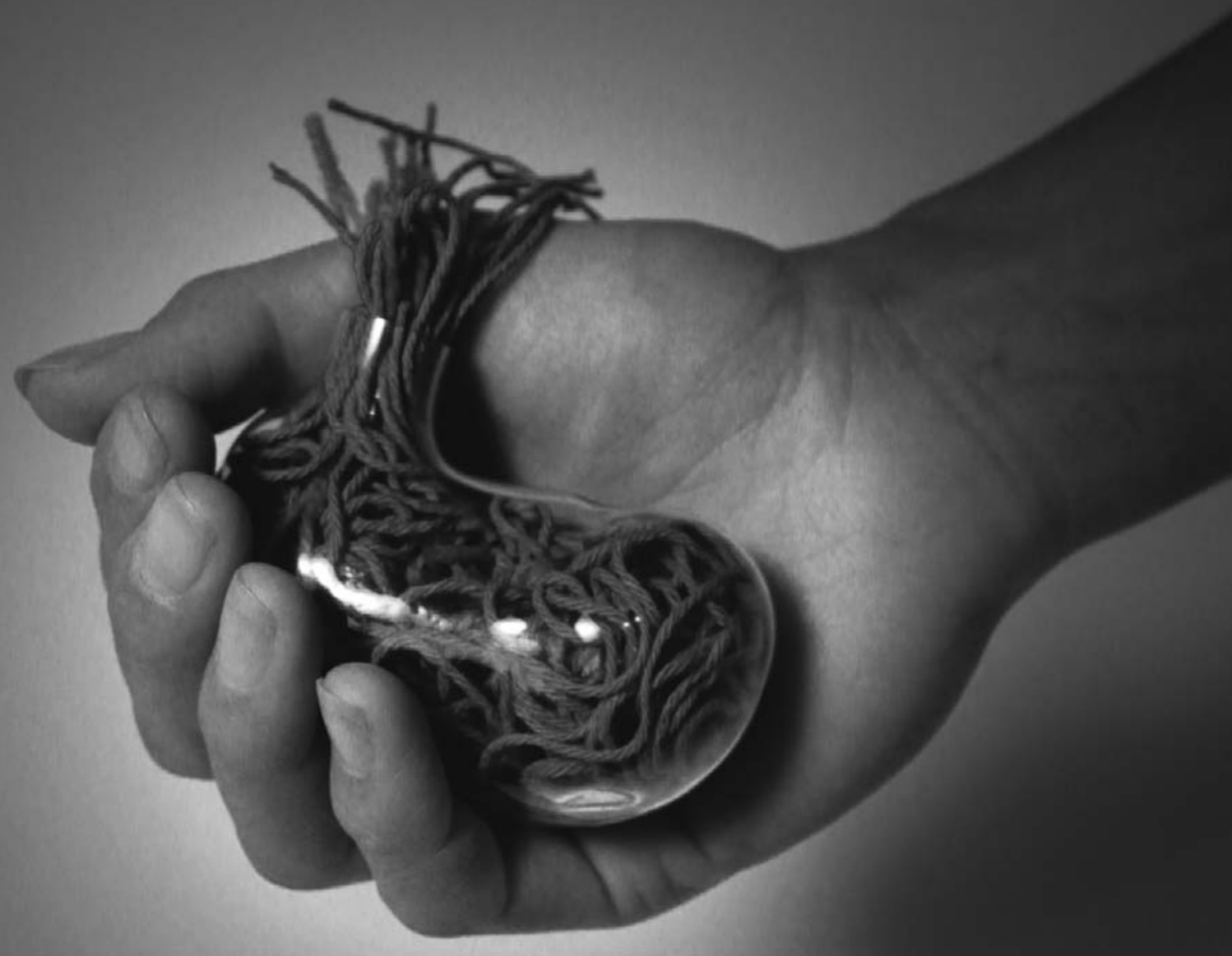

R.H.D. Vaes

M.R.M. Scheltinga

Eur J Vasc Endovasc Surg. 20I2 Oct;44(4: 452-6. 


\section{Abstract}

\section{Objective}

Chronic hand ischaemia is occasionally observed in haemodialysis patients with a brachiocephalic fistula using the Gracz technique. Open venous side branches of the access may contribute to lower peripheral perfusion pressures. This study reports on the effects of access side branch ligation (SBL) on ischemia in patients with HAIDI (haemodialysis access induced distal ischemia).

\section{Design, materials and methods}

Hand ischaemia was quantified using a published questionnaire (HIQ minimal o points: no ischaemia, maximal 500: excruciating ischemia). Finger pressures $\left(\mathrm{P}_{\mathrm{dig}}, \mathrm{mmHg}\right)$, digital brachial index (DBI) and access flow were measured before and after SBL.

\section{Results}

Twenty-two patients were operated for grade 2-4 HAIDI during 7 years, and I2 underwent SBL (as single procedure $n=5$, preceeding banding/DRIL $n=7$ ). Hand ischaemia was attenuated after SBL only $(\mathrm{n}=5$, HIQ $216 \pm 39$ vs $73 \pm 26, \mathrm{P}=0.03)$. A $25 \%$ increase was observed in both $\mathrm{P}_{\text {dig }}(\mathrm{n}=\mathrm{I} 2$, before SBL: $57 \pm 8 \mathrm{~mm} \mathrm{Hg}$, after: $72 \pm 8 \mathrm{~mm} \mathrm{Hg}, \mathrm{P}=0.012$ ) and DBI (before SBL: $0.49 \pm 0.06$, after: $0.6 \mathrm{I} \pm 0.04, \mathrm{P}=0.006$ ). Access flow did not change. All patients successfully resumed dialysis.

\section{Conclusion}

Side branch ligation may be effective as single or adjunctive surgical procedure in the treatment of HAIDI in the presence of a Gracz fistula. 


\section{Introduction}

An autologous arteriovenous fistula (AVF) based at the brachial artery occasionally (4-9 \%) leads to progressive hand ischaemia (HAIDI, haemodialysis access induced distal ischaemia) $(\mathrm{I}, 2)$. The ischaemia may be acute, subacute or chronic ( $<24$ hours, $\mathrm{I}-30$ days, or $>\mathrm{I}$ month after AVF construction, respectively) (2). Chronic HAIDI is the most frequently occurring form, and this type is probably associated with continuing atherosclerosis of inflow arteries combined with a loss of blood pressure at the level of the arteriovenous anastomosis (2-4). Moreover, ongoing dilation of venous portions of the AVF likely contributes to a progressive loss of loco regional blood pressure over time (2). If patients have a brachial artery based Gracz fistula, patent venous side branches may also contribute to an additional pressure loss.

Although an initial treatment regimen may be conservative, most HAIDI patients require an invasive procedure. If one accepts the premise that hand ischaemia is due to loco regional hypotension, a first step is arterial inflow visualization aimed at identification haemodynamically significant proximal stenotic disease. However, an inflow stenosis may be present in just a small number of patients with severe hand ischaemia $(5,6)$. If endovascular treatment of possible inflow stenosis does not alleviate ischaemic symptoms, most authors agree on instituting vascular surgery including distal revascularisation with interval ligation (DRIL), proximalisation of arterial inflow (PAI), revision using distal inflow (RUDI) or banding, depending on preoperative access flow $(7-\mathrm{I} 4)$.

The role of patent venous side branches (SB) of the AVF's outflow tract in case of a brachial artery based Gracz fistula in the etiology of HAIDI is unclear.. One may hypothesize that open $\mathrm{SBs}$ contribute to loss of arterial blood pressure due to shunting. As a consequence, open SBs may worsen distal ischaemia. As most SBs due to their deep position are unsuited for needling, ligation will usually not reduce dialysis capacity. A recent study on endovascular treatment of SBs in HAIDI reported encouraging results (I5). Data on open SBL as a treatment option for HAIDI are not available. Aim of the present study was to report on the results of SBL in patients with clinically significant hand ischaemia in the presence of an autologous brachial artery based AVF. We hypothesized that simple ligation of the access' venous side branches would lead to attenuation of hand ischaemia with improved finger pressures. 


\section{Materials and methods}

\section{Study population}

The study was performed between January 2005 and February 2012 in the Maxima Medical Center (MMC), Veldhoven, The Netherlands. The MMC is an 850-bed hospital accommodating 200.000 patients in a semirural environment. A commonly used technique in this institution is the creation of a brachial artery based AVF termed a Gracz fistula. The Gracz type fistula entails mobilizing of the median cubital vein or a deep perforating branch that is subsequently connected to the brachial artery. Using this technique, outflow is usually via both the upper arm cephalic and basilic vein.

Some roo patients receive chronic haemodialysis on two locations of the MMC (Veldhoven and Eindhoven). Access flow is measured in duplicate every two months as suggested by KDOQI using standard two-needle dilution techniques (HDor, Transonic Systems Inc, New York, USA). Detection and surgical treatment of haemodialysis vascular access related hand ischaemia is conducted using a standard protocol including intraoperative monitoring of access flow and finger pressures. By making an incision in the axillary region, access is gained to the main outflow vein used for measuring access flow. This is a standard part of our operative protocol but no extra incisions were required. Therefore the local Medical Ethics Committee judged that approval for the present study was not required as this approach is considered standard care in our department.

Nephrologists and surgeons have a special interest in the management of hand ischaemia in the presence of an AVF. Most nurses are familiar with the symptoms of HAIDI. Patients that report symptoms possibly associated with ischaemia are discussed in a weekly multidisciplinary meeting. Patients are subsequently interviewed at the outpatient vascular department. A published questionnaire qualifying and quantifying hand ischaemia is used to score symptomatology (hand ischaemic questionnaire, HIQ) (I6). This HIQ scores severity and frequency of five cardinal symptoms including pain, cramps, coldness, loss of strength and diminished sensibility. Ischaemic scores may range from o (no symptoms associated with ischaemia) to 500 (maximal symptoms).

A physical examination including hand inspection and radial artery palpation is performed. Reversibility of the ischaemia is determined using a fistula compression test. If a combination of the patient's history, physical examination and HIQ strongly suggests HAIDI, patients underwent finger plethysmography with and without fistula compression (Vasoguard Nicolet $8 \mathrm{MHz}$, Scimet, Bristol, UK ). Both a $<50 \mathrm{~mm} \mathrm{Hg}$ finger pressure $\left(\mathrm{P}_{\mathrm{dg}}\right.$, in $\left.\mathrm{mmHg}\right)$ or a $<0.6$ digital brachial index (DBI) are accepted cut-off points of hand ischaemia (I7). Patients were graded according to a 
published I-4 scale analogous to the Fontaine classification (Appendix I) (2). Invasive diagnostics were indicated if patients suffered from a grade $2 b, 3$ or 4 HAIDI. These patients underwent an angiography via the groin for identification and possibly optimization of arterial inflow stenosis. The AVF's anastomosis and venous outflow tract including SBs were visualized (Figure I). If multidisciplinary agreement on an invasive strategy was attained, patients were informed on the nature of the operative procedure and verbally and in writing consented to its specifics. Patients qualified for the present trial if they:

I. harboured a brachial artery based arteriovenous fistula,

2. were suffering from at least a HAIDI grade $2 b$ and,

3. angiography detected venous $\mathrm{SB}$ in a $3-5 \mathrm{~cm}$ area in proximity to the anastomosis.

Patients were excluded if signs of impaired mental capacity or a language barrier were present.

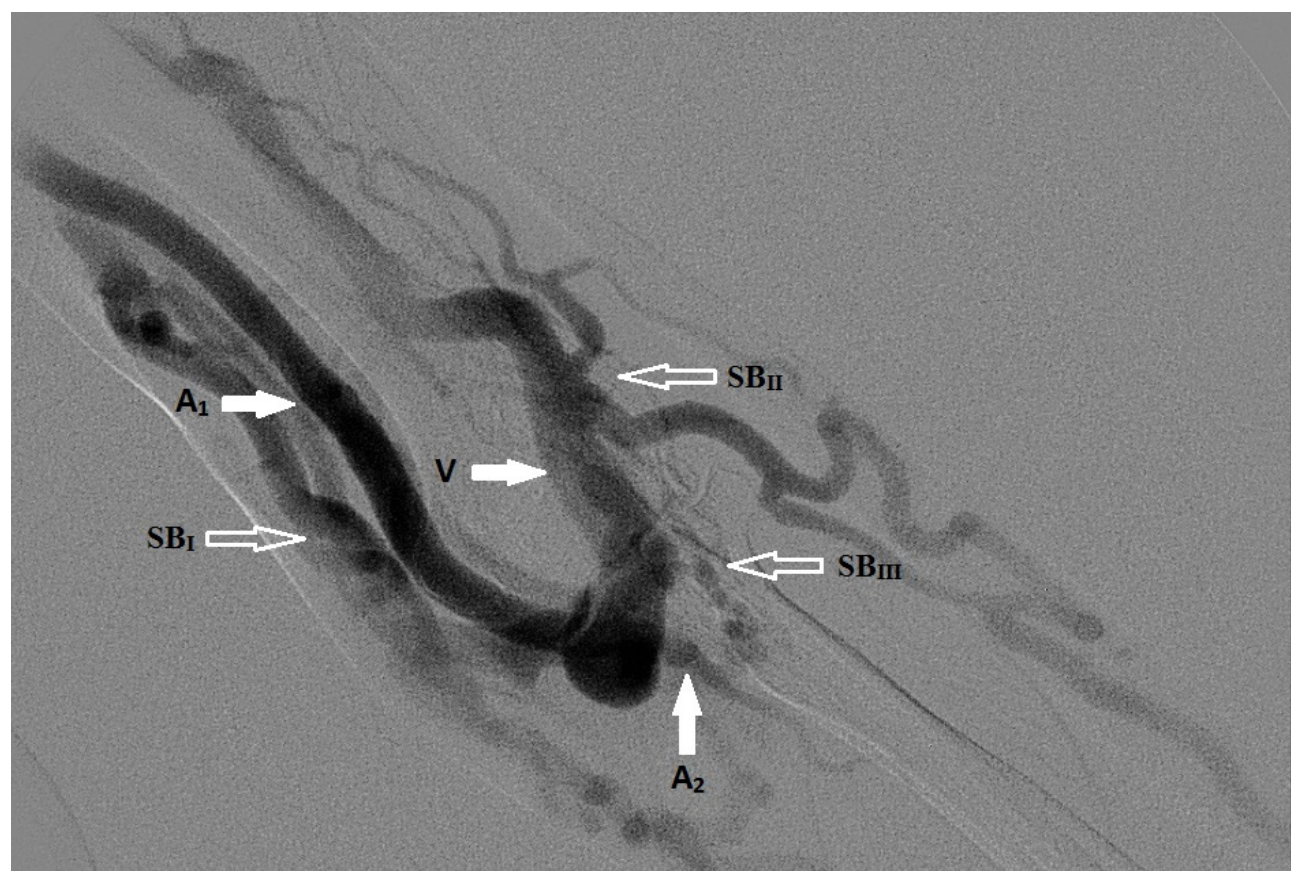

Figure 1. Angiographic view of a left sided Gracz fistula with a brachial inflow artery (A1) and a small radial artery (A2), a small basilic vein (SBI) and a distended cephalic outflow vein (V) with two side branches (SBII and SBIII). Both side branches and the basilic vein were surgically ligated (SBI-III).

\section{Operative protocol}

Patients received general anaesthesia. Heart rate (HR, in beats/min), blood pressure (SBP, systolic blood pressure; DBP, diastolic blood pressure, $\mathrm{mmHg}$ ) were obtained from the contralateral arm at regular intervals via an on-line electrocardiogram (ECG) and a sphygmomanometer. $\mathrm{P}_{\text {dig }}$ of 
the index finger of the affected hand was serially determined using a plethysmographic technique under strict sterile conditions (VasoGuard Nicolet, 8 Mhz, Scimed Ltd, Bristol, UK)

Following sterile exposure of the entire arm, a longitudinal $2 \mathrm{~cm}$ incision downstream towards the axillary region was used to gain access to the main outflow vein (upper arm cephalic or basilic) as determined by the angiography. On line access flow measurements were obtained using Optimax flow probes and ultrasonic transit time technique (HT 33 3 , both Transonic Systems Inc, New York, USA). The arteriovenous anastomosis and neighbouring SBs as dictated by the angiography were dissected over a $3-5 \mathrm{~cm}$ area using the initial skin incision previously used for AVF creation. After a I minute equilibration time period, access flow, HR, SBP, DBP and $\mathrm{P}_{\text {dig }}$ were measured. The dissected SBs were ligated (Figure 2). All parameters were measured again I minute after the last SB was ligated.

If $\mathrm{P}_{\text {dig }}$ and digital brachial index (DBI) did not increase above published cut-off points $\left(\mathrm{P}_{\mathrm{dig}}>50\right.$ $\mathrm{mmHg}, \mathrm{DBI}>0.6$ ), patients additionally underwent banding (if access flow >I L/min) or distal revascularization (<I L/min). Patients were allowed dialysis on the same or next day if required by the blood results. Six weeks post-operatively, patients were evaluated for residual symptoms of hand ischaemia using the HIQ and a physical examination.

\section{Definitions and analysis}

Data recording and statistical analyses were performed using SPSS version 17.0 (SPSS Inc., Chicago, IL, USA). Access flow just before SBL was set at Ioo\%, and access flow values after SBL were expressed as a percentage thereof. These values were not expressed in absolute numbers as systemic blood pressure (and consequent arm blood flow) during general anaesthesia is considerably lower compared to values obtained during conscious states. A Wilcoxon-signed rank test was used to determine the effect of $\mathrm{SBL}$ on $\mathrm{BP}, \mathrm{HR}, \mathrm{P}_{\mathrm{dig}}$ and DBI. All results were expressed as mean $\pm \mathrm{SEM}$ (standard error of the mean). A $\mathrm{P}$ value of <..05 was considered significant.

\section{Results}

During the seven year study period, a Gracz AVF was constructed in I4O patients. Of this population, 22 patients underwent revision for stage 2b-4 HAIDI. Angiography did not demonstrate significant stenosis in the inflow arteries in any patient $(n=22)$. Twelve patients met all three inclusion criteria whereas Io did not because they had no side branches within $3^{-5} \mathrm{~cm}$ of the anastomosis ( $\mathrm{n}=\mathrm{I} 2$, age $69 \pm 5$ years, 5 female and 7 male, Table I). None of these twelve patients included suffered from tissue loss (Table I). Angiography demonstrated I-3 possibly 


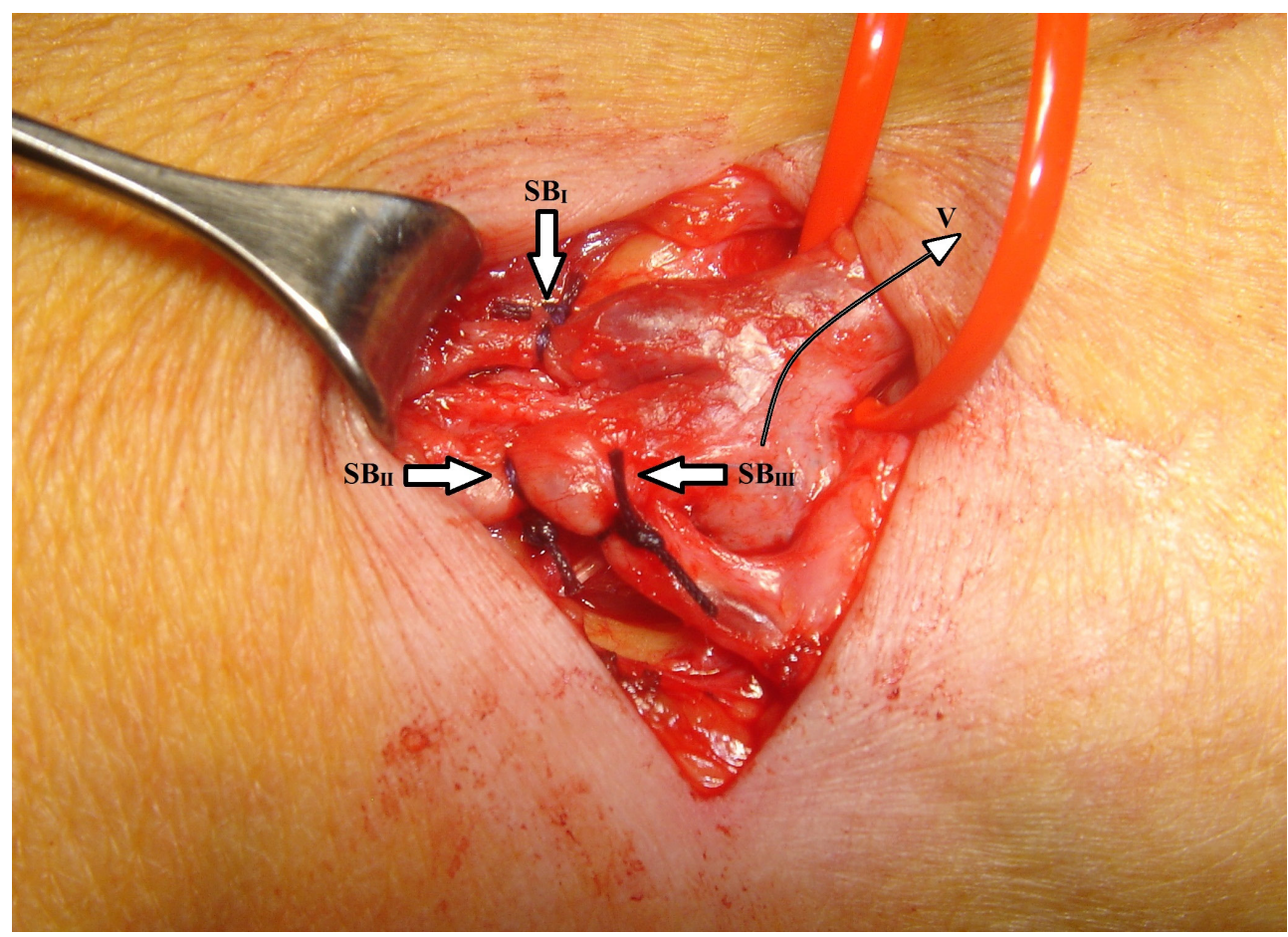

Figure 2. Peroperative view of ligated side branches (SBI-III) in a Gracz fistula. The venous outflow tract $(\mathrm{V})$ is marked with the long arrow, the brachial artery is not visible.

Table I. Demographics of patients with hand ischaemia undergoing elbow access side branch ligation.

\begin{tabular}{ll}
\hline $\mathrm{N}$ & 12 \\
Age (mean \pm SEM) & $69 \pm 5$ \\
Gender (male/female) & $7 / 5$ \\
Diabetes Mellitus (yes/no) & $1 / 11$ \\
Hypertension (yes/no) & $8 / 4$ \\
Peripheral arterial occlusive disease (yes/no) & $4 / 8$ \\
Coronary arterial disease (yes/no) & $5 / 7$ \\
Brachial artery based AVF & 12 \\
Time after AVF construction (months) & $25 \pm 8$ \\
Grade of HAIDI (2b/3/4) & $8 / 4 / 0$ \\
\hline
\end{tabular}

hemodynamically important SBs per study patient. A total of 25 side-branches were ligated (basilic vein $\mathrm{n}=\mathrm{IO}$, other $\mathrm{n}=\mathrm{I5}$ ). SBL as a single surgical treatment option was deemed sufficient (improved intraoperative $\mathrm{P}_{\mathrm{dig}}>50 \mathrm{mmHg}, \mathrm{DBI}>0.6$ ) in five patients. Just one of these five patients underwent a basilic vein ligation as a single therapeutic option only. The remaining seven individuals additionally underwent a second procedure during the very same operation as 
these two parameters were not improved sufficiently (banding $n=5$, distal revascularization using a venous bypass $n=I$, basilic vein transposition $n=I$ ).

The time between AVF construction and revision for HAIDI was $25 \pm 8$ months. SBL resulted in a higher $\mathrm{P}_{\text {dig }}$ in all patients $\left(\mathrm{n}=\mathrm{I} 2, \mathrm{P}_{\mathrm{dig}} 57 \pm 8\right.$ vs. $72 \pm 8 \mathrm{mmHg}, \mathrm{P}=0.0 \mathrm{o}$; $\mathrm{DBI} 0.49 \pm 0.06$ vs. $0.6 \mathrm{I}$ $\pm 0.04, P=0.01$, Figure 3 ). Ligation had no effect on SBP or HR but DBP rose slightly ( $n=I 2$, $5^{\mathrm{I}} \pm 4$ to $\left.55 \pm 5 \mathrm{mmHg}, \mathrm{P}=0.04\right)$. Intraoperative access flow did not change in the five patients undergoing SBL only ( $n=5$, Ioo\% vs. $99.6 \% \pm 0.4, p=0.600$, Table II).

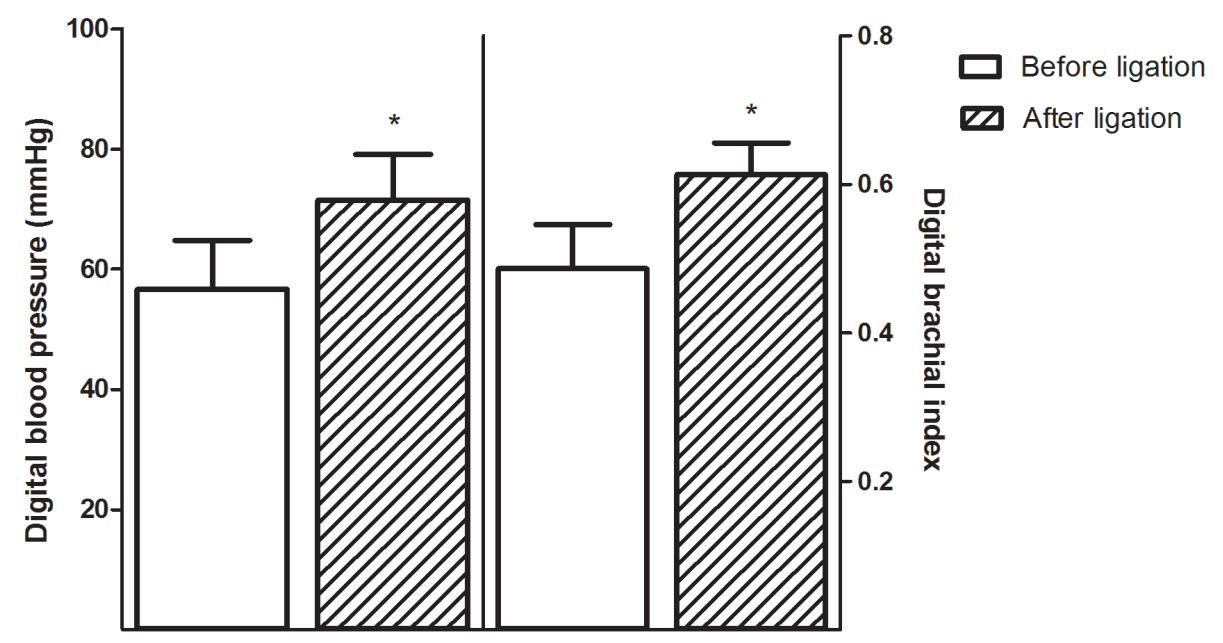

Figure 3. Digital blood pressure $(\mathrm{mmHg})$ and digital brachial index before and after side branch ligation in patients with hand ischemia $\left(\mathrm{n}=12,{ }^{*} \mathrm{p}<0.05\right)$.

Table II. Hemodynamic effects of side branch ligation in patients with hand ischemia in the presence of an autologous elbow fistula.

\begin{tabular}{llll} 
& Before ligation & After ligation & P \\
\hline Systolic BP $(\mathrm{mmHg}, \mathrm{n}=12)$ & $113 \pm 8$ & $116 \pm 8$ & 0.53 \\
Diastolic BP $(\mathrm{mmHg}, \mathrm{n}=12)$ & $51 \pm 4$ & $55 \pm 5$ & 0.04 \\
Heart rate (beats/sec, $\mathrm{n}=11)$ & $61 \pm 3$ & $62 \pm 3$ & 0.62 \\
Peroperative flow $(\%, \mathrm{n}=7)$ & 100 & $99.6 \pm 0.4$ & 0.60 \\
\hline
\end{tabular}

All twelve patients underwent an uncomplicated dialysis session on either the same or the first postoperative day. Ischemic symptoms obtained at the first outpatient control after six weeks were significantly attenuated in the patients receiving SBL as a single surgical procedure $\left(n=5, H I Q_{\text {pre }}\right.$ $2 \mathrm{I} 6 \pm 39$ vs. $\left.\mathrm{HIQ}_{\text {post }} 73 \pm 26, \mathrm{P}=0.043\right)$. Postoperative access flows were not different compared to preoperatively $(\mathrm{n}=5$, pre: $600 \pm \mathrm{I} 60 \mathrm{~mL} / \mathrm{m}$, post: $750 \pm \mathrm{I} 60 \mathrm{~mL} / \mathrm{m}, \mathrm{P}=0.27)$. Ischemic symptoms 
were also effectively treated in the remaining 7 patients receiving both a SBL and an additional AVF revision, ( $\mathrm{n}=7, \mathrm{HIQ}$ pre $208 \pm 57$ vs. $\mathrm{HIQ}_{\text {post }} 45 \pm 29, \mathrm{P}=0.043$ ) whereas access flows were decreased although not significant ( $\mathrm{n}=7$, pre $2215 \pm 488 \mathrm{~mL} / \mathrm{m}$, post: $967 \pm 98 \mathrm{~mL} / \mathrm{m}, \mathrm{P}=$ o.I2). Postoperative tissue loss was not present in any of the twelve patients.

Perioperative complications associated with SBL were not observed. However, one patient developed an aneurysmal enlargement just proximal to the banding site leading to an occlusion I year after revision. A second patient developed a venous outflow stenosis leading to access occlusion after 18 months. Recurrent hand ischaemia or access occlusion were not observed, neither after SBL alone ( $n=5$, mean FU $38 \pm 14$ months) nor after a combined procedure $(n=7$, mean FU $29 \pm 9$ months).

\section{Discussion}

Side branch ligation (SBL) is incidentally indicated after a newly constructed AVF as a way of promoting maturation of the main outflow tract (I8). However, most venous portions of an AVF do not require SBL but demonstrate an overall dilatation over time as a response to arterial blood pressure (BP). If one accepts the premise that progressive hand ischaemia is due to a loss of arterial BP originating anywhere between heart and dialysis hand, therapy should focus on identifying that source of BP loss. If angiography excludes a stenotic subclavian, axillary or brachial artery, a BP decrease may in part be caused by the total venous outflow including main tract and its branches. As a consequence, ligating SBs with preservation of the main tract was hypothesized to attenuate BP loss. One earlier report incorporating five patients with hand ischaemia supports this hypothesis as symptoms were diminished following endovascular SB coiling (I5). The present study in I2 patients with signs of clinically relevant chronic HAIDI is the first to report on SBL as a single $(n=5)$ or an adjunctive procedure $(n=7)$, and the results strongly suggest the validity of this concept.

The initial diagnostic work-up in patients with suspected chronic HAIDI as presented in the current study, is non-invasive and straight forward. History is characteristic as most patients report typical symptoms of hand ischemia whereas physical examination aimed at identifying signs of hand ischaemia is simple. Radial artery pulsations are often absent or weak but may return after manual AVF compression $(3,4)$. However, if an AVF has several outflow tracts including basilic vein and/or distal cephalic vein, a compression test is probably less diagnostic as both the inflow artery and venous branches may accidently be compressed. Lowered finger pressures $\left(\mathrm{P}_{\mathrm{dig}}<50 \mathrm{~mm}\right.$ $\mathrm{Hg}$ ) may increase after consecutively compressing these venous branches. Duplex analysis may 
identify significant flow in outflow veins including SBs. Ideally, a combination of plethysmography and Duplex may unveil the hemodynamic importance of SBs including the basilic vein.

A first invasive step in the management of patients with suspected chronic HAIDI is visualization of the inflow arterial tree. Arterial inflow must be optimized prior to instituting open surgical procedures such as distal revascularization. Some authors advice to perform endovascular angioplasty even if the arterial inflow stenosis may seem limited (6, 19, 20). Although an angioplasty of a $50 \%$ stenosis may be highly effective, this criterion is somewhat questionable (6, I9-22). It should be appreciated that the hemodynamic effect of just angiographically 'minor' stenosis may be substantial in a high flow system as typically observed in a dialysis arm $(3,5,23)$. If a beneficial effect of angioplasty is doubted, intraluminal pressure measurements may quantify the hemodynamic effect of such a limited stenosis (24). Interestingly, an inflow stenosis was not present in any of the 22 patients undergoing angiography in the seven year study period in our institution. However, pressure measurements were not performed.

If the arterial blood pressure loss is not due to stenotic inflow disease, a next step is the evaluation of the hemodynamic consequences of SBs during an endovascular or open surgical procedure. Several issues require addressing. The effect of any invasive procedure on finger perfusion should be monitored intraoperatively using plethysmography while ideally simultaneously measuring access flow (II, 25). The goal is to attain an increase in finger pressures while sufficient access flow for adequate haemodialysis is maintained. Another possible issue is the safety of a corrective AVF procedure. The systemic hemodynamic effects after manipulating a large flow AVF may be underestimated. For example, immediate cardiac death after AVF ligation has been reported, most probably due to acute intravascular overload (26). Increased blood pressures are routinely observed after AVF occlusion (27). The present study shows that SBL resulted in slightly higher diastolic blood pressure but systolic blood pressures and heart rates remained unaltered. Access flow as measured in the outflow vein used for needling also did not change, resulting in an uncomplicated haemodialysis postoperatively in all patients.

What is the potential role of SBL in the therapeutic armamentarium for chronic HAIDI? Once surgery is indicated, any invasive procedure should be guided using intraoperative plethysmography and ideally access flow. If the diagnostic work up reveals $\mathrm{SBs}$, these structures require dissection and ligation as a possible first step. If the $\mathrm{P}_{\text {dig }}$ (or DBI) is not pushed beyond the generally accepted cut off point, one must continue with an additional (and more invasive) procedure such as proximalization of arterial inflow (PAI), distal revascularization interval ligation (DRIL), 
revision using distal inflow (RUDI) or banding. Conversely, these techniques may be less effective if hemodynamically important SB are left untreated.

Can onset of a type of HAIDI that is exclusively due to patent side branches be prevented at the time of fistula creation? The present study included patients harbouring an AVF that was usually constructed between the brachial artery and the deep perforating elbow vein (Gracz) (28). It is unknown whether this type of AVF preferentially leads to HAIDI compared to other brachial artery based fistulas. In the Gracz type of AVF, outflow usually occurs via both the cephalic and the basilic upper arm vein. If basilic outflow appears dominant (compared to cephalic flow) according to a peroperative compression test, one may decide to ligate the basilic vein. By doing so, maturation of the cephalic pathway is stimulated whereas this type of side branch HAIDI is prevented. However, it is currently unclear whether routine basilic vein ligation is necessary when the cephalic vein appears dominant on an intraoperative compression test. In our opinion SBL at the time of fistula creation as a means to prevent hand ischemia should not routinely be performed as the chances on successful maturation may be lowered.

In conclusion, open venous side branches of an autologous brachial artery based haemodialysis fistula, as in a Gracz fistula, may contribute significantly to chronic hand ischaemia. Side branch ligation may be considered as an adjunctive surgical procedure in the treatment of haemodialysis access induced hand ischaemia. 


\section{References}

I. Padberg FT, Jr., Calligaro KD, Sidawy AN. Complications of arteriovenous hemodialysis access: recognition and management. J Vasc Surg. 2008 Nov;48(5 Suppl):55 S-8oS.

2. Scheltinga MR, van Hoek F, Bruijninckx CM. Time of onset in haemodialysis access-induced distal ischaemia (HAIDI) is related to the access type. Nephrol Dial Transplant. 2009 Oct;24(Io):3198-204.

3. Scheltinga MR, Bruijninckx CM. Haemodialysis Access-induced Distal Ischaemia (HAIDI) is Caused by Loco-regional Hypotension but not by Steal. Eur J Vasc Endovasc Surg. 20Ir Nov 25.

4. Wixon CL, Hughes JD, Mills JL. Understanding strategies for the treatment of ischemic steal syndrome after hemodialysis access. J Am Coll Surg. 2000 Sep;I9I(3):30I-Io.

5. Scali ST, Huber TS. Treatment strategies for access-related hand ischemia. Semin Vasc Surg. 2OII Jun;24(2):128-36.

6. DeCaprio JD, Valentine RJ, Kakish HB, Awad R, Hagino RT, Clagett GP. Steal syndrome complicating hemodialysis access. Cardiovasc Surg. 1997 Dec;5(6):648-53.

7. Minion DJ, Moore E, Endean E. Revision using distal inflow: a novel approach to dialysis-associated steal syndrome. Ann Vasc Surg. 2005 Sep;r9(5):625-8.

8. Berman SS, Gentile AT, Glickman MH, Mills JL, Hurwitz RL, Westerband A, et al. Distal revascularizationinterval ligation for limb salvage and maintenance of dialysis access in ischemic steal syndrome. J Vasc Surg. I997 Sep;26(3):393-402; discussion -4.

9. Knox RC, Berman SS, Hughes JD, Gentile AT, Mills JL. Distal revascularization-interval ligation: a durable and effective treatment for ischemic steal syndrome after hemodialysis access. J Vasc Surg. 2002 Aug;36(2):250-5; discussion 6.

Io. Sessa C, Riehl G, Porcu P, Pichot O, Palacin P, Maghlaoua M, et al. Treatment of hand ischemia following angioaccess surgery using the distal revascularization interval-ligation technique with preservation of vascular access: description of an I8-case series. Ann Vasc Surg. 2004 Nov;18(6):685-94.

II. Scheltinga MR, Van Hoek F, Bruyninckx CM. Surgical banding for refractory hemodialysis access-induced distal ischemia (HAIDI). J Vasc Access. 2009 Jan-Mar;Io(I):43-9.

I2. Schneider CG, Gawad KA, Strate T, Pfalzer B, Izbicki JR. T-banding: a technique for flow reduction of a hyperfunctioning arteriovenous fistula. J Vasc Surg. 2006 Feb;43(2):402-5.

I3. van Hoek F, Scheltinga M, Luirink M, Pasmans H, Beerenhout C. Banding of hemodialysis access to treat hand ischemia or cardiac overload. Semin Dial. 2009 Mar-Apr;22(2):204-8.

I4. Zanow J, Kruger U, Scholz H. Proximalization of the arterial inflow: a new technique to treat access-related ischemia. J Vasc Surg. 2006 Jun;43(6):I2I6-2I; discussion 2I.

15. Kariya S, Tanigawa N, Kojima H, Komemushi A, Shomura Y, Shiraishi T, et al. Transcatheter coil embolization for steal syndrome in patients with hemodialysis access. Acta Radiol. 2009 Jan;50(I):28-33.

I6. van Hoek F, Scheltinga MR, Kouwenberg I, Moret KE, Beerenhout CH, Tordoir JH. Steal in hemodialysis patients depends on type of vascular access. Eur J Vasc Endovasc Surg. 2006 Dec;32(6):710-7.

I7. van Hoek F, Scheltinga MR, Luirink M, Raaymakers LC, van Pul C, Beerenhout CH. Access flow, venous saturation, and digital pressures in hemodialysis. J Vasc Surg. 2007 May;45(5):968-73.

I8. Falk A. Optimizing hemodialysis arteriovenous fistula maturation. J Vasc Access. 20II Jan-Mar;I2(I):I-3.

I9. Asif A, Leon C, Merrill D, Bhimani B, Ellis R, Ladino M, et al. Arterial steal syndrome: a modest proposal for an old paradigm. Am J Kidney Dis. 2006 Jul;48(I):88-97.

20. Duijm LE, Overbosch EH, Liem YS, Planken RN, Tordoir JH, Cuypers PW, et al. Retrograde catheterization of haemodialysis fistulae and grafts: angiographic depiction of the entire vascular access tree and stenosis treatment. Nephrol Dial Transplant. 2009 Feb;24(2):539-47.

21. Valji K, Hye RJ, Roberts AC, Oglevie SB, Ziegler T, Bookstein JJ. Hand ischemia in patients with hemodialysis access grafts: angiographic diagnosis and treatment. Radiology. I995 Sep;196(3):697-701.

22. Balaji S, Evans JM, Roberts DE, Gibbons CP. Treatment of steal syndrome complicating a proximal arteriovenous bridge graft fistula by simple distal artery ligation without revascularization using intraoperative pressure measurements. Ann Vasc Surg. 2003 May;17(3):320-2.

23. Ramuzat A, How TV, Bakran A. Steal phenomenon in radiocephalic arteriovenous fistula. In vitro haemodynamic and electrical resistance simulation studies. Eur J Vasc Endovasc Surg. 2003 Mar;25(3):246-53.

24. Reifsnyder T, Arnaoutakis GJ. Arterial pressure gradient of upper extremity arteriovenous access steal syndrome: treatment implications. Vasc Endovascular Surg. 20Io Nov;44(8):650-3. 
25. Chemla ES, Morsy M, Anderson L, Whitemore A. Inflow reduction by distalization of anastomosis treats efficiently high-inflow high-cardiac output vascular access for hemodialysis. Semin Dial. 2007 JanFeb;20(I):68-72.

26. Pascual J, Martins J, Bouarich H, Galeano C, Barrios V, Marcen R, et al. Sudden death after arteriovenous fistula ligation in a renal transplant patient. Ann Vasc Surg. 2008 Jan;22(I):I34-5.

27. Vaes RHD, Beerenhout CH, Tordoir J, Scheltinga MR. Hemodynamic effects of vascular access compression in haemodialysis patients. J Vasc Access. 20I4 May-Jun;15(3):I63-8

28. Gracz KC, Ing TS, Soung LS, Armbruster KF, Seim SK, Merkel FK. Proximal forearm fistula for maintenance hemodialysis. Kidney Int. I977 Jan;II(I):7I-5. 



\section{CHAPTER - IV}

\section{Venous side branch ligation as a first step treatment for haemodialysis access induced hand ischaemia: effects on access flow volume and digital perfusion}

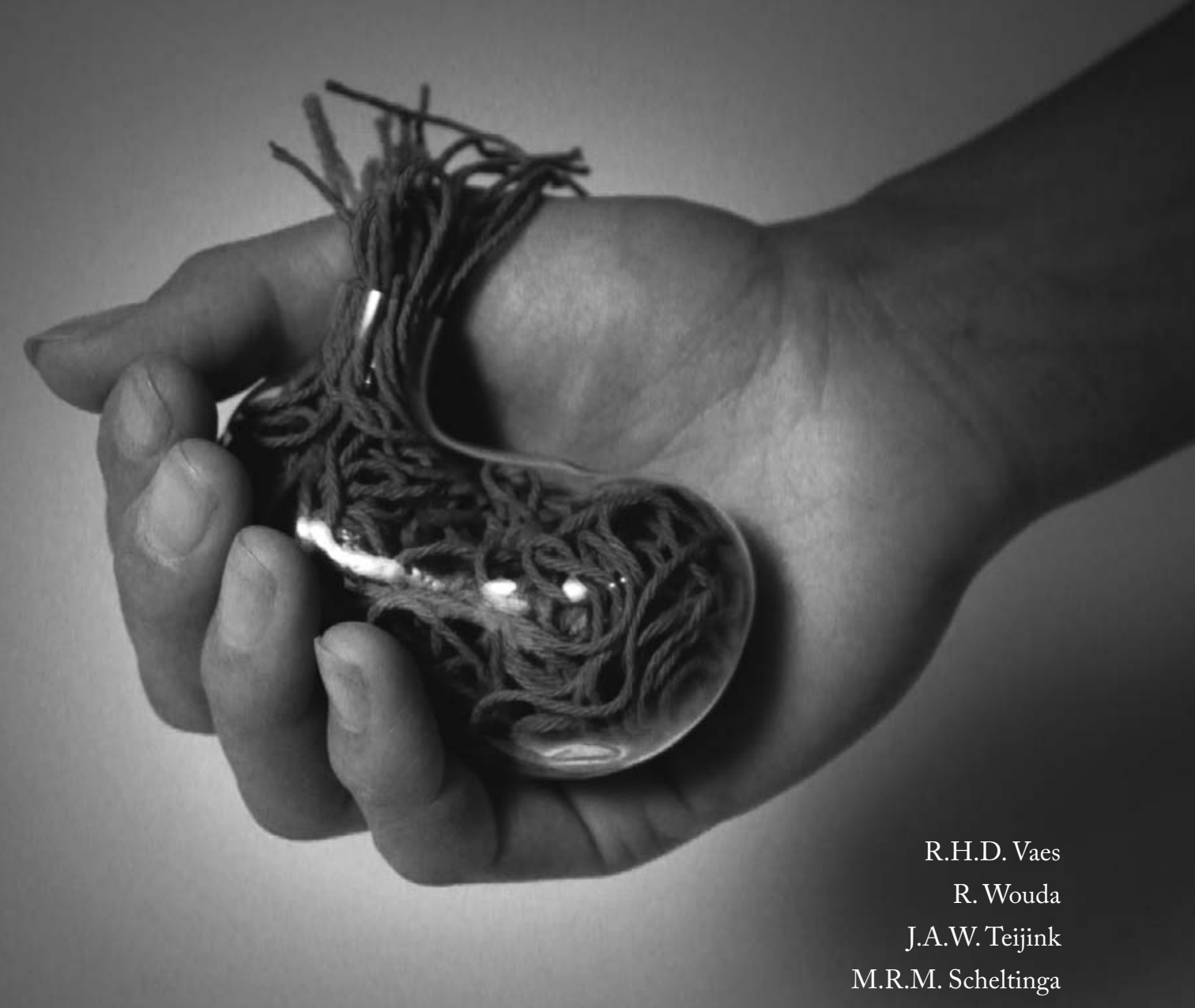

Eur J Vasc Endovasc Surg. 2015 Dec;50(6):810-4. 


\begin{abstract}
Objective

Haemodialysis access induced distal ischemia (HAIDI) induced by an autogenous arteriovenous fistula (AVF) is due to loss of blood pressure somewhere along the arterial blood supply of the arm. In some patients, side branches of the access' venous outflow tract may contribute to this blood pressure loss. Beneficial effects of side branch ligation (SBL) as a first step approach on ischemic symptoms were earlier reported. However, effects on access flow and AVF function after prolonged follow up are unknown.
\end{abstract}

\title{
Materials and methods
}

Prior to SBL, HAIDI patients with a brachial artery based AVF were studied using a questionnaire quantifying hand ischemia, digital brachial index (DBI, finger-plethysmography) and Duplex analysis. Access flow volume, patency rates, hand perfusion and complications were determined during a I2 month observation period following SBL.

\section{Results}

In nine years, SBLs were performed in 20 haemodialysis patients, either as single operative procedure $(\mathrm{n}=\mathrm{IO})$ or supplemented $(\mathrm{n}=\mathrm{IO})$ with additional surgical techniques during the same procedure (banding, $n=5$; basilic vein transposition, $n=4$; DRIL, $n=I$ ). Follow up data after I2 months were available in 18 patients. One patient with progressive hand ischemia required access ligation 3 months after SBL. Hand ischemia was attenuated or abolished in the remaining I7 patients (94\% clinical success rate). DBI improved from $0.5 \mathrm{I} \pm 0.05$ (pre-operative) to $0.68 \pm 0.04$ (direct postoperative) and $0.83 \pm 0.07$ (at one year follow-up). One year primary, assisted primary and secondary patency rates were $67 \%$ ( $12 / 18), 83 \%\left(\mathrm{I}_{5} / \mathrm{r} 8\right)$ and $89 \%$ (I6/I8), respectively. Mean access flows remained acceptable at 7 io $\pm 70 \mathrm{ml} / \mathrm{min}$.

\section{Conclusions}

Ligation of non-functional venous side branches of an autogenous brachial artery based AVF causing hand ischemia leads to prolonged attenuation of hand ischemia whereas access flow volumes are maintained after one year of follow up. Side branch ligation must be considered prior to embarking on more invasive surgery for HAIDI. 


\section{Introduction}

A brachial artery based AVF (arteriovenous fistula) for haemodialysis (HD) is occasionally associated with a long-term sequela such as aneurysm formation, high access flow or haemodialysis access induced distal ischemia (HAIDI) ( $\mathrm{I}-3)$. Hand hypo-perfusion may initially be experienced only during a dialysis session, but some individuals develop progressive ischemia leading to a limited hand function and reduced quality of life (4). Up to $9 \%$ of $\mathrm{HD}$ populations require an evaluation for HAIDI in due course $(4,5)$.

The pathophysiological mechanism underlying lower limb ischemia and HAIDI may be comparable. Loss of perfusion pressure anywhere between the heart and distal portions of an extremity both characterize HAIDI and lower limb ischemia (6). If hand ischemia in a HD patient is progressive, diagnostic efforts are directed towards visualizing the source of blood pressure loss (as in lower limb ischemia). If lowered hand digital pressures are not due to a drop in systemic blood pressure (cardiac origin) or a stenosed axillary or brachial inflow artery feeding the access, blood pressure loss is possibly associated with the AVF's low pressure venous outflow system ('pressure sink') (7). A surgical AVF revision such as venous outflow banding is based on attenuation of blood pressure loss at the arteriovenous junction (8). Conversely, incremental banding resulted in corresponding increases in finger pressures and attenuation of ischemic symptoms in one population with HAIDI (9).

A recent study demonstrated that ligating the AVF's venous side branches (side branch ligation, SBL) immediately resulted in increased finger pressures and attenuation of symptomatic hand ischemia (Io). It was concluded that SBL effectively reduces the pressure loss around the anastomosis. Moreover, the effectiveness of an additional flow reducing technique such as banding or DRIL is improved as excess shunting of blood is reduced. However, the long-term effects of a SBL first approach on hand perfusion, access flows and AVF patency are unknown. The present research was undertaken to study these parameters in HD patients who previously underwent SBL for haemodialysis access induced distal ischemia. In comparison to our previous study additional patients were included. It was hypothesized that a SBL first approach effectively treats hand ischemia without compromising AVF function. 


\section{Materials and methods}

\section{General information}

Presently, some iıo patients undergo chronic HD in Máxima Medical Center in Veldhoven and Eindhoven, The Netherlands. The preferred brachial artery based AVF in our institution is the 'Gracz fistula'. In this type of AVF, the median antecubital vein or its deep perforating vein is mobilized and anastomized to the brachial artery. AVF outflow in most instances occurs via both the cephalic and basilic vein. Patients possibly suffering from HAIDI are discussed in a weekly multidisciplinary meeting. If hand ischemia is deemed likely, patients are invited for further analyses at our vascular outpatient clinic. The patient is then interviewed and the dialysis hand is inspected. By manually blocking the AVF's venous outflow tract, including its side branches (SB), the ischemia is considered reversible if a warmer hand is experienced and radial artery pulsations return ('compression test') .

If HAIDI is likely, the patient is invited to complete a questionnaire quantifying hand ischemia (HIQ, 2, II). Although a HIQ score may not always accurately reflect the severity of HAIDI, previous studies have demonstrated that HIQ scores (o, no ischemia, 500, maximal ischemia) reliably predict the presence of HAIDI $(2,8,9)$. A finger pressure (Pdig) with and without compression is obtained in our vascular laboratory (VasoGuard Nicolet, 8 Mhz, Scimed Ltd, Bristol, UK, 8). Patients with minimally a type $2 \mathrm{~b}$ HAIDI undergo imaging of the access' arterial inflow and venous outflow using a Duplex or angiography (4, II, I2). If venous side branches $(\mathrm{SBs})$ in a $3-5 \mathrm{~cm}$ area in proximity to the anastomosis are present, a $\mathrm{SBL}$ procedure is offered as a first step surgical approach with additional flow reducing surgery when deemed necessary during the same procedure. All patients with a brachial artery based AVF with symptoms of at least type $2 \mathrm{~b}$ HAIDI and with venous $\mathrm{SBs}$ in a $3-5 \mathrm{~cm}$ area in proximity to the anastomosis were included in this study.

The first patient undergoing a SBL approach in our institution was operated in 2005 (9). During a $\mathrm{SBL}$ procedure, visible venous outflow SBs are ligated using a standard open approach. The effect is monitored with the use of digital pressures (VasoGuard Nicolet, $8 \mathrm{Mhz}$, Scimed Ltd, Bristol, $\mathrm{UK}$ ) and access flow measurements using an ultrasonic transit time technique (Optimax flow probes, HT 313, Transonic Systems Inc, New York, USA). If digital pressures do not increase or hand perfusion does not improve as subjectively judged on the basis of radial pulsations or digital skin colour, additional surgery such as banding (if flow is > I L/min) or distal revascularization 
interval ligation (DRIL, $<\mathrm{I} \mathrm{L} / \mathrm{min}$ ) is performed during the same operative procedure as previously published $(2, \mathrm{I} 3)$.

\section{Characteristics of present follow up study}

Immediate effects of SBL were reported previously (Io). All patients from this previous study were also included in the current study. For the purpose of the present follow up study, primary, assisted primary and secondary access patency rates were calculated after a one year follow up period. Clinical data were collected from standard nephrological and surgical electronic patient files. Access flows of operated patients were prospectively monitored and recorded every two months using a standard two-needle dilution techniques (HDor, Transonic Systems Inc, New York, USA) as suggested by DOQI (I4). Symptoms possibly associated with recurrent or residual HAIDI were quantified using the HIQ. Digital pressure measurements at one year were obtained in a portion of the patients. All patients gave oral informed consent for their treatment and follow up. As all of these evaluations are considered standard of care by our hospital dialysis specialists, approval of the local Medical Ethics Committee was not requested.

\section{Statistical analysis}

SPSS software version I7.o was used for data collection and statistical analysis (SPSS Inc, Chicago, I11). Distribution of data was studied for normality whereas the Wilcoxon-signed rank test compared differences between variables. A repeated measures ANOVA was performed to analyse access flow over time. A two-way ANOVA determined group differences in access flow over time. Follow up period was expressed in months as mean $( \pm \mathrm{SEM})$. Results were expressed as mean $( \pm$ SEM). Patency rates were expressed as recommended by the Society for Vascular Surgery and the American Association for Vascular Surgery ( 15 ). A P value of <0.05 was considered significant.

\section{Results}

Between January 2005 and December 2013, 46 HD patients were diagnosed with HAIDI in a single institution. These 46 patients represent $5 \%$ of the total population receiving chronic HD at any time during this 9 years observation period. As six HAIDI patients successfully underwent endovascular treatment of an arterial inflow stenosis and two patients with HAIDI type $2 \mathrm{~A}$ received conservative treatment, a total of $3^{8}$ patients were operated. In this surgical HAIDI population, seven patients received banding, six AVFs were ligated. Another two patients underwent basilic vein transposition whereas two received a DRIL. Clinically significant SBs following physical examination or Duplex were not identified in any of these I7 patients. 
Of the 38 patients requiring surgery, SBL was possible in the remaining 2I patients (55\%). All 2I underwent a SBL first approach although one patient was excluded as she had a radiocephalic AVF. All 20 brachial artery based AVF's were Gracz type. Demographics of this study population are depicted in table $\mathrm{r}$. Ten individuals underwent SBL as a single operative procedure. However, in the remaining ten patients, a SBL was supplemented with banding $(n=5)$, basilic vein transposition $(n=4)$ or DRIL $(n=1)$ in the same operative session (Io).

Table 1. Demographic data on patients undergoing side branch ligation for HAIDI

\begin{tabular}{ll}
\hline N & 20 \\
Age (Mean \pm SEM) & $69 \pm 3$ \\
Gender (male/female) & $10 / 10$ \\
Diabetes mellitus (yes/no) & $5 / 15$ \\
Peripheral arterial disease (yes/no) & $4 / 16$ \\
Hypertension (yes/no) & $11 / 9$ \\
HAIDI type (2b/3/4) & $8 / 11 / 1$ \\
\hline
\end{tabular}

During the I2 months follow up period following SBL, two of these 20 patients died (requested discontinuation of dialysis, $\mathrm{n}=\mathrm{I}$; heart failure, $\mathrm{n}=\mathrm{I}$ ). Eighteen patients reached the $\mathrm{I} 2$ months end point (SBL only $n=8$; SBL with additional flow reduction technique, $n=10$ ). During this one year observation period, one patient demonstrated progressively lower access flows and recurrent signs of hand ischemia due to diffuse atherosclerosis necessitating ligation and construction of a PTFE thorax loop arteriovenous graft (AVG) 3 months after SBL. AVFs of two additional patients occluded, one due to aneurysm formation resolved by successful revision Io months after SBL whereas a second AVF was successfully revised after one month using a PTFE upper arm loop AVG.

Three non-ischemic complications were observed during follow up. One patient developed symptoms of venous congestion six months after SBL only in the presence of an access flow $>\mathrm{I} 600$ $\mathrm{ml} / \mathrm{min}$ requiring flow reducing surgery using a revision using distal inflow (RUDI). Moreover, two patients underwent endovascular angioplasty of a significant stenosis of the brachial artery because of diminishing access flows, both nine months after SBL (SBL only, n=r; SBL with additional $\mathrm{BT}, \mathrm{n}=\mathrm{I})$. Primary, assisted primary and secondary access patency rates following $\mathrm{SBL}$ were $67 \%$ (I2/18), $83 \%(\mathrm{I} 5 / \mathrm{I} 8)$ and $89 \%$ (I6/I8), respectively.

Access flows are depicted in Figure I. In patients undergoing SBL only ( $\mathrm{n}=\mathrm{IO}$ ), access flow did not change immediately after the operation (IIO० \pm 320 vs IoIo \pm Io० $\mathrm{ml} / \mathrm{min}$ ). Moreover, 
flow remained well above the critical thrombosis threshold ( $400 \mathrm{ml} / \mathrm{min}$ ) during the $\mathrm{I} 2 \mathrm{months}$ postoperative observation period ( $7 \mathrm{IO} \pm 70 \mathrm{ml} / \mathrm{min}, \mathrm{n}=\mathrm{IO}$ ). Over time access flow did not significantly decrease although a trend was observed $(\mathrm{P}=0.07)$ using a repeated measures ANOVA. In contrast, postoperative access flow in patients undergoing SBL and a supplemental procedure ( $\mathrm{n}=\mathrm{IO}$ ) increased to $\mathrm{I} 42 \mathrm{O} \pm 200 \mathrm{ml} / \mathrm{min}$ at $\mathrm{I} 2$ months follow up, $(\mathrm{P}=0.24$, using repeated measures ANOVA). The two-way ANOVA showed a statistically significant interaction between study groups and time on access flow $(\mathrm{P}=0.0 \mathrm{I})$. This effect is mainly due to access flow differences in the study groups $(\mathrm{P}=0.0 \mathrm{I})$ and not due to time $(\mathrm{P}=0.96)$.

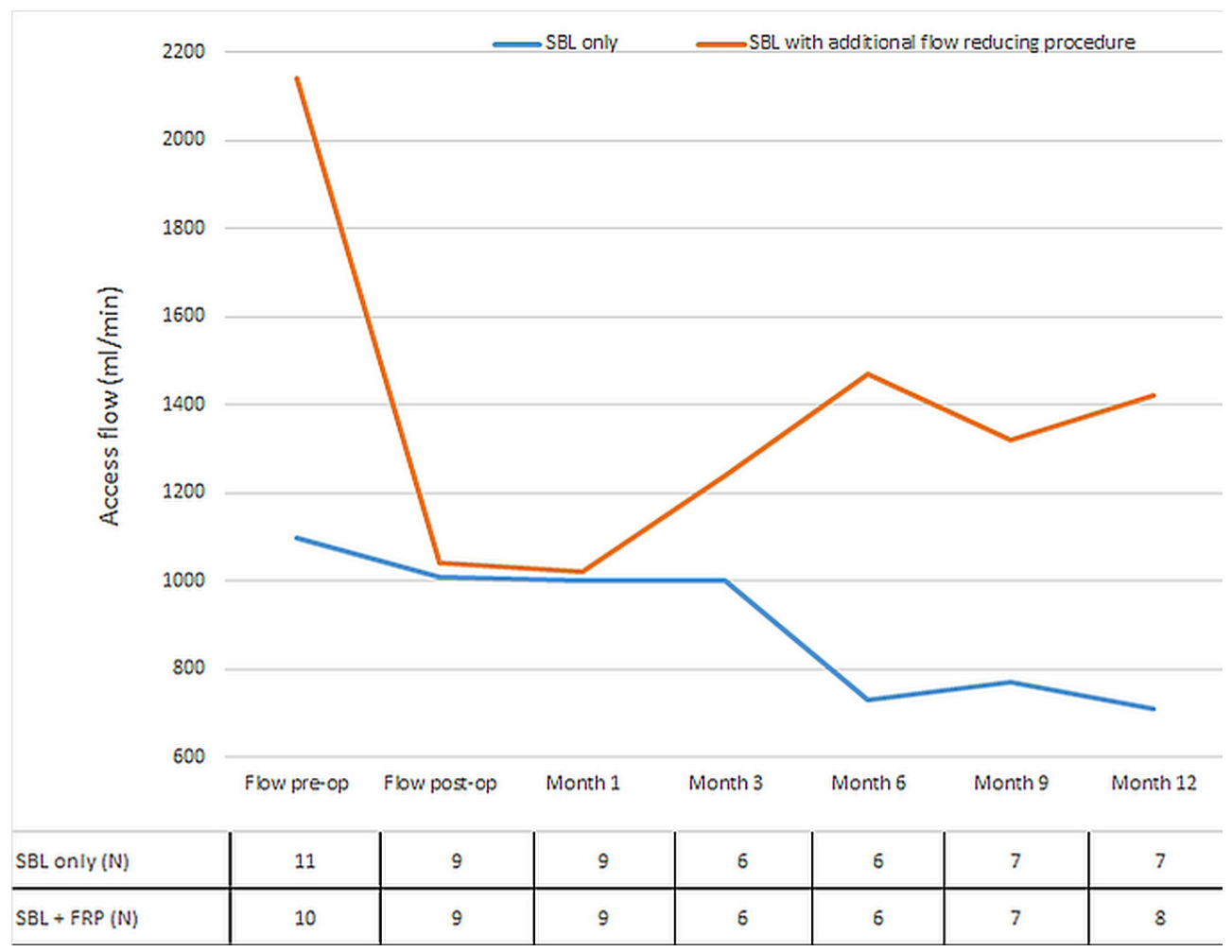

Figure 1. Mean access flow $(\mathrm{ml} / \mathrm{min})$ before and after side branch ligation (SBL) with and without additional flow reducing procedure (FRP) in patients with HAIDI.

Table 2 demonstrates effects of SBL on subjectively and objectively obtained parameters of hand ischemia. Immediately following SBL, scores reflecting ischemia dropped threefold. Moreover, hand ischemic scores were still more than twice as low compared to preoperatively at $\mathrm{I} 2$ months of follow up. DBI remained well above o.6, a generally accepted cut off point for ischemia, both immediately postoperatively as well as at the one year follow up (o.68 \pm 0.04 and $0.83 \pm 0.07$, 
respectively). Except for the one patient requiring access ligation due to progressive occlusive disease, no other patient underwent a novel evaluation or surgical procedure for recurrent hand ischemia during this time period. Therefore, a 94\% (I7/I8) SBL success rate was obtained.

Table 2. Ischemic scores and digital pressures following side branch ligation (SBL) in patients with HAIDI

\begin{tabular}{llll}
\hline & Before SBL & Immediately after SBL & $\mathbf{1 2 \pm 0 ~ m o n t h s ~ a f t e r ~ S B L ~}$ \\
\hline Hand ischemic score $^{\mathrm{a}}$ & $184 \pm 21$ & $60 \pm 15^{\mathrm{b}}$ & $79 \pm 35^{\mathrm{b}}$ \\
& $(\mathrm{n}=18)$ & $(\mathrm{n}=18)$ & $(\mathrm{n}=8)$ \\
Digital brachial index (Pdig/Psyst) & $0.51 \pm 0.05$ & $0.68 \pm 0.04$ & $0.83 \pm 0.07^{\mathrm{c}}$ \\
& $(\mathrm{n}=20)$ & $(\mathrm{n}=20)$ & $(\mathrm{n}=8)$ \\
\hline
\end{tabular}

a. 0 points, no signs ischemia -500 points, maximal, severe ischemia*

b. $\mathrm{P}<.05$ compared to before SBL

c. $\mathrm{P}<.05$ compared to before and immediately after SBL

\section{Discussion}

Haemodialysis access induced distal ischemia may be found in up to $9 \%$ of unselected dialysis populations $(4,5)$. If conservative measures (treating anaemia, gloves, optimization of medication) or a minimally invasive procedure (inflow angioplasty) fail, most surgeons would argue that a first line of invasive treatment is dictated by access flow volume. If flows exceed $\mathrm{I} .5^{-2} .0 \mathrm{~L} / \mathrm{min}$, reducing access flow using banding or RUDI will likely lead to increased hand perfusion and attenuation of hand ischemia (2). If access flow <I L/min, inflow proximalisation or DRIL may be preferred (I6).

However, it must be realized that an inappropriate loss of perfusion pressure along the hearthand axis intensifies symptoms of HAIDI. Therefore, treatment should also be aimed towards attenuating these causes for loss of blood pressure. The AVF's non-functional venous SBs were recently found to potentially contribute to limb blood pressure loss. One study demonstrated that SBL indeed optimized hand perfusion whereas immediate post-ligation access flows were essentially unaltered (Io). The results of the present one year follow up study demonstrate that access flow were maintained following SBL whereas hand perfusion remained sufficient in the vast majority of patients.

Several findings contribute to the diagnosis HAIDI. The patient's history (pain, cold hand, diminished strength, cramps, diminished sensibility) may seem subjective but these symptoms and signs can be objectively scored using a published hand ischemic questionnaire (2, Io, I7). Mean scores in dialysis populations not suffering from HAIDI were found to range from $35^{-60}$ on a 
o-500 point scale. In contrast, a $153 \pm 33$ score was demonstrated in type $2 \mathrm{~b}-4$ HAIDI requiring flow reduction. Successful surgery reduced postoperative scores to normal values ( $42 \pm 15)$ (2, Io, I7). In the present study, SBL immediately reduced the ischemic score from $184 \pm 20$ to $60 \pm 15$. SBL is durable and an effective treatment for HAIDI on the long term as scores were maintained at a $79 \pm 35$ level after one year.

If symptoms of hand ischemia are insufficiently attenuated following conservative measures, arterial stenotic lesions (if present) require angioplasty. In the present study population, an arterial inflow lesion was endovascularly corrected leading to an improved hand perfusion in $\mathrm{I}_{3} \%(6 / 46)$. If this first step of a minimally invasive approach for HAIDI is unsuccessful, a next step is a non-invasive evaluation of the hemodynamic consequences of open SBs of the access' venous outflow, if present. During an initial outpatient department evaluation, manually compressing the $\mathrm{AVF}$ and/or its SBs may subjectively lead to a warmer hand whereas distal radial pulsations may become more prominent. Digital pressures may indeed increase following these compression tests. In addition, Duplex analysis allows for assessing flow volume along these open SBs. Combining all of these findings may allow for the planning of an operative treatment plan and may predict whether 'a SBL only'-approach is successful, or whether an additional surgical technique is probably necessary. However, intraoperative findings such as increased plethysmographic finger pressures, more prominent distal pulsations, and improved hand skin colour, maintained access flow volume and access thrills also dictate if SBL suffices.

Any HAIDI treatment is aimed at diminishing symptoms of hand ischemia whereas access flow volume is maintained allowing for an ongoing effective haemodialysis. The ideal surgical technique is minimally invasive, effective and durable. In the present cohort of 46 patients, 38 patients required some sort of surgical procedure. Of these, $53 \%(20 / 38)$ underwent ligation of side branches around a brachial artery based AVF as a first minimally invasive approach, either exclusively $(26 \%, \mathrm{I} / 38)$ or as an adjunct preceding a flow reductive technique such as banding $(26 \%, \mathrm{ro} / 38)$. Interestingly, just SBL was successful in abolishing hand ischemia in $22 \%(\mathrm{Io} / 46)$ of the total population with HAIDI undergoing surgery. Therefore, it is concluded that SBL is a simple and safe first step in the surgical approach of HAIDI patients.

The present study suffers from shortcomings including incomplete data sets of flows and finger pressures at various time points during the one year study period. Some patients may have rejected invasive surgery but were not registered as such, potentially introducing a selection bias. The 
choice to combine various types of surgical techniques is solely dependent on the senior author's preference and subjective judgement during the surgical procedure.

In conclusion, a 'venous side branch ligation first approach' for the treatment of hand ischemia in the presence of an autogenous brachial artery-based haemodialysis is an effective modality for hand ischemia in over half of the patients with HAIDI. Access flow volumes are maintained after one year of follow up allowing ongoing proper haemodialysis. If venous side branches are deemed to contribute to loss of perfusion pressure, ligation is mandatory prior to executing more invasive types of surgery. 


\section{References}

I. Pasklinsky G, Meisner RJ, Labropoulos N, Leon L, Gasparis AP, Landau D, et al. Management of true aneurysms of hemodialysis access fistulas. J Vasc Surg. 20II May;53(5):I29I-7.

2. van Hoek F, Scheltinga M, Luirink M, Pasmans H, Beerenhout C. Banding of hemodialysis access to treat hand ischemia or cardiac overload. Semin Dial. 2009 Mar-Apr;22(2):204-8.

3. Yeager RA, Moneta GL, Edwards JM, Landry GJ, Taylor LM, Jr., McConnell DB, et al. Relationship of hemodialysis access to finger gangrene in patients with end-stage renal disease. J Vasc Surg. 2002 Aug;36(2):245-9; discussion 9.

4. Scheltinga MR, van Hoek F, Bruijninckx CM. Time of onset in haemodialysis access-induced distal ischaemia (HAIDI) is related to the access type. Nephrol Dial Transplant. 2009 Oct;24(Io):3I98-204.

5. Padberg FT, Jr., Calligaro KD, Sidawy AN. Complications of arteriovenous hemodialysis access: recognition and management. J Vasc Surg. 2008 Nov;48(5 Suppl):55S-80S.

6. Scheltinga MR, Bruijninckx CM. Haemodialysis access-induced distal ischaemia (HAIDI) is caused by loco-regional hypotension but not by steal. Eur J Vasc Endovasc Surg. 20I2 Feb;43(2):218-23.

7. Wixon CL, Hughes JD, Mills JL. Understanding strategies for the treatment of ischemic steal syndrome after hemodialysis access. J Am Coll Surg. 2000 Sep;I9I(3):30I-Io.

8. Scheltinga MR, Van Hoek F, Bruyninckx CM. Surgical banding for refractory hemodialysis access-induced distal ischemia (HAIDI). J Vasc Access. 2009 Jan-Mar;Io(I):43-9.

9. van Hoek F, Scheltinga MR, Luirink M, Raaymakers LC, van Pul C, Beerenhout CH. Access flow, venous saturation, and digital pressures in hemodialysis. J Vasc Surg. 2007 May;45(5):968-73.

Io. Vaes RH, Scheltinga MR. Side Branch Ligation for Haemodialysis-access-induced Distal Ischaemia. Eur J Vasc Endovasc Surg. 2012 Oct;44(4):452-6.

II. Vaes RH, Tordoir JH, Scheltinga MR. Blood flow dynamics in patients with hemodialysis access-induced hand ischemia. J Vasc Surg. 20I3 Jun 22.

I2. Tordoir JH, Dammers R, van der Sande FM. Upper extremity ischemia and hemodialysis vascular access. Eur J Vasc Endovasc Surg. 2004 Jan;27(I):I-5.

I3. Berman SS, Gentile AT, Glickman MH, Mills JL, Hurwitz RL, Westerband A, et al. Distal revascularizationinterval ligation for limb salvage and maintenance of dialysis access in ischemic steal syndrome.J Vasc Surg. I997 Sep;26(3):393-402; discussion -4.

I4. K/DOQI clinical practice guidelines for cardiovascular disease in dialysis patients. Am J Kidney Dis. 2005 Apr;45(4 Suppl 3):SI-I53.

I5. Sidawy AN, Gray R, Besarab A, Henry M, Ascher E, Silva M, Jr., et al. Recommended standards for reports dealing with arteriovenous hemodialysis accesses. J Vasc Surg. 2002 Mar;35(3):603-10.

I6. Schanzer H, Schwartz M, Harrington E, Haimov M. Treatment of ischemia due to "steal" by arteriovenous fistula with distal artery ligation and revascularization. J Vasc Surg. I988 Jun;7(6):770-3.

I7. van Hoek F, Scheltinga MR, Kouwenberg I, Moret KE, Beerenhout CH, Tordoir JH. Steal in hemodialysis patients depends on type of vascular access. Eur J Vasc Endovasc Surg. 2006 Dec;32(6):710-7. 



\section{CHAPTER - V}

Resolution of severe haemodialysis access induced distal ischaemia using a femoroaxillary bypass graft

R.H.D. Vaes

M.R.M. Scheltinga

EJVES Extra. 20II; 22: e6I-e63 


\section{Abstract}

\section{Introduction}

Elbow arterio-venous fistulas (AVF) may lead to debilitating hand ischaemia, even after several years of successful haemodialysis. If impaired arterial inflow is identified as the cause of ischaemia, endovascular techniques are usually successful in restoring hand perfusion.

\section{Report}

This paper reports of a patient with severe haemodialysis access-induced distal ischaemia (HAIDI) due to subclavian artery occlusion 5 years after AVF construction. As both endovascular and open carotid or subclavian surgical techniques were contraindicated, recovery from hand ischaemia was achieved by the use of a femoro-axillary bypass graft.

\section{Discussion}

The common femoral artery is a viable alternative inflow location for bypass grafting in HAIDI if commonly used upper body arterial sources are less suitable or unavailable. 


\section{Introduction}

The onset of haemodialysis access-induced distal ischaemia ( HAIDI) largely depends on type of access. Autogenous elbow arterio-venous fistulas (AVF) are nowadays favoured at the expense of grafts but pose a higher risk on hand ischaemia (I).

An obligatory first minimally invasive step in the treatment of HAIDI is endovascular optimization of the access' arterial inflow $(2,3)$. Subsequent first line invasive treatment options such as banding, distal revascularization interval ligation (DRIL), proximalization of arterial inflow (PAI) or revision using distal inflow (RUDI) tend to fail if the arm's arterial inflow remains insufficient after angioplasty or recanalization. Incidentally upper body arterial inflow blockades are not correctable. In that case an alternative vascular approach is required.

We report total recovery from severe distal ischaemia due to an autogenous elbow AVF using femoro-axillary bypass grafting in a patient with bilateral subclavian artery occlusion.

\section{Case history}

A 77 year-old male received a radiocephalic AVF because of end-stage renal disease. His medical history included a left-brain hemisphere cerebrovascular accident and pacemaker implantation for AV-block. As AVF maturation deemed insufficient after four months, a brachiocephalic AVF was constructed in the left arm in 2004. Some two months later, he reported a cold left hand and loss of grip strength. Access flow was $1190 \mathrm{ml} / \mathrm{min}$. An ischaemic left hand without motor loss was observed. He scored 290 points using a validated questionnaire determining grade of ischaemia (range o (no ischaemia) to 500 (maximal ischaemia)). Severe HAIDI is associated with a mean ischaemic score of $153 \pm 33$ (I). Standard angiography of the aortic arch, subclavian and axillary arteries demonstrated no apparent arterial stenosis while the AVF's outflow predominantly occurred through the basilic vein. It was decided to perform a basilic vein transposition with ligation of an upper arm cephalic vein. Postoperatively, symptoms of HAIDI had disappeared and the ischaemic score diminished to 78 points whereas the AVF access flow was $500-600 \mathrm{ml} / \mathrm{min}$.

After five years he gradually developed severe left thumb ischaemia while access flow had dropped to $300-350 \mathrm{ml} / \mathrm{min}$. His ischaemic score was again very high (300 points). A standard angiography demonstrated an occluded left subclavian artery. The interventional radiologists hesitated to attempt an arterial recanalization in proximity of open carotid systems as they feared a second cerebrovascular accident. A (right) subclavian to (left) subclavian bypass graft was impossible as the right subclavian artery was also occluded. A carotid subclavian bypass was refused by 
the patient as he feared for a novel cerebrovascular accident. An aortic-subclavian bypass was onsidered too risky due to comorbidity. Meanwhile, thumb ischaemia worsened to a state that the patient was on maximal pain medication.

A novel physical examination of the left leg revealed normal pulsations of the common femoral artery and posterior tibial artery. The femoral pulsations were considered adequate enough so additional angiography was not necessary. The multidisciplinary dialysis team then decided to perform femoro-axillary bypass grafting as a means of restoring the arm's arterial inflow. An $8 \mathrm{~mm}$ femoro-axillary bypass graft (Gelsoft, Vascutek/Terumo, Ann Arbor, MI, USA) was surgically inserted. Immediately after surgery, an intense AVF thrill returned whereas fingers of the left hand appeared better perfused. Three weeks after surgery the thumb had healed, dialysis sessions occurred uncomplicated with an access flow of $750 \mathrm{ml} / \mathrm{min}$ and his ischaemic score had decreased to just 5 points. Eighteen months postoperatively, the patient is doing fine whereas a CT-angiography demonstrated a patent femoral-axillary bypass graft (figure I).

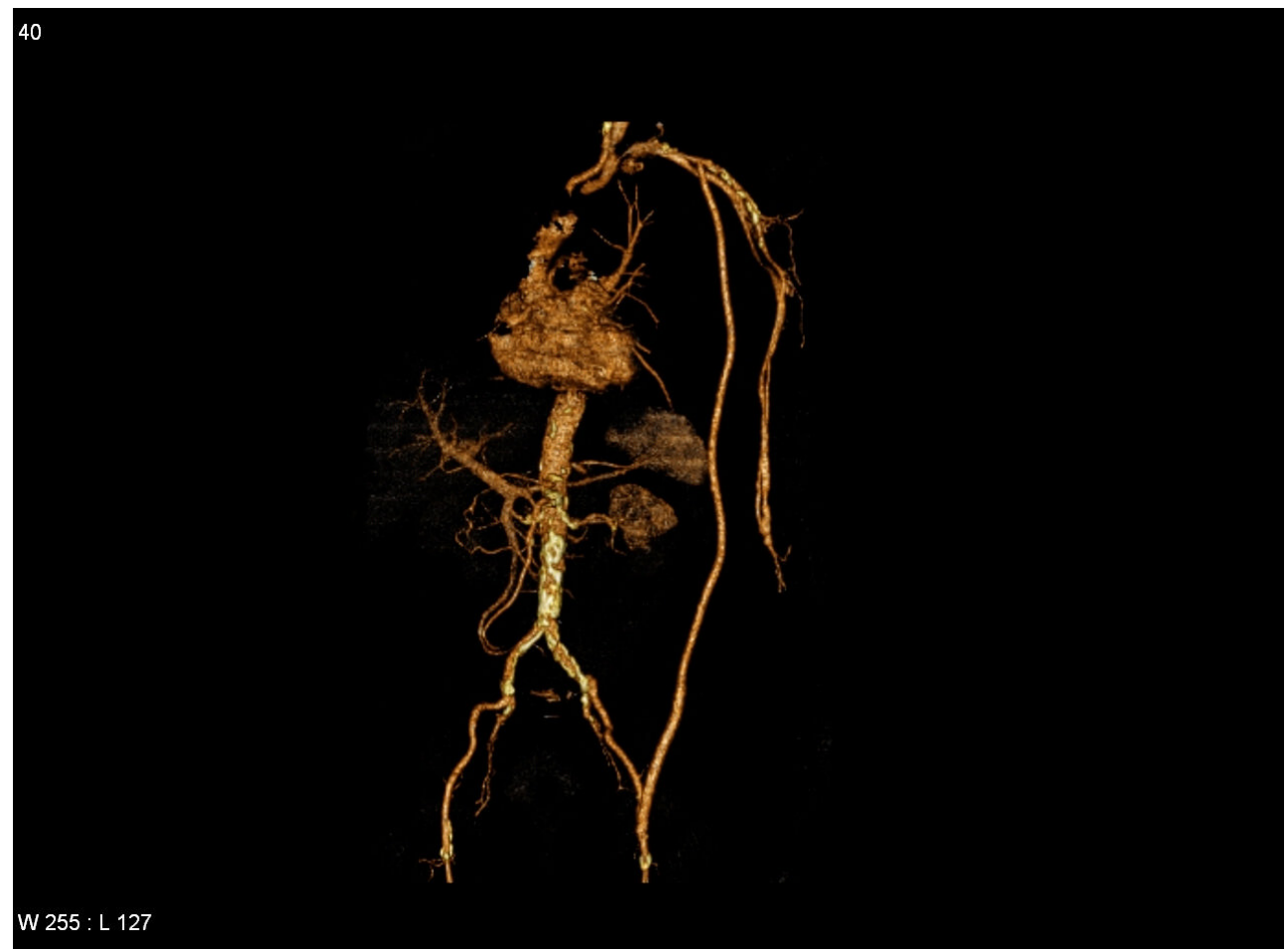

Figure 1. CT-angiography reconstruction showing a patent femoro-axillary bypass. 


\section{Discussion}

When a haemodialysis patient experiences HAIDI several years after construction of an autogenous elbow AVF, ischaemia is probably due to ongoing atherosclerosis in the arm's arterial vasculature. The very first step in the evaluation is visualization of the arterial tree from aortic arch to the hand $(2,3)$. Stenotic inflow disease is preferentially treated by an endovascular technique. If such a technically successful procedure fails to alleviate ischaemia, the next treatment option may be open surgery, the type of which is determined by the magnitude of the access flow. Continuing treatment failure with persistent hand ischaemia after a seemingly successful intervention may be caused by severe atherosclerosis in lower arm and hand vasculature. Under these circumstances, the only remaining treatment option to mitigate ongoing ischaemia and impending sepsis may be AVF ligation.

The present patient developed HAIDI some 5 years after his brachiocephalic AVF was converted into a transposed basilic vein access. Angiography revealed bilateral subclavian stenotic disease with open carotids. As an endovascular approach entailing manipulation with risk on hemispheric embolic disease was feared, peripheral bypass grafting constituted an invasive option with an acceptable risk profile. The use of bypass grafts originating from leg arteries for resolution of arm ischaemia following trauma or subclavian steal syndrome was popularized in the late 1970 's $(4,5)$. Our case may be the first to undergo a femoro-subclavian bypass graft for treatment of HAIDI.

In conclusion, the common femoral artery is a viable alternative inflow location for bypass grafting in HAIDI if commonly used upper body arterial sources are less suitable or unavailable.

\section{References}

I. Hoek F, Scheltinga MR, Kouwenberg I, Moret KE, Beerenhout CH and Tordoir JH. Steal in hemodialysis patients depends on type of vascular access. Eur J Vasc Endovasc Surg 2006; 32: 710-717

2. DeCaprio JD, Valentine RJ, Kakish HB, Awad R, Hagino RT and Clagett GP. Steal syndrome complicating hemodialysis access. Cardiovasc Surg 1997; 5: 648-653.

3. Duijm LE, Overbosch EH, Liem YS, Planken RN, Tordoir JH, Cuypers PW, Douwes-Draaijer P, de Haan MW. Retrograde catheterization of haemodialysis fistulae and grafts: angiographic depiction of the entire vascular access tree and stenosis treatment. Nephrol Dial Transplant 2009; 24: 539-47

4. Holleman JH, Hardy JD, Williamson JW, Raju S, Neely WA. Arterial surgery for arm ischemia. Ann Surg I980; I27: 727-736

5. Schax M, Doetsch N, Zerkowski HR Femoro-axillary bypass, a rarely used form of revascularization in occlusions of the supra-aortic vessels. Thor Cardiovasc Surg 1988; 36: 276-80 



\section{Chapter - VI}

\section{Systemic effects of a high flow arteriovenous fistula for haemodialysis}

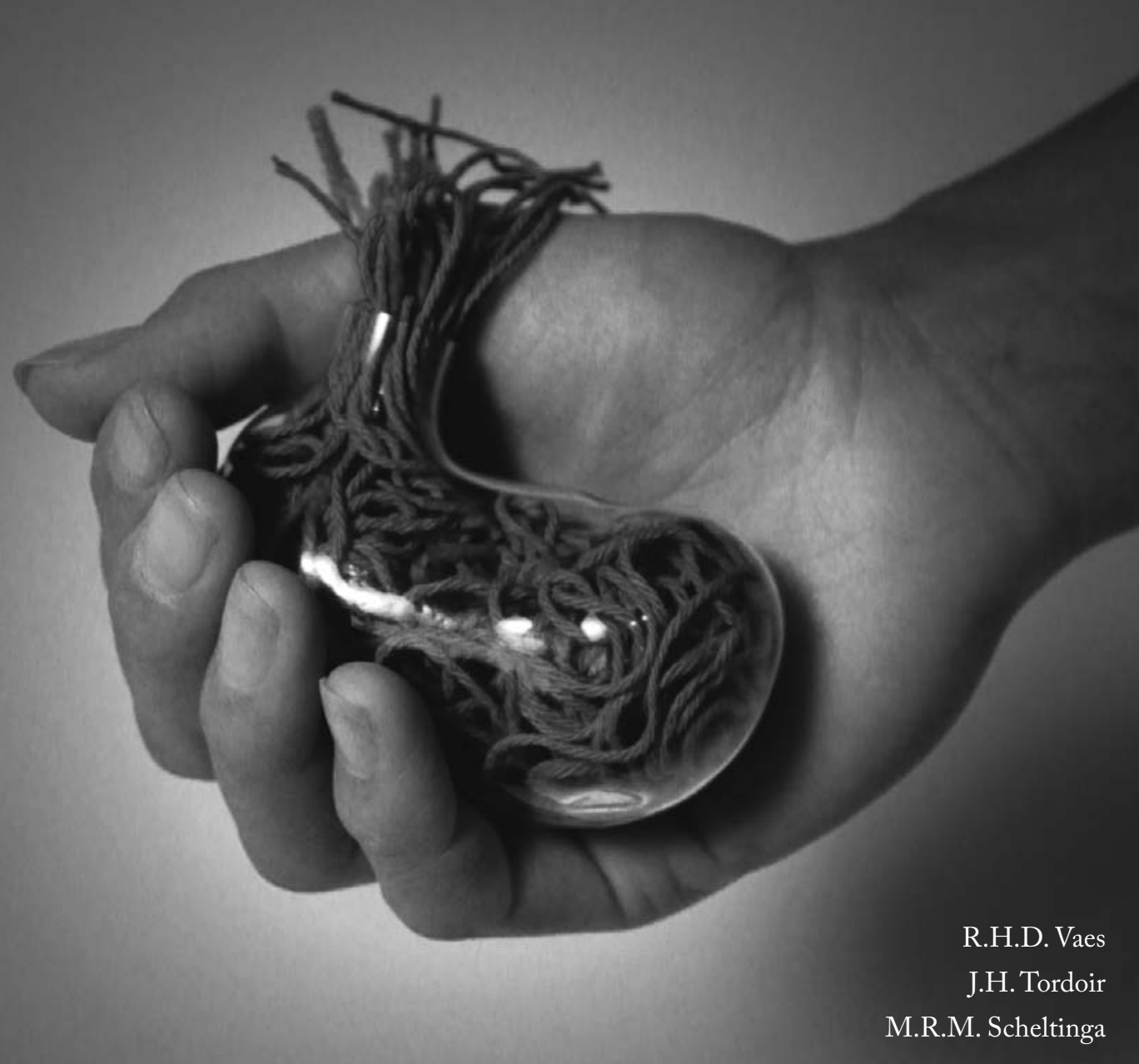

J Vasc Access. 20I4 May-Jun;15(3):I63-8 


\section{Abstract}

\section{Purpose}

Absolute treatment criteria for reducing access volume of a high flow access (HFA, access flow $>2$ $\mathrm{L} / \mathrm{min}$ ) are absent. Previous studies suggested that a HFA may influence the systemic circulation including blood pressure (BP) and heart rate (HR). The aim of the study was to determine these parameters after access clamping in haemodialysis patients undergoing flow reducing access surgery.

\section{Methods}

Systolic BP, diastolic BP and HR in HFA patients undergoing flow reducing surgery were measured intraoperatively before and after access clamping. Data were compared to values obtained in patients receiving surgery for severe hand ischemia due to an access (HAIDI, haemodialysis access induced distal ischaemia).

\section{Results}

In eight years, 34 patients underwent surgery for HFA $(n=23)$ or HAIDI $(n=I I)$. Preoperative access flows in HFA were larger compared to HAIDI (3026 $\pm \mathrm{I} 47$ vs Io $78 \pm \mathrm{I} 39 \mathrm{ml} / \mathrm{min}$ respectively, $\mathrm{p}<0.00 \mathrm{I}$ ). Temporary clamping ( $\mathrm{I} 5$ seconds) caused a $\mathrm{I} 2 \pm 2 \mathrm{mmHg}$ increase in SBP (III \pm 6 to I23 $\pm 6 \mathrm{mmHg}, \mathrm{p}<0.05)$ and a $6 \pm \mathrm{ImHg}$ rise in $\mathrm{DBP}(57 \pm 4$ to $63 \pm 5 \mathrm{mmHg}, \mathrm{p}<0.05)$ in HFA patients. In contrast, SBP and DBP increases were not significant in HAIDI patients $(+6 \pm 3$ and $+2 \pm 2 \mathrm{mmHg}$ respectively, $\mathrm{p}=0.37)$. HR was modestly reduced in both groups following access clamping $(-3 \pm \mathrm{I}$ beats/min). The relationship between access flow volume and alterations in SBP best fitted a quadratic regression model suggesting cardiovascular exhaustion with progressively higher access flows $>2-2.5 \mathrm{~L} / \mathrm{min}$.

\section{Conclusions}

A high flow access may influence systemic hemodynamics in some haemodialysis patients. The findings of this study may contribute to a tailored management of a high flow fistula in this population. 


\section{Introduction}

A $400-600 \mathrm{~mL} / \mathrm{min}$ flow in an arteriovenous fistula (AVF) is usually sufficient for an effective exchange of waste products during haemodialysis (HD). Occasionally, an autogenous AVF continues to mature over the years leading to a so-called 'high flow access' (HFA). If high flow is present in an access, patients usually harbour a brachial artery based fistula as opposed to a radial artery based AVF. Although a HFA allows easy needling, chronic high flow potentially exhausts cardiovascular reserve. An exact description of a HFA is lacking but a $2 \mathrm{~L} / \mathrm{min}$ cut-off point is pragmatically chosen for defining a HFA. For instance, cardiac failure occurred more frequently in HD patients harbouring an access with a flow above this threshold (I).

In dialysis practice, high flow is often an accidental finding that is obtained at a routine access flow measurement (2). If high flow is confirmed on repetitive occasions, the question arises whether the HFA should undergo flow reducing surgery (3). Such a decision depends on the patient's history and on the clinical situation. Some HFA patients may develop progressive fatigue, weight gain and dyspnoea but these symptoms are also frequently encountered in HD patients and do not specifically point towards a 'symptomatic' HFA. On the one hand, it makes sense that a HFA patient with a compromised cardiac functioning should receive access flow reducing surgery as the ongoing high flow sooner or later leads to additional cardiac events. On the other hand, surgery should maybe postponed in an example of a healthy young HFA patient with a normal cardiac function awaiting kidney transplantation.

It is unclear whether findings obtained at physical examination contribute to decision making in a HFA patient although tachycardia may indicate a high flow access (4). Some have suggested that digitally compressing a HFA leads to increased blood pressures (BP) and depressed heart rates (HR) whereas others doubted these phenomena (4-7). The presence of such a cardiovascular response possibly reflects the HFA's systemic effects on the host's circulation (5) but the relevance of such a finding is unknown.

The decision to initiate invasive management of a HFA is controversial due to the absence of absolute treatment criteria. As a consequence, clinicians need objective parameters justifying an invasive treatment regimen in this fragile patient population. The aim of the study was to investigate whether access compression leads to a significant $\mathrm{BP}$ and $\mathrm{HR}$ response in HFA patients when compared to hemodialysis patients with a normal access flow. If a disproportionate 
circulatory reaction is observed, this finding may contribute to decision making. It was also hypothesized that the magnitude of alterations in BP and HR reflected fistula flow volume.

\section{Materials and methods}

\section{Study populations}

This prospective study was performed between March 2003 and September $201 \mathrm{I}$ in Maxima Medical Center, Veldhoven, The Netherlands as part of an ongoing project on studying long term complications of an autologous brachial artery based access $(3,8)$. The dialysis center currently accommodates approximately Ioo HD patients. We perform approximately roo access related operations yearly. Access flow is routinely measured every two months using dilutional techniques (HDor, Transonic Systems Inc, New York, USA) in all of our HD patients.

Two groups of HD patients were studied. The first group contained patients with an autologous access demonstrating flows $>2 \mathrm{~L} / \mathrm{min}$ on at least three previous occasions ('HFA'-group). These patients were scheduled to undergo flow reducing surgery as advised by a multidisciplinary team consisting of a surgeon, a cardiologist, a nephrologist and a vascular access nurse. Inclusion and exclusion criteria as well as the results of surgery in a portion of these patients $(n=9)$ were published previously (3).

The second group included patients with an autologous access having flows $<2.0 \mathrm{~L} / \mathrm{min}$. These patients were scheduled to undergo surgery for type $2 \mathrm{~b}-4 \mathrm{~b}$ haemodialysis access induced distal ischaemia ('HAIDI'-group). Specifics, inclusion and exclusion criteria as well as the immediate effects of surgery on hand ischemia were earlier reported in a portion $(\mathrm{n}=\mathrm{IO})$ of the patients $(3)$.

Prior to surgery, HFA and HAIDI patients were asked to finish a published questionnaire that quantifies hand ischaemia (HIQ, hand ischemic questionnaire) (8, 9). A HIQ score reflects severity and frequency of symptoms associated with hand ischaemia (pain, cramps, coldness, loss of strength and diminished sensibility). HIQ scores range from o (no symptoms of ischaemia) to 500 points (maximal symptoms). HIQ scores in a general dialysis population not reporting hand ischaemia were between 35 to 50 points (9). Successful AVF revision using banding in HAIDI patients reduced mean HIQ scores from I53 $_{3}$ to 42 points (3).

Demographics, risk factors for atherosclerosis, type of AVF and access flows were obtained from hand written dialysis charts and electronic patient charts. General exclusion criteria were impaired mental capacity or a language barrier. The study was performed according to the declaration of 
Helsinki. All patients were informed on the nature of the study and consented to its specifics. The MMC Medical Ethics Committee declared that their approval for this study was not necessary.

\section{Measurement protocol}

The surgical protocol was reported previously (3). In short, all patients received general anesthesia. HR and blood pressure values (SBP, systolic blood pressure; DBP, diastolic blood pressure) were obtained from the contralateral arm using an oscillatory technique via a noninvasive automated cuff sphygmomanometer (Aisys, GE Medical, Hoevelaken, The Netherlands). Following sterile exposure, the AVF anastomosis and a $3-5 \mathrm{~cm}$ proximal portion of its major venous outflow tract were dissected. A separate $2 \mathrm{~cm}$ incision downstream towards the axilla exposed the venous outflow tract allowing access flow monitoring using an ultrasonic transit time technique with Optimax flow probes (Transonic Systems Inc, New York, USA). These online access flow measurements are a standard part of our operative protocol. Following a 5 minute equilibration period, baseline HR, SBP and DBP were obtained once just before clamping of the venous outflow tract, and once again after 15 seconds of clamping. A standard vascular clamp was used for the clamping procedure. Following these measurements, the operation was continued with a flow restricting technique (banding, side branch ligation, DRIL) as previously reported (3).

\section{Definitions and analysis}

A SPSS version I7.0 was used for statistical analysis (SPSS Inc., Chicago, IL, USA). All results were expressed as mean \pm SEM (standard error of the mean). A P value of $<0.05$ was considered significant. Mean arterial pressure (MAP) was calculated using the equation $\mathrm{MAP}=(\mathrm{SBP}+$ $\left.2^{*} \mathrm{DBP}\right) / 3$. Statistical differences between groups were analysed using Fisher exact test and MannWhitney U tests. A Wilcoxon-signed rank test was used to determine the effect of clamping on $\mathrm{HR}$ and SBP/DBP in both groups. The Pearson correlation test determined correlations between flow and HR and SBP/DBP. Any relationship between access flow, MAP, SBP, DBP and HR were studied using linear and non-linear analysis.

\section{Results}

A total of 34 patients underwent intraoperative AVF clamping just prior to the flow reducing surgery (banding $n=20$, side branch ligation $n=9$, basilic transposition $n=4, D R I L n=1$ ). Preoperative access flow was higher in the HFA group $(n=23)$ compared to HAIDI ( $\mathrm{n}=\mathrm{Ir}$; HFA $3026 \pm \mathrm{I} 47$ vs HAIDI I078 $\pm 139 \mathrm{~mL} / \mathrm{min}, \mathrm{p}<0.00 \mathrm{I})$. HFA patients were more than two decades younger (5 \pm 4 yr) compared to the HAIDI group (72 $\pm 4 \mathrm{yr}, \mathrm{p}<\mathrm{O} . \mathrm{OoI})$. Interestingly, diabetes was not observed in the HFA group and only twice in HAIDI patients. All 34 patients harboured autologous AVFs, 
the vast majority constructed with the brachial artery $(32 / 34,96 \%)$. Hand ischaemic scores were lower in the HFA compared to the HAIDI group (IO4 \pm 30 vs I7I $\pm 29, \mathrm{p}<0.05$, Table I)

Table I. Demographics of patients with a high flow access (HFA, $>2 \mathrm{~L} / \mathrm{min}$ ) and hand ischemia (HAIDI, < $2 \mathrm{~L} / \mathrm{min}$ )

\begin{tabular}{|c|c|c|c|}
\hline & HFA $(n=23)$ & HAIDI $(n=11)$ & $\mathrm{p}$ \\
\hline Access flow $(\mathrm{ml} / \mathrm{min})$ & $3026 \pm 147$ & $1078 \pm 139$ & $<0.001$ \\
\hline Men/women & $10 / 13$ & $9 / 2$ & 0.06 \\
\hline Age (years) & $51 \pm 4$ & $72 \pm 4$ & 0.005 \\
\hline AVF age (months)* & $36 \pm 9$ & $19 \pm 6$ & 0.18 \\
\hline Diabetes Mellitus (n) & 0 & 2 & 0.32 \\
\hline Hypertension (n) & 11 & 3 & 0.46 \\
\hline Peripheral arterial occlusive disease (n) & 4 & 6 & 0.04 \\
\hline Coronary artery disease (n) & 2 & 4 & 0.05 \\
\hline Beta-blockade (n) & 14 & 6 & 0.32 \\
\hline Hand Ischaemic Questionnaire score & $104 \pm 30$ & $171 \pm 29$ & 0.04 \\
\hline Radio-cephalic & 1 & 0 & \\
\hline Brachiocubital (Gracz) & 16 & 10 & \\
\hline Basilic vein transposition & 5 & 0 & \\
\hline Brachio-cephalic & 1 & 0 & \\
\hline Ulnar-basilic vein transposition & 0 & 1 & \\
\hline
\end{tabular}

*Time between AVF construction and flow reducing surgery (months).

AVF clamping always reduced access flow to zero as confirmed by the ultrasonic transit time technique. Fifteen seconds after clamping, a $12 \pm 2 \mathrm{mmHg}$ increase of SBP was observed in the HFA group (SBP III \pm to I2 $3 \pm 6 \mathrm{mmHg}, \mathrm{p}<0.05$, figure I). Moreover, a $6 \pm \mathrm{I} \mathrm{mmHg}$ rise in DBP was found $(57 \pm 4$ to $63 \pm 5 \mathrm{mmHg}, \mathrm{p}<0.05$, figure 2$)$. In contrast, increases in SBP and DBP were smaller and not significant in HAIDI (SBP II6 \pm 9 to $122 \pm 9 \mathrm{mmHg},+6 \pm 3 \mathrm{mmHg}, \mathrm{p}=$ o.I; DBP $48 \pm 4$ to $50 \pm 4 \mathrm{mmHg},+2 \pm 2 \mathrm{mmHg}, \mathrm{p}=\mathrm{O} .37$, figure $\mathrm{I}$ and 2 ). Data on $\mathrm{HR}$ were not obtained in a portion of the patients (HFA, $n=7$; HAIDI, $n=4)$. However, a small but significant drop in HR was observed in the remaining 23 patients of both study groups $(-3 \pm \mathrm{I}$ beats $/ \mathrm{min}, \mathrm{p}<0.05)$ (figure 3 ).

The relationship between access flow volume and haemodynamic parameters are depicted in figure 4 and 5. A quadratic regression model best described changes in SBP and MBP after clamping in relation to access flow volume (figure 4 and 5 respectively). Both curves suggest that systemic responses were blunted in HFA patients with access flows in excess to $2.0-2.5 \mathrm{~L} / \mathrm{min}$. 


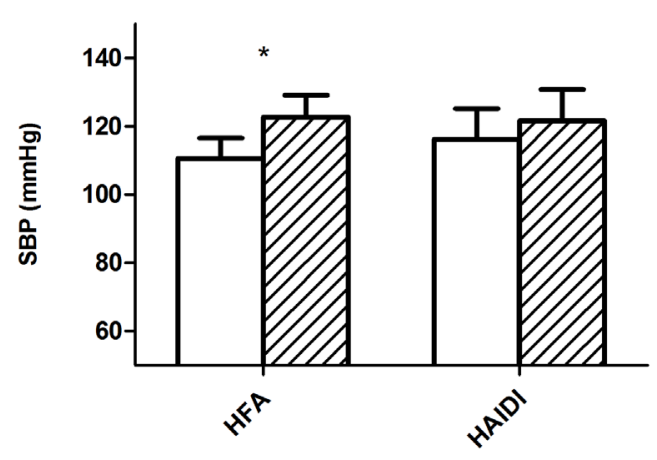

Figure 1. After access clamping, systolic blood pressures significantly increased in patients with a HFA (access flow 3026 147 $\mathrm{ml} / \mathrm{min}$ ) but not in patients with HAIDI $(1078 \pm 139 \mathrm{ml} /$ $\min )\left({ }^{*} \mathrm{p}<0.05\right)$

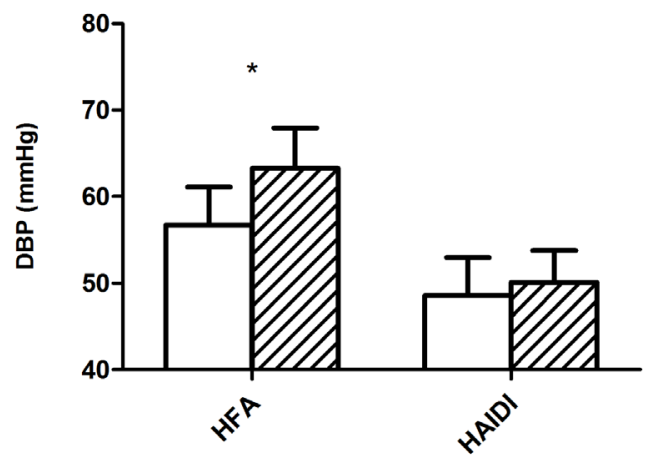

$\square$ Open AVF Z Closed AVF

Figure 2. After access clamping, diastolic blood pressures significantly increased in patients with a HFA (access flow $3026 \pm 147$ $\mathrm{ml} / \mathrm{min}$ ) but not in patients with HAIDI $(1078 \pm 139 \mathrm{ml} /$ $\min )($ p $<0.05)$

Figure 3. After access clamping, heart rate decreased in a similar fashion in patients with a HFA and with HAIDI $(* \mathrm{p}<0.05)$ 


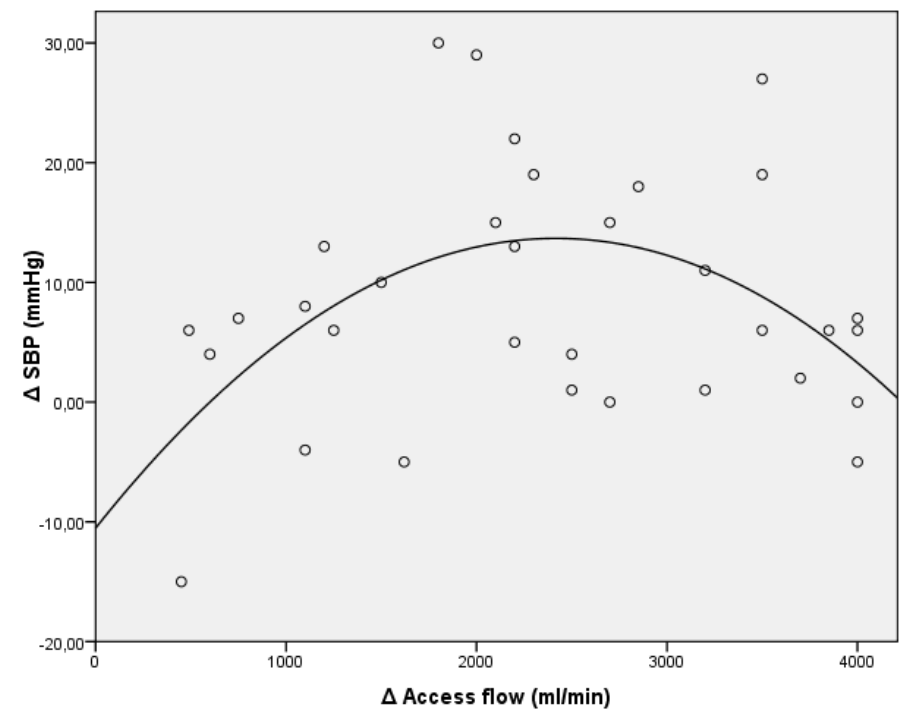

Figure 4. Relationship between changes in systolic blood pressure (SBP) following clamping and access flow volume $(y=$ $-4.145^{*} 106 \mathrm{x} 2+0.02 \mathrm{x}$ $-10.528 ; \mathrm{r}=0.48, \mathrm{p}<0.05$, $\mathrm{n}=33)$.

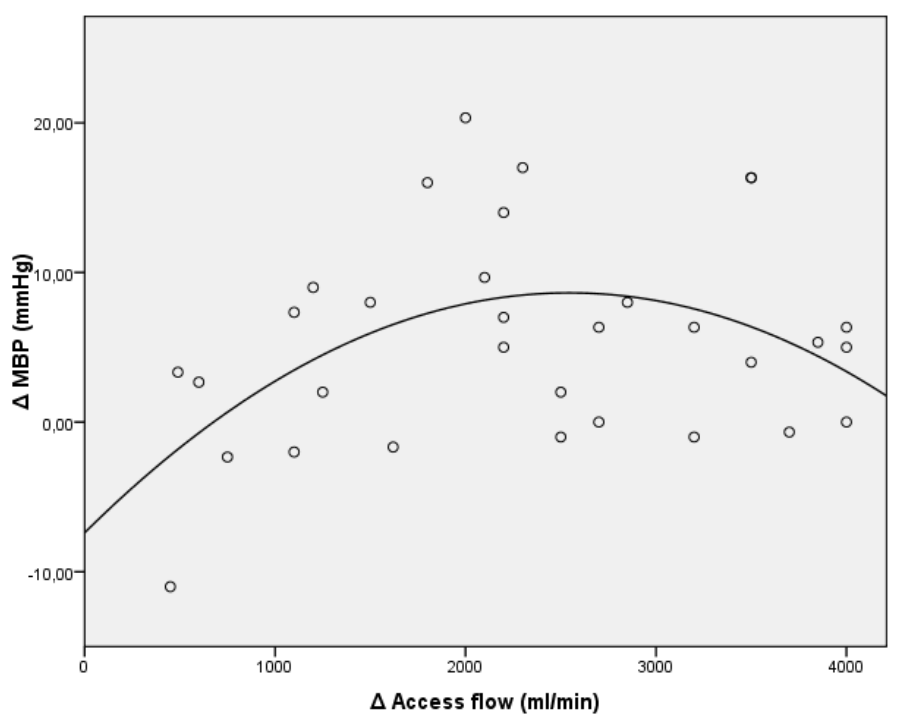

Figure 5. Relationship between changes in mean blood pressure (MBP) and access flow $(\mathrm{y}=-2.479 * 106 \times 2$ $+0.13 \mathrm{x}-7.399 ; \mathrm{r}=0.46$, $\mathrm{p}<0.05, \mathrm{n}=32$ ). 


\section{Discussion}

Surgically reducing flow volume in hemodialysis patients with a high flow access (HFA) is controversial. Potentially beneficial effects such as cardiac reserve protection should be balanced against possible (although probably minimal) harm associated with the anaesthetic technique and the surgery itself. Nowadays, absolute criteria necessitating HFA treatment are absent. However, it is reasonable to suggest that, if systemic cardiovascular abnormalities are indeed observed in the presence of a HFA, decision making may be influenced. Temporary dialysis access clamping immediately increases peripheral vascular resistance. This manoeuvre may potentially unveil the short term hemodynamic influence of the HFA. Aim of this study therefore was to investigate whether dialysis access compression would result in changes in blood pressure (BP) and heart rate $(\mathrm{HR})$ that were more pronounced in HFA patients compared to patients having a normal access flow. Results of the study suggest that the host's hemodynamic responses are, to a certain part, affected by the access volume.

It was earlier demonstrated that vascular access compression increases vascular resistance leading to augmented BP and consequently reduced HR and cardiac output via the baroreceptor-vagal nerve axis $(7$, Io). However, such a response may be diverse. For instance, a study in successfully transplanted patients harbouring a I.3 L/min AVF found a linear relationship between HR decrease and mean BP increase (II). In the present study, a substantial increase in SBP (I2 \pm 2 $\mathrm{mmHg}$ ) and $\mathrm{DBP}(6 \pm \mathrm{I} \mathrm{mmHg}$ ) was demonstrated after clamping a $3 \mathrm{~L} / \mathrm{min}$ flow access but not so in HAIDI patients with a I L/min AVF. Interestingly however, access flow and changes in blood pressure were not linearly related. Studying curve characteristics show that cardiovascular exhaustion occurs with progressively higher access flows, particularly in patients with AVF flow in excess to $2-2.5 \mathrm{~L} / \mathrm{min}$. These findings are in line with a study by Basile et al demonstrating that cardiac events are more likely to occur in patients with a $\mathrm{HFA}>2 \mathrm{~L} / \mathrm{min}(\mathrm{I})$.

Together with an increased BP, one would also expect a lower HR following AVF clamping. Small changes in HR after 60 seconds of clamping were observed in another study although more prominent drops after to minutes of AVF occlusion have also been found (I2, I3). A lowered $\mathrm{HR}$ is a homeostatic response leading to lowered cardiac output as a means to compensate for higher peripheral resistances (5, I2, I4, I5). The HR decrease after AVF compression was previously described as the Nicoladoni-Branham sign and was thought to reflect the hemodynamic significance of a fistula $(4, \mathrm{I} 6)$. A modest but statistically significant three beat decrease in HR was observed in both patient groups in the current study. A relationship between access flow and 
HR was absent. These data indicate that a positive Nicoladoni-Branham sign in itself does not reflect the hemodynamic significance of a HFA.

It is hypothesized that an attenuated (lower than expected) BP response in the presence of high flow may be due to an impaired autonomic function and especially baroreflex sensitivity (BRS) in these HFA patients. The baroreflex system is responsible for controlling short term fluctuations in arterial BP (I7). An impaired BRS is a prominent characteristic of heart failure (I8). A failing $\mathrm{BRS}$ is also found in patients with chronic kidney disease, hypertension, coronary artery disease, myocardial infarction and heart failure preceding death (I7, I9). Successful renal transplantation improved abnormal autonomic function (19, 20). An unbalanced BP/HR response following HFA clamping supports the hypothesis that the augmented cardiac risks in HFA patients are associated with a failing autonomic function. Conversely, one may hypothesize that attenuating high flow protects cardiac reserve by improving the host's autonomic function.

Management of a HFA must be viewed in relation to the detrimental consequences of chronic kidney disease on cardiac performance. There is ample data demonstrating that impaired kidney functioning adversely effects the heart. For instance, a diminished glomerular filtration rate in relative healthy individuals is associated with an increased risk on cardiac death (2I). Once depending on $\mathrm{HD}$, a disproportional high percentage (up to $50 \%$ ) may die of cardiac failure (22, 23). High death rates are preferentially observed in HD populations compared to peritoneal dialysis (24). Myocardial perfusion is chronically reduced in HD patients and is even further impaired during a dialysis session $(25,26)$. Therefore, HFA treatment aimed at protecting cardiac reserve in HD patients intuitively makes sense and is highly recommended.

The decision to execute flow reducing surgery is supported by the concomitant presence of hand ischemia as also observed in the present population of HFA patients. Interestingly, hand ischemic scores were more than twice as high (IO4 \pm 30 points) compared to scores obtained in an average dialysis population ( $35^{-5}$ o points) or in postoperative HAIDI patients that successfully underwent surgery $(42 \pm 5)(3,9)$ Flow reduction in HFA patients likely alleviates symptoms of hand ischemia. The presence of debilitating hand ischemia in a HFA patient should support a decision to perform access flow reducing surgery but its absence should not postpone such a decision.

The present study has several limitations. Firstly, all patients underwent measurements in an unconscious state characterized by a BP that is substantially lower compared to a value that is observed during conscious states. Access clamping during surgery using a locoregional technique 
and a conscious state likely results in even more pronounced alterations in BP and HR. A differential response after clamping was hypothetically related to demographic study group differences as the HFA group contained more females of younger age. However, a correlation between these parameters was not found. Moreover, use of medication including beta-blocking agents was evenly distributed among the two study groups ( HFA 61\% (I4/23) vs HAIDI 66\%, $6 / \mathrm{II}, \mathrm{p}=0.32$ ). Therefore, the observed group differences in haemodynamical responses are likely related to access flow volume and not to other parameters.

It is unsure how findings of the present study contribute to the overall management of a HFA patient in clinical practise. Cardiac overload demonstrated by echocardiography in a symptomatic patient should lead to a decision to perform access flow reducing surgery. The present study in a fistula compression model in unconscious patients demonstrates that a HFA also has a systemic haemodynamic effect on the short term. HFA compression in conscious outpatients will lead to even larger changes in BP and HR. Future studies using access compression in an outpatient population may allow for the development of a bedside method that identifies patients benefitting from flow reduction.

In conclusion, a high flow access may influence systemic hemodynamics in haemodialysis patients. Findings of this study may contribute to a tailored management of a high flow fistula in this population. 


\section{References}

I. Basile C, Lomonte C, Vernaglione L, Casucci F, Antonelli M, Losurdo N. The relationship between the flow of arteriovenous fistula and cardiac output in haemodialysis patients. Nephrol Dial Transplant. 2008;23(I):282-7.

2. Clinical practice guidelines for vascular access. Am J Kidney Dis. 2006;48 Suppl I:S248-73.

3. van Hoek F, Scheltinga M, Luirink M, Pasmans H, Beerenhout C. Banding of hemodialysis access to treat hand ischemia or cardiac overload. Semin Dial. 2009;22(2):204-8.

4. Ahearn DJ, Maher JF. Heart failure as a complication of hemodialysis arteriovenous fistula. Ann Intern Med. I972;77(2):20I-4.

5. Chemla ES, Morsy M, Anderson L, Whitemore A. Inflow reduction by distalization of anastomosis treats efficiently high-inflow high-cardiac output vascular access for hemodialysis. Semin Dial. 2007;20(I):68-72.

6. Dikow R, Schwenger V, Zeier M, Ritz E. Do AV fistulas contribute to cardiac mortality in hemodialysis patients? Semin Dial. 2002;15(I):I4-7.

7. Nickerson JL, Elkin DC, Warren JV. The effect of temporary occlusion of arteriovenous fistulas on heart rate, stroke volume, and cardiac output. J Clin Invest. I95I;30(2):215-9.

8. Vaes RH, Scheltinga MR. Side Branch Ligation for Haemodialysis-access-induced Distal Ischaemia. Eur J Vasc Endovasc Surg. 2012;44(4):452-6.

9. van Hoek F, Scheltinga MR, Kouwenberg I, Moret KE, Beerenhout CH, Tordoir JH. Steal in hemodialysis patients depends on type of vascular access. Eur J Vasc Endovasc Surg. 2006;32(6):710-7.

Io. Nakano J, Deschryver C. Effects of Arteriovenous Fistula on Systemic and Pulmonary Circulations. Am J Physiol. 1964;207:1319-24.

II. Velez-Roa S, Neubauer J, Wissing M, Porta A, Somers VK, Unger P, et al. Acute arterio-venous fistula occlusion decreases sympathetic activity and improves baroreflex control in kidney transplanted patients. Nephrol Dial Transplant. 2004;I9(6):I606-I2.

I2. von Bibra H, Castro L, Autenrieth G, McLeod A, Gurland HJ. The effects of arteriovenous shunts on cardiac function in renal dialysis patients--an echocardiographic evaluation. Clin Nephrol. 1978;9(5):205-9.

13. Bos WJ, Zietse R, Wesseling KH, Westerhof N. Effects of arteriovenous fistulas on cardiac oxygen supply and demand. Kidney Int. I999;55(5):2049-53.

I4. Ori Y, Korzets A, Katz M, Perek Y, Zahavi I, Gafter U. Haemodialysis arteriovenous access--a prospective haemodynamic evaluation. Nephrol Dial Transplant. I996;II(I):94-7.

I5. Timmis AD, McGonigle RJ, Weston MJ, McLeod AA, Jackson G, Jewitt DE, et al. The influence of hemodialysis fistulas on circulatory dynamics and left ventricular function. Int J Artif Organs. 1982;5(2):IoI-4.

I6. Nicoladoni C. Phlebarteriectasie der rechten oberen Extremität. Arch Kleinische Chirurgie. I875;18:252-74.

17. La Rovere MT, Pinna GD, Raczak G. Baroreflex sensitivity: measurement and clinical implications. Ann Noninvasive Electrocardiol. 2008;13(2):I9I-207.

I8. La Rovere MT, Pinna GD, Maestri R, Robbi E, Caporotondi A, Guazzotti G, et al. Prognostic implications of baroreflex sensitivity in heart failure patients in the beta-blocking era. J Am Coll Cardiol. 2009;53(2):I93-9.

19. Rubinger D, Backenroth R, Sapoznikov D. Restoration of baroreflex function in patients with end-stage renal disease after renal transplantation. Nephrol Dial Transplant. 2009;24(4):1305-I3.

20. Rubinger D, Sapoznikov D, Pollak A, Popovtzer MM, Luria MH. Heart rate variability during chronic hemodialysis and after renal transplantation: studies in patients without and with systemic amyloidosis. J Am Soc Nephrol. 1999;Io(9):I972-8I.

2I. MacRae JM, Levin A, Belenkie I. The cardiovascular effects of arteriovenous fistulas in chronic kidney disease: a cause for concern? Semin Dial. 2006;19(5):349-52.

22. Schou M, Torp-Pedersen C, Gustafsson F, Abdulla J, Kober L. Wall motion index, estimated glomerular filtration rate and mortality risk in patients with heart failure or myocardial infarction: a pooled analysis of I8, oro patients. Eur J Heart Fail. 2008;10(7):682-8.

23. Tian JP, Wang T, Wang H, Cheng LT, Tian XK, Lindholm B, et al. The prevalence of left ventricular hypertrophy in Chinese hemodialysis patients is higher than that in peritoneal dialysis patients. Ren Fail. 2008;30(4):39I-400.

24. Trespalacios FC, Taylor AJ, Agodoa LY, Bakris GL, Abbott KC. Heart failure as a cause for hospitalization in chronic dialysis patients. Am J Kidney Dis. 2003;4I(6):I267-77.

25. Dasselaar JJ, Slart RH, Knip M, Pruim J, Tio RA, McIntyre CW, et al. Haemodialysis is associated with a pronounced fall in myocardial perfusion. Nephrol Dial Transplant. 2009;24(2):604-Io. 
26. Venkataraman R, Hage FG, Dorfman T, Heo J, Aqel RA, de Mattos AM, et al. Role of myocardial perfusion imaging in patients with end-stage renal disease undergoing coronary angiography. Am J Cardiol. 2008;IO2(II):I45I-6. 



\section{Chapter - VII}

\section{High flow access and cardiac failure in haemodialysis patients. An overview on pathophysiology, diagnostics and treatment options}

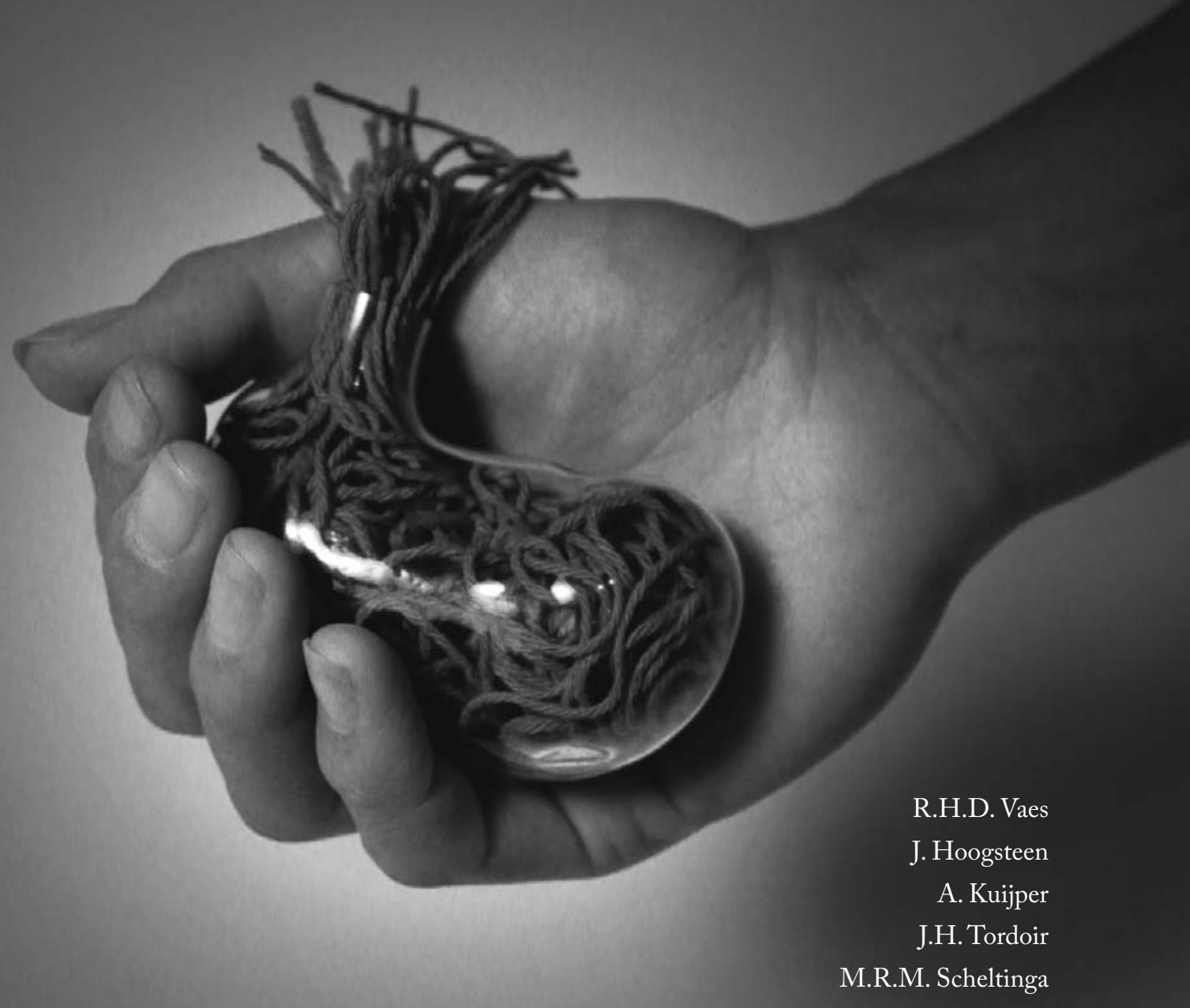

Submitted to Nephrol Dial Transplant plus 


\section{Abstract}

\section{Purpose}

Patients with end stage renal disease (ESRD) receiving an arteriovenous fistula (AVF) for haemodialysis (HD) occasionally (2-4\%) develop a high flow access (HFA, access flow $>2 \mathrm{~L} / \mathrm{min}$ ) over time. In the upcoming years, the incidence of HFA will rise due to increasing numbers of HD patients, prolonged population longevity and a shift towards more proximally positioned arm AVF's. Management of HFA is under debate. It is intuitive that persistently high flows create a burden on cardiac reserve. Aim of this overview is to discuss adverse effects of ESRD on cardiac function and to provide an overview on the diagnosis and treatment of HFA in HD patients.

\section{Overview}

Chronic kidney disease (CKD) patients are at risk for cardiovascular events. Once on renal replacement therapy (RRT), up to $35 \%$ of patients develop signs of congestive heart failure over time. Left ventricular hypertrophy, anaemia, intradialytic volume overload and HD itself jeopardize cardiac function. AVF creation poses an additional burden on cardiac capacity. Cardiac output is increased through stimulated ventricular contractility, higher stroke volume and an increased heart rate demanding an increased endocardial oxygen supply that may not always be delivered. High flow in a HD patient may develop by a hitherto unknown trigger. Ongoing vascular remodelling of both arterial and venous components of the AVF may occur, preferentially in younger $\mathrm{HD}$ patients ( $<50$ years) with a brachial artery based AVF. On the other hand, surgical access flow reduction may attenuate cardiac failure in symptomatic patients. The role of preemptive HFA flow reduction in asymptomatic individuals is debated. A banding procedure for access flow reduction was recently found to be associated with a $50 \%$ one year recurrence rate. A revision using distal inflow (RUDI) technique is possibly more promising although long term efficacy is to be determined.

\section{Conclusion}

Patients with kidney failure are at risk of developing cardiac insufficiency due to a variety of pathophysiological pathways. The development of high flow due to the presence of a brachial artery based AVF likely poses an additional burden on cardiac reserve in these HD patients. The role of access flow reducing techniques and particularly RUDI for high access flow must be determined in the near future. 


\section{Introduction}

A portion of patients with end stage renal disease (ESRD) choose to receive an arteriovenous fistula (AVF) for haemodialysis (HD). Several loco-regional and systemic complications associated with the presence of an AVF may develop on the long term including hand ischaemia and/or high flow (I). Diagnosis and treatment of hand ischaemia has received a fair amount of attention in recent years and is relatively straight forward (2-4). In contrast, management of a high flow access $(\mathrm{HFA},>2 \mathrm{~L} / \mathrm{min}$ through the AVF) is a matter of debate (5)

Nephrologists and vascular surgeons are likely confronted more frequently in the near future with a HFA. Various ongoing trends may explain this increased exposure. First, absolute numbers of ESRD patients requiring renal replacement therapy (RRT) will rise in the coming decades. For instance, prevalence counts in the United States increased from 485,012 in 2005 to 636,905 patients in 2012 and are destined to increase even further the upcoming years. Second, larger numbers of $\mathrm{HD}$ patients will receive an autologous AVF rather than grafts or venous catheters as stimulated by the Kidney Disease Outcome Quality Initiative (KDOQI) (6). Typically, high flow preferentially develops in AVFs but is seldom observed in the presence of an arteriovenous graft (AVG). Third, constructing an access with a brachial artery (brachio-cephalic AVF, BC-AVF) is nowadays increasingly required compared to an access with a radial artery (radiocephalic AVF, $\mathrm{RC}-\mathrm{AVF}$ ) in our presently obese and diabetic populations with suboptimal arm vasculatures. A $\mathrm{BC}-\mathrm{AVF}$ has an intrinsic capacity to generate larger flow volumes and poses a risk factor for the development of a HFA. Fourth, overall management of HD patients will continue to improve leading to prolonged population longevity but also to a protracted exposure to a continuously (and possibly inappropriately) maturing AVF and its systemic haemodynamic effects (6-Io).

Due to these tendencies, care providers are confronted with an expanding population of ageing HD patients having AVFs with a large flow volume. Although a HFA in itself is advantageous as it allows for easy needling and effective ultrafiltration, systemic vascular capacity including cardiac function may be compromised on the long term. Aim of the present study is twofold. Adverse effects of ESRD on cardiac function are discussed. An overview of diagnosis and treatment of a HFA is provided.

\section{Chronic kidney disease and cardiac function}

The presence of chronic kidney disease (CKD) in itself adversely affects cardiac function. A gradual increased risk on a cardiovascular event is observed with decreasing glomerular filtration 
rate (GFR). For instance, this risk is increased by $343 \%$ in patients with a $<15 \mathrm{ml} / \mathrm{min} / \mathrm{r} .73 \mathrm{~m} 2$ GFR compared to a $>60 \mathrm{ml} / \mathrm{min} / \mathrm{I} .73 \mathrm{~m} 2 \mathrm{GFR}$ (II). Up to $35 \%$ of all dialysis patients demonstrate signs of congestive heart failure (CHF) (I2-I4). Mortality rates are inversely proportional to declining GFR, especially if patients also suffer from left ventricular systolic dysfunction (II, I5). Evidence is therefore overwhelming that patients with $\mathrm{CKD}$ are at risk for developing cardiac complications on the long term.

\section{Risk factors in ESRD patients contributing to cardiac dysfunction}

There are several known risk factors for cardiac dysfunction in ESRD patients including left ventricular hypertrophy (LVH), anaemia, interdialytic volume overload and HD itself.

\section{Left ventricular hypertrophy}

Almost $75 \%$ of all ESRD patients demonstrate signs of left ventricular hypertrophy (LVH) already prior to initiation of $\mathrm{HD}\left(\mathrm{I}_{3}, \mathrm{I} 6\right)$. $\mathrm{LVH}$ is a strong risk factor for coronary heart disease (CHD), heart failure and all-cause mortality as well as cardiac mortality (I7-20). Suffering from LVH at the start of HD is an independent predictor of death after two years of dialysis treatment (I3). Once on HD, both eccentric and concentric hypertrophy may aggravate LVH (I6, 2I).

\section{Anaemia}

As GFR falls, erythropoietin production drops leading to anemia. Low hemoglobin ( $\mathrm{Hb}$ ) levels are associated with the development of de novo and recurrent cardiac failure and even mortality (22). A < $\mathrm{IO} \mathrm{g} / \mathrm{dl} \mathrm{Hb}$ level is found to lead to hemodynamic adaptations as a means to increase cardiac output to meet tissue oxygen demands (I6). Long term increased cardiac output due to chronic anaemia may lead to LVH. However, these events are to some point reversible if the anaemia is adequately corrected $(\mathrm{I} 2,2 \mathrm{O}, 23)$.

\section{Interdialytic volume load}

The risk on sudden death is markedly increased in the first I2 hours after a HD session as large amounts of fluids and toxins are removed in a relative short period of time (24). Another sudden death incidence peak is associated with long interdialytic periods ( $>48$ hours), especially between 60 and 72 hours $(24,25)$. It is suggested that a combination of volume overload and accumulation of toxins and electrolytes causes this excess death rate (24). Conversely, daily HD sessions may successfully attenuate $\mathrm{LVH}$, hypertension and serum levels of brain natriuretic peptide (BNP) as interdialytic volume changes are understandably smaller $(26,27)$. Moreover, frequent HD (five 
to six times a week) has favourable effects on regional wall motion abnormalities (RWMA), left ventricular mass and death compared to regular 2-3 week haemodialysis sessions $(28,29)$.

\section{Haemodialysis}

Myocardial perfusion may be markedly reduced in HD patients due to progressive coronary artery disease on the one hand and LVH on the other hand. These events could lead to an impaired coronary blood flow, even in the absence of coronary artery stenosis. Moreover, vessels are stiffer in HD patients due to uraemia and atherosclerosis $(8,30,3 \mathrm{I})$. The HD itself also leads to a significantly impaired myocardial blood flow whereas a higher flow is actually required (3234). These phenomena may induce myocardial ischaemia during HD. RWMAs and ventricular arrhythmias may temporarily occur during HD sessions as a sign of an impaired myocardial perfusion $(32,34)$. Additionally, RWMAs and ventricular arrhythmias increase the risk for sudden death in the first twelve hours after a $\operatorname{HD}$ session $(24,35)$. However, these ischaemic sequelae are not always clinically apparent $(32,34)$. Recurrent myocardial ischaemia may cumulatively lead to persistent left ventricular dysfunction known as 'myocardial stunning' thereby contributing to the development of heart failure and increased mortality $\left(35^{-}-37\right)$.

\section{AVF construction and heart function}

A peak in all cause mortality and mortality due to cardiovascular disease is observed in the first two months after HD initiation (38). Increased death rates are possibly also associated with increased requirements of cardiac capacity due to maturation of the AVF. AVF creation leads to an immediate increase in cardiac output through stimulated ventricular contractility, higher stroke volume and an increased heart rate (IO, 39, 40). Unfortunately, subendocardial oxygen supply may decrease while an elevation is required, leading to higher risk on myocardial ischaemia (33, 4I). The augmented cardiac burden induced by a newly constructed AVF is reflected by a higher cardiac marker release including atrial and brain natriuretic peptide (ANP and BNP, respectively) (Io, $42,43)$. Left ventricular end diastolic diameter and fractional shortening are also significantly enlarged in the first week after AVF construction (42). Moreover, both left ventricular mass and left ventricular mass index are significantly increased at one, three and twelve months after AVF creation $(9,43)$.

Several studies therefore indicate that an AVF induces an additional cardiac burden in HD patients, although some evidence is circumstantial. For instance, left ventricular hypertrophy is predominantly observed in HD patients but not in patients undergoing peritoneal dialysis (44). Conversely, LVH was attenuated after AVF ligation in successfully transplanted patients $(45,46)$. 
Symptoms of cardiac failure appeared reversible after flow reducing surgery in HD patients with a HFA (I, 47-50). It is currently uncertain whether the long term risk on cardiovascular death is attenuated after flow reducing surgery as the etiology of cardiac failure in the presence of kidney insufficiency and HD is multifactorial.

\section{High flow access}

\section{Definition and pathofysiology}

Most HD patients have an AVF with access flows between $400-1000 \mathrm{~mL} / \mathrm{min}$ flow. A minimal $300-400 \mathrm{~mL} / \mathrm{min}$ access flow allows for an adequate exchange of waste products during a 2-3 hours HD session. An AVF with a flow $>2000 \mathrm{~mL} / \mathrm{min}$ is termed a high flow access (HFA). This cut-off point is somewhat pragmatically chosen as HFA patients sustain an additional risk of developing cardiac failure above this threshold $(47,50)$. One may consider a HFA as the end result of a too successfully matured AVF. The pathophysiology of a HFA may be explained as follows. Once the arteriovenous anastomosis is constructed, large quantities of arterial blood are shunted into a low resistance venous system. As a consequence, flow in the 'feeding' artery will increase to allow for these enlarged flows. Wall shear stress (WSS) in both the inflow artery and outflow veins will increase. Endothelial cells residing in the vascular wall subsequently release nitric-oxide (NO) which induces vascular dilatation due to smooth muscle cells relaxation $\left(5 \mathrm{I}, 5_{2}^{2}\right)$. This chain of events may lead to a vicious circle. However, it usually takes a number of years before cardiac remodeling eventually leads to a failure in cardiac function. Under these circumstances, long lasting tachycardia and/or left ventricular hypertrophy with a progressive diastolic stiffness contribute to heart failure with preserved ejection fraction or tachycardiomyopathy (I, 53, 54).

\section{Risk factors of HFA}

It is unknown why some patients develop a HFA whereas others do not. Vascular remodeling may continue by some unknown trigger mediated by augmented flows in these individuals. A brachial artery based AVF (rather than a radiocephalic AVF) and young age are risk factors for the onset of HFA (55). Conversely, diabetes mellitus may protect for HFA, possible due to impaired vascular endothelial functioning with diminished venous and arterial vasodilation and remodeling $(55-57)$. Prolonged exposure to uraemia prior to initiation of renal replacement therapy may also compromise AVF maturation and limit the onset of $\operatorname{HFA}\left(30,5^{8}\right)$.

\section{Diagnostic pathway for HFA}

HD patients routinely undergo access flow measurements (6). A two-needle dilution technique is usually practiced although brachial artery flow determined by Duplex may be a superior approach 
for the measurement of total flow through the AVF and its side branches (59). Consultation of a cardiologist is advised if the $2000 \mathrm{~mL} / \mathrm{min}$ threshold level is attained on 2-3 consecutive occasions $(\mathrm{I}, 48,49)$. Cardiac evaluation is probably also indicated if the patient has a $1000-2000 \mathrm{~mL} / \mathrm{min}$ AVF in the presence of a limited cardiac reserve due to earlier comorbidity (past myocardial infarction, heart failure with or without preserved ejection fraction).

Weight gain, dyspnea during exercise or in rest, orthopnea, edema or tachycardia are specific symptoms reflecting progressive heart failure and may also indicate progressive coronary artery disease. Cardiac symptoms and quality of life may serially be monitored using a validated Minnesota questionnaire (6o). Physical examination in most patients with a HFA demonstrates an intense thrill in occasionally grossly dilated arm veins. A simple access compression test may possibly quantify the effect of a HFA on systemic hemodynamics however its clinical utility is still under debate (6I). By digitally compressing the HFA's venous outflow tracts, the access' intravascular distribution volume is suddenly annihilated. If the contribution of an open access to systemic hemodynamics is substantial, one may observe systemic adaptations following this maneuver. A recent study on access compression in HFA patients showed that systolic blood pressure immediately increased while heart rates were reduced (6I). However, depressed heart rates did not adequately compensate for the increased blood pressure when compared to the response in patients with a normal flow AVF (6I). It is hypothesized that functioning of the autonomic nervous system is depressed in HFA patients. These individuals may be less capable of adequately regulating blood pressure and heart rate. An echocardiography may find signs of LVH with or without systolic or diastolic dysfunction $(62,63)$.

Several issues require discussion. Firstly, subtle systolic functional abnormalities may be present in HD patients although ejection fraction may be entirely normal ( $\left.\mathrm{I}_{3}, 62,63\right)$. Moreover, it is uncertain whether routine echocardiography may ascertain additional effects of an open vascular access on left ventricular dimensions (I6). More sensitive monitoring programs or diagnostics modalities such as cardiovascular magnetic resonance may be mandatory, particularly in case of a poor window precluding a reliable echocardiography. For instance, one may decide to subject any new HD patient to an annual echocardiography. One may also serially study novel cardiac biomarkers including ANP and BNP as a means of detecting cardiac overload $(42,43)$. However, these measurements require extensive validation prior to widespread use. 


\section{Treatment of HFA}

Once an HFA is diagnosed, management is coordinated by a team consisting of a nephrologist, a cardiologist, a interventional radiologist and a vascular surgeon. A first line of treatment is conservative. Anaemia, hypertension or electrolyte dysbalance are corrected if required. High frequency dialysis with or without ultrafiltration may be started in asymptomatic patients with signs of volume overload $(26,28)$. If coronary disease is present, a cardiologist will decide whether an endovascular evaluation is initiated as a means to evaluate options for improving myocardial perfusion.

Invasive treatment for a HFA is indicated once conservative and minimally invasive options have failed to adequately mitigate symptoms of hemodynamic overload in the presence of a Iooo-2000 $\mathrm{mL} / \mathrm{min}$ AVF flow, or if the access flow exceeds the $2000 \mathrm{~mL} / \mathrm{min}$ cut-off point in asymptomatic patients $(5,64)$. A decision for invasive treatment is supported by the presence of other long term AVF complications such as hand ischaemia. After all, flow reducing surgery will likely improve hand perfusion $(\mathrm{I}, 65)$. Goal of any invasive therapy is to reduce access flow while dialysis efficacy is maintained. It is advised to monitor access flow during any operation as AVF patency must be guaranteed (66). In addition, systemic hemodynamics may require close monitoring in the early postoperative phase as severe hypertension and cardiac death due to acute volume overload after access revision have occasionally been reported $(6 \mathrm{I}, 67)$.

Ligation as a first treatment modality of a HFA is considered obsolete. This technique is incidentally used as a last resort option if all alternative surgical options have failed. Endovascular coiling or surgical ligation of hemodynamically significant side branches of the HFAs outflow tract will increase total HFA outflow resistance and decrease total access flow. However, side branch ligation has hitherto only been found effective as an adjunctive procedure in chronic hand ischaemia but the technique is not performed for $\operatorname{HFA}(68,69)$.

Reducing the diameter of the AVF anastomosis or the venous outflow tract by banding or plication is a frequently used technique with a $95 \%$ success rate (Table I). The chances on success increase when access flow is monitored during the operation whereas occlusion is prevented (70). These techniques are relatively easy to perform under a loco-regional anesthetic technique. However, the long term efficacy of banding for HFA is doubted $(55,7 \mathrm{I})$. A recent study in 50 patients undergoing banding for high flow in brachial artery based AVFs showed a $50 \%$ recurrence rate one year later. Young patients and an immediate postbanding access flow $>1000 \mathrm{ml} / \mathrm{min}$ were risk factors for a recurrence $(55)$. 


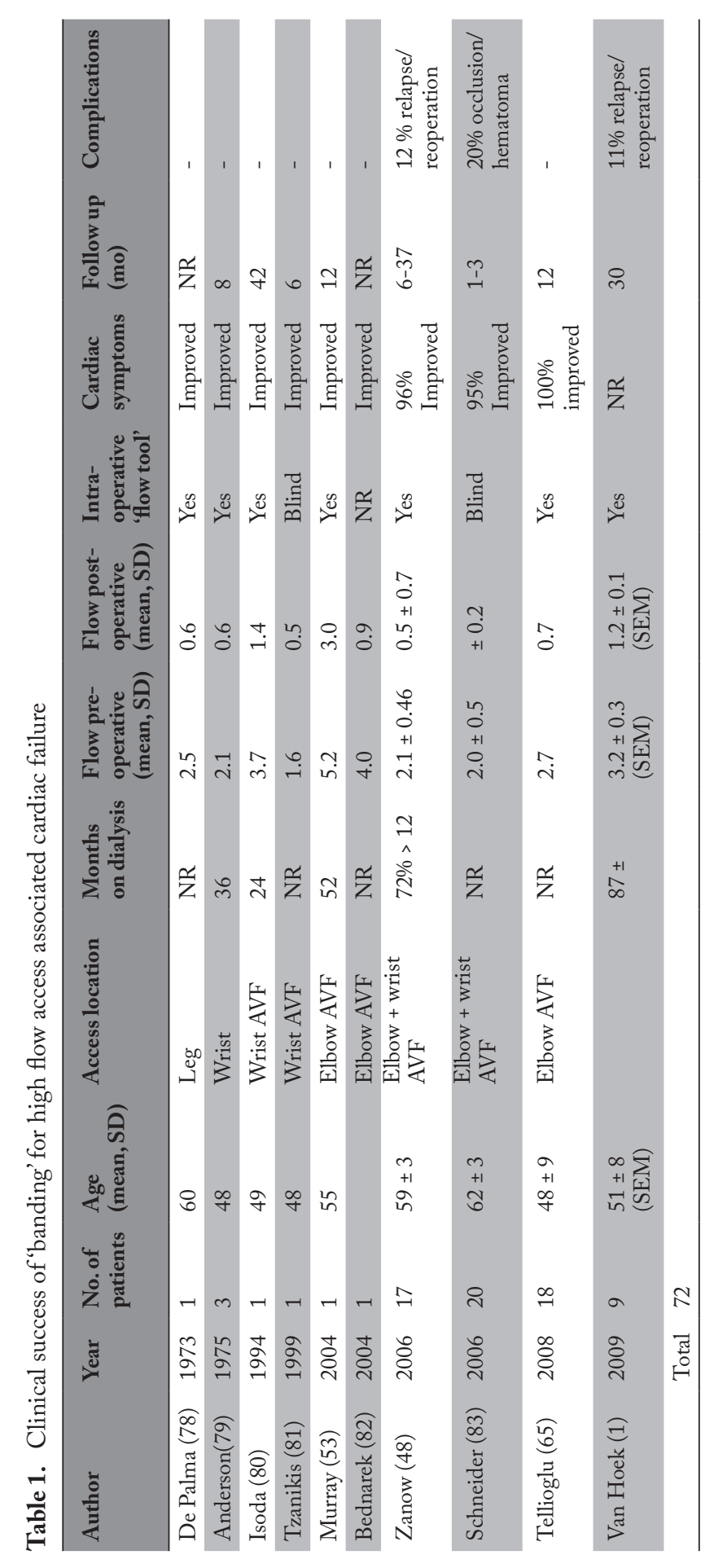




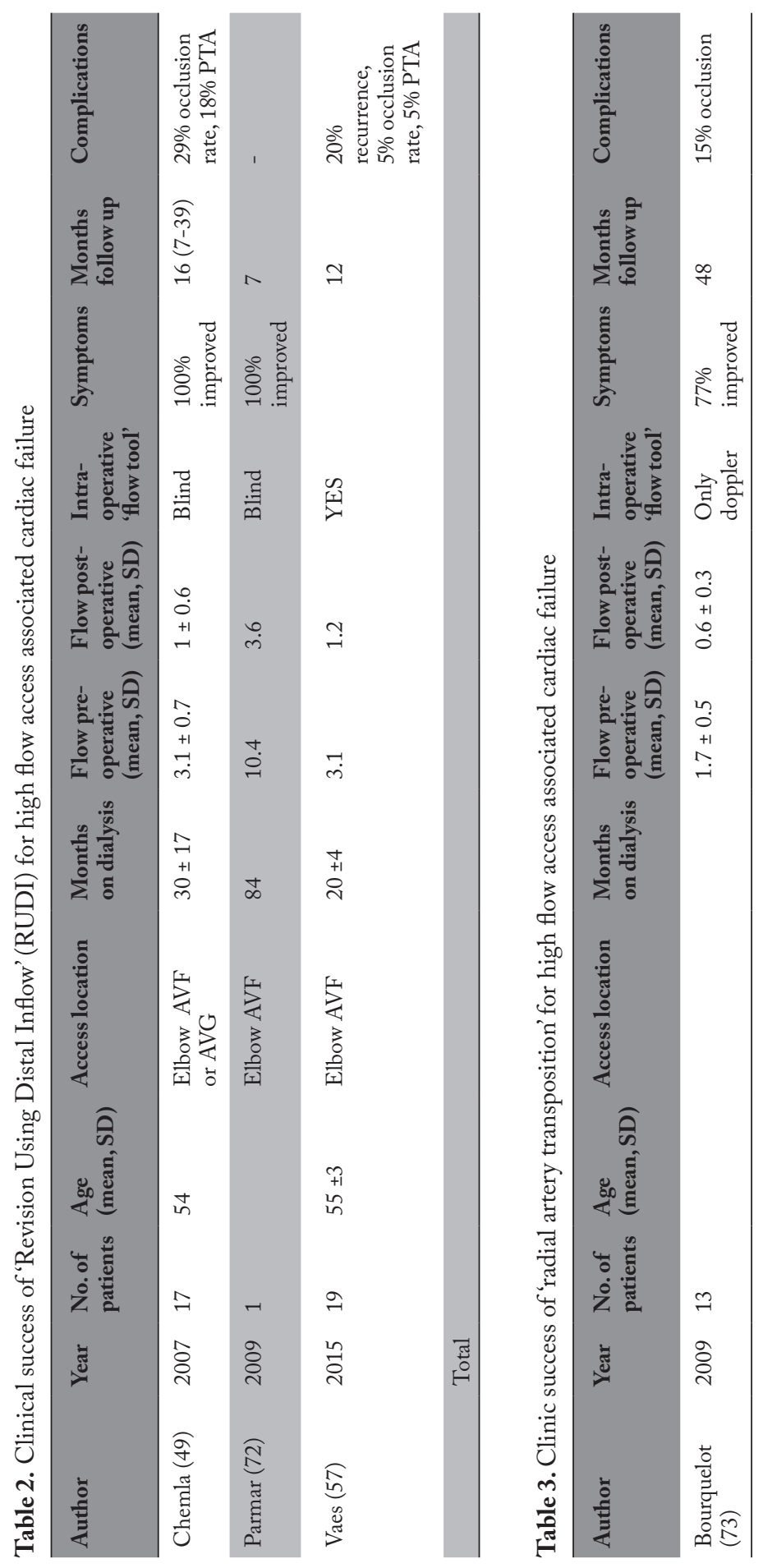


A technique termed revision using distal inflow (RUDI) may be more effective in a brachial artery based HFA. The HFAs venous outflow tract is connected to a smaller capacity radial or ulnar artery using a short stretch of vein or PTFE $(49,57,72)$. Immediate success rates appear comparable to banding but the procedure is more invasive requiring general anesthesia if saphenous vein is used (Table 2). One year after a RUDI, a low $20 \%$ recurrence ratre was found (57). A variant is to revascularize the venous outflow tract using a transposed radial artery (Table 3) (73).

Most HFAs are brachial artery based. If high flow develops in a radio-cephalic access, a technique termed proximal radial artery ligation (PRAL) is available. By ligation of the radial artery just proximal to the anastomosis, access flow is reduced as it solely depends on the ulnar artery, palmar arch and distal radial artery (74).

\section{Discussion}

A minimal $300-400 \mathrm{ml} / \mathrm{min}$ AVF access flow is required for an adequate exchange of waste products. However, most AVFs demonstrate larger flows, usually between 500-1000 $\mathrm{ml} / \mathrm{min}$ (66). In the near future, nephrologists and vascular surgeons are increasingly confronted with HD patients developing an inappropriately high access flow. It should be realized that cardiac function in a substantial portion of $\mathrm{HD}$ patients is already compromised due to a variety of pathophysiological mechanisms. It is intuitive that HFA likely poses an additional risk for cardiac reserve in this patient population $\left(47,5^{\circ}\right)$. However, it may take years of exposure to a HFA before signs of hemodynamic overload, systolic and or diastolic heart failure and cardiomyopathy may become clinically apparent.

An asymptomatic HFA patient may be subjected to a standardized monitoring program including evaluation of cardiac symptoms using published questionnaires (6o). If diagnosed with a HFA, each patient should undergo a standard physical examination. Potential hemodynamic effects of the HFA may be estimated by an access compression test. Moreover, such preoperative testing may possibly predict dangerous postoperative blood pressure increases $(67,75)$.

Indications for surgery aimed at access flow reduction are currently not specified. Flow reducing surgery may be indicated if other forms of treatment aimed at maintaining cardiac reserve are exhausted. However, symptoms of (acute or chronic) hemodynamic overload and heart failure in the presence of a HFA may be a reason for intervention. Timing of access flow reducing surgery in a symptomless HFA patient is also not defined (64). Currently, cardiac and hemodynamic evaluations are arbitrarily advised after three consecutive access flow measurements above the $2 \mathrm{~L} /$ 
min threshold. Determination of the cardiac status using a single echocardiography is notoriously unreliable as most HD patients already demonstrate left ventricular alterations at the start of HD therapy $(\mathrm{I} 3,2 \mathrm{O})$. However, timed echocardiographies may demonstrate ongoing deterioration.

The optimal surgical technique for curbing a HFA is a matter of preference. Most older studies have reported on banding whereas RUDI and PRAL techniques were proposed more recently $(\mathrm{I}, 53,73,74)$. Banding is a very successful option in reducing access flow on the short term if this technique is guided by intra-operative access flow measurements. However, it should be realized that banding (as all other treatments) is a symptomatic treatment modality that does not put a stop to the ongoing remodeling that characterizes an autologous access in young patients $(\mathrm{I}, 48)$. Therefore, the long term efficacy of banding for HFA may be less optimal (55). Alternatively, one may prefer a RUDI technique in younger patients but long term data are sparse. Randomized trials and long term data are not available.

There is no consensus on the need for closure of an AVF or HFA in patients that have successfully undergone a kidney transplantation. Some are reluctant to close a well-functioning dialysis access as an intact facility may be required in the future. However, an persistently open AVF in kidney transplant patients may lead to LVH due to volume and pressure overload which is associated with an increased risk for mortality and morbidity $(19,76)$. Although some studies showed that left ventricular mass and hypertrophy significantly decreased after access ligation, other studies contradicted this improvement $(45,46,77)$.

In conclusion, patients undergoing HD are at risk of developing cardiac insufficiency due to a variety of pathophysiological pathways. The development of high flow through an autologous access such as a brachiocephalic fistula likely poses an additional burden on the cardiac reserve. Surgery aimed at reducing access flow is successful on the short term. However, long term efficacy of these techniques in terms of preserving cardiac reserve must be determined in randomized controlled trials. 


\section{References}

I. van Hoek F, Scheltinga M, Luirink M, Pasmans H, Beerenhout C. Banding of hemodialysis access to treat hand ischemia or cardiac overload. Semin Dial. 2009 Mar-Apr;22(2):204-8.

2. Gupta N, Yuo TH, Konig Gt, Dillavou E, Leers SA, Chaer RA, et al. Treatment strategies of arterial steal after arteriovenous access. J Vasc Surg. 20II Jul;54(I):I62-7.

3. Scali ST, Huber TS. Treatment strategies for access-related hand ischemia. Semin Vasc Surg. 2OII Jun;24(2):I28-36.

4. Scheltinga MR, Bruijninckx CM. Haemodialysis access-induced distal ischaemia (HAIDI) is caused by loco-regional hypotension but not by steal. Eur J Vasc Endovasc Surg. 2012 Feb;43(2):218-23.

5. Scheltinga M, Hoek van F. Banding for high flow hemodialysis access. J Tordoir: Vascular access. Turino: Edizione Minverva Medica; 2009. p. I4I-50.

6. Clinical practice guidelines for vascular access. American journal of kidney diseases : the official journal of the National Kidney Foundation. 2006 Jul;48 Suppl r:S248-73.

7. Holman E. Abnormal arteriovenous communications. Great variability of effects with particular reference to delayed development of cardiac failure. Circulation. I965 Dec;32(6):Ioor-9.

8. McIntyre CW. Haemodialysis-induced myocardial stunning in chronic kidney disease - a new aspect of cardiovascular disease. Blood purification. 2010;29(2):105-Io.

9. Ori Y, Korzets A, Katz M, Erman A, Weinstein T, Malachi T, et al. The contribution of an arteriovenous access for hemodialysis to left ventricular hypertrophy. American journal of kidney diseases : the official journal of the National Kidney Foundation. 2002 Oct;40(4):745-52.

Io. Ori Y, Korzets A, Katz M, Perek Y, Zahavi I, Gafter U. Haemodialysis arteriovenous access--a prospective haemodynamic evaluation. Nephrology, dialysis, transplantation : official publication of the European Dialysis and Transplant Association - European Renal Association. I996 Jan;II(I):94-7.

II. Go AS, Chertow GM, Fan D, McCulloch CE, Hsu CY. Chronic kidney disease and the risks of death, cardiovascular events, and hospitalization. The New England journal of medicine. 2004 Sep 23;35I(I3):I296-305.

I2. Harnett JD, Foley RN, Kent GM, Barre PE, Murray D, Parfrey PS. Congestive heart failure in dialysis patients: prevalence, incidence, prognosis and risk factors. Kidney international. 1995 Mar;47(3):884-90.

I3. Foley RN, Parfrey PS, Harnett JD, Kent GM, Martin CJ, Murray DC, et al. Clinical and echocardiographic disease in patients starting end-stage renal disease therapy. Kidney international. 1995 Jan;47(I):I86-92.

I4. System USRD. USRDS 20 Ir Annual Data Report: Atlas of End-Stage Renal Disease in the United States. Bethesda, MD: 20Ir.

I5. Schou M, Torp-Pedersen C, Gustafsson F, Abdulla J, Kober L. Wall motion index, estimated glomerular filtration rate and mortality risk in patients with heart failure or myocardial infarction: a pooled analysis of I8,oro patients. Eur J Heart Fail. 2008 Jul;io(7):682-8.

16. London GM. Left ventricular alterations and end-stage renal disease. Nephrology, dialysis, transplantation : official publication of the European Dialysis and Transplant Association - European Renal Association. 2002;I7 Suppl I:29-36.

I7. Kannel WB. Left ventricular hypertrophy as a risk factor: the Framingham experience. J Hypertens Suppl. 199I Dec;9(2):S3-8; discussion S-9.

I8. Brown DW, Giles WH, Croft JB. Left ventricular hypertrophy as a predictor of coronary heart disease mortality and the effect of hypertension. Am Heart J. 2000 Dec;I4O(6):848-56.

I9. Silberberg JS, Barre PE, Prichard SS, Sniderman AD. Impact of left ventricular hypertrophy on survival in end-stage renal disease. Kidney international. 1989 Aug;36(2):286-90.

20. Parfrey PS, Foley RN, Harnett JD, Kent GM, Murray DC, Barre PE. Outcome and risk factors for left ventricular disorders in chronic uraemia. Nephrology, dialysis, transplantation : official publication of the European Dialysis and Transplant Association - European Renal Association. 996 Jul;II(7):I277-85.

2I. Malik J, Tuka V, Mokrejsova M, Holaj R, Tesar V. Mechanisms of chronic heart failure development in end-stage renal disease patients on chronic hemodialysis. Physiological research / Academia Scientiarum Bohemoslovaca. 2009;58(5):6r3-2I.

22. Foley RN, Parfrey PS, Harnett JD, Kent GM, Murray DC, Barre PE. The impact of anemia on cardiomyopathy, morbidity, and and mortality in end-stage renal disease. American journal of kidney diseases : the official journal of the National Kidney Foundation. r996 Jul;28(I):53-6I.

23. Silberberg J, Racine N, Barre P, Sniderman AD. Regression of left ventricular hypertrophy in dialysis patients following correction of anemia with recombinant human erythropoietin. Can J Cardiol. I990 Jan-Feb;6(I):I-4. 
24. Bleyer AJ, Hartman J, Brannon PC, Reeves-Daniel A, Satko SG, Russell G. Characteristics of sudden death in hemodialysis patients. Kidney international. 2006 Jun;69(I2):2268-73.

25. Foley RN, Gilbertson DT, Murray T, Collins AJ. Long interdialytic interval and mortality among patients receiving hemodialysis. The New England journal of medicine. 20II Sep 22;365(I2):I099-IO7.

26. Ozkahya M, Ok E, Cirit M, Aydin S, Akcicek F, Basci A, et al. Regression of left ventricular hypertrophy in haemodialysis patients by ultrafiltration and reduced salt intake without antihypertensive drugs. Nephrology, dialysis, transplantation : official publication of the European Dialysis and Transplant Association - European Renal Association. I998 Jun;I3(6):I489-93.

27. Odar-Cederlof I, Bjellerup P, Williams A, Blagg CR, Twardowski Z, Ting G, et al. Daily dialyses decrease plasma levels of brain natriuretic peptide (BNP), a biomarker of left ventricular dysfunction. Hemodialysis international International Symposium on Home Hemodialysis. 2006 Oct;Io(4):394-8.

28. Chertow GM, Levin NW, Beck GJ, Depner TA, Eggers PW, Gassman JJ, et al. In-center hemodialysis six times per week versus three times per week. The New England journal of medicine. 2010 Dec 9;363(24):2287300.

29. Jefferies HJ, Virk B, Schiller B, Moran J, McIntyre CW. Frequent hemodialysis schedules are associated with reduced levels of dialysis-induced cardiac injury (myocardial stunning). Clinical journal of the American Society of Nephrology : CJASN. 2oII Jun;6(6):I326-32.

30. Aitken E, Jackson A, Kong C, Coats P, Kingsmore D. Renal function, uraemia and early arteriovenous fistula failure. BMC nephrology. 2014;15:I79.

3r. van Golde JM, Ruiter MS, Schaper NC, Voo S, Waltenberger J, Backes WH, et al. Impaired collateral recruitment and outward remodeling in experimental diabetes. Diabetes. 2008 Oct;57(10):2818-23.

32. McIntyre CW, Burton JO, Selby NM, Leccisotti L, Korsheed S, Baker CS, et al. Hemodialysis-induced cardiac dysfunction is associated with an acute reduction in global and segmental myocardial blood flow. Clinical journal of the American Society of Nephrology : CJASN. 2008 Jan;3(r):19-26.

33. Bos WJ, Zietse R, Wesseling KH, Westerhof N. Effects of arteriovenous fistulas on cardiac oxygen supply and demand. Kidney international. 1999 May;55(5):2049-53.

34. Dasselaar JJ, Slart RH, Knip M, Pruim J, Tio RA, McIntyre CW, et al. Haemodialysis is associated with a pronounced fall in myocardial perfusion. Nephrology, dialysis, transplantation : official publication of the European Dialysis and Transplant Association - European Renal Association. 2009 Feb;24(2):604-Io.

35. Burton JO, Korsheed S, Grundy BJ, McIntyre CW. Hemodialysis-induced left ventricular dysfunction is associated with an increase in ventricular arrhythmias. Renal failure. 2008;30(7):70I-9.

36. Burton JO, Jefferies HJ, Selby NM, McIntyre CW. Hemodialysis-induced cardiac injury: determinants and associated outcomes. Clinical journal of the American Society of Nephrology: CJASN. 2009 May;4(5):9I4-20.

37. Braunwald E, Kloner RA. The stunned myocardium: prolonged, postischemic ventricular dysfunction. Circulation. 1982 Dec;66(6):II46-9.

38. Saran RL, Y.; Robinson, B.;. US Renal Data System 2014 annual data report: epidemiology of kidney disease in the United States. American journal of kidney diseases : the official journal of the National Kidney Foundation. 20I5;66(I):30I-6.

39. Guyton AC, Hall JE. Textbook of medical physiology. Io ed. Philadelphia: Elsevier Science; 2000 2000. I064 p.

40. MacRae JM, Levin A, Belenkie I. The cardiovascular effects of arteriovenous fistulas in chronic kidney disease: a cause for concern? Semin Dial. 2006 Sep-Oct;19(5):349-52.

4I. Savage MT, Ferro CJ, Sassano A, Tomson CR. The impact of arteriovenous fistula formation on central hemodynamic pressures in chronic renal failure patients: a prospective study. American journal of kidney diseases : the official journal of the National Kidney Foundation. 2002 Oct;40(4):753-9.

42. Iwashima Y, Horio T, Takami Y, Inenaga T, Nishikimi T, Takishita S, et al. Effects of the creation of arteriovenous fistula for hemodialysis on cardiac function and natriuretic peptide levels in CRF. American journal of kidney diseases : the official journal of the National Kidney Foundation. 2002 Nov;40(5):974-82.

43. Hiremath S, Doucette SP, Richardson R, Chan K, Burns K, Zimmerman D. Left ventricular growth after I year of haemodialysis does not correlate with arteriovenous access flow: a prospective cohort study. Nephrology, dialysis, transplantation : official publication of the European Dialysis and Transplant Association - European Renal Association. 2010 Aug;25(8):2656-6r.

44. Tian JP, Wang T, Wang H, Cheng LT, Tian XK, Lindholm B, et al. The prevalence of left ventricular hypertrophy in Chinese hemodialysis patients is higher than that in peritoneal dialysis patients. Renal failure. 2008;30(4):39I-400. 
45. Unger P, Velez-Roa S, Wissing KM, Hoang AD, van de Borne P. Regression of left ventricular hypertrophy after arteriovenous fistula closure in renal transplant recipients: a long-term follow-up. Am J Transplant. 2004 Dec;4(I2):2038-44.

46. van Duijnhoven EC, Cheriex EC, Tordoir JH, Kooman JP, van Hooff JP. Effect of closure of the arteriovenous fistula on left ventricular dimensions in renal transplant patients. Nephrology, dialysis, transplantation : official publication of the European Dialysis and Transplant Association - European Renal Association. 200I Feb;16(2):368-72.

47. Basile C, Lomonte C, Vernaglione L, Casucci F, Antonelli M, Losurdo N. The relationship between the flow of arteriovenous fistula and cardiac output in haemodialysis patients. Nephrology, dialysis, transplantation : official publication of the European Dialysis and Transplant Association - European Renal Association. 2008 Jan;23(I):282-7.

48. Zanow J, Petzold K, Petzold M, Krueger U, Scholz H. Flow reduction in high-flow arteriovenous access using intraoperative flow monitoring. Journal of vascular surgery : official publication, the Society for Vascular Surgery [and] International Society for Cardiovascular Surgery, North American Chapter. 2006 Dec;44(6):1273-8.

49. Chemla ES, Morsy M, Anderson L, Whitemore A. Inflow reduction by distalization of anastomosis treats efficiently high-inflow high-cardiac output vascular access for hemodialysis. Semin Dial. 2007 JanFeb;20(I):68-72.

50. Schier T, Gobel G, Bosmuller C, Gruber I, Tiefenthaler M. Incidence of arteriovenous fistula closure due to high-output cardiac failure in kidney-transplanted patients. Clinical transplantation. 2013 NovDec;27(6):858-65.

5I. Corpataux JM, Haesler E, Silacci P, Ris HB, Hayoz D. Low-pressure environment and remodelling of the forearm vein in Brescia-Cimino haemodialysis access. Nephrology, dialysis, transplantation : official publication of the European Dialysis and Transplant Association - European Renal Association. 2002 Jun;I7(6):I057-62.

52. Zakrzewicz A, Secomb TW, Pries AR. Angioadaptation: keeping the vascular system in shape. News Physiol Sci. 2002 Oct;17:I97-20I.

53. Murray BM, Rajczak S, Herman A, Leary D. Effect of surgical banding of a high-flow fistula on access flow and cardiac output: intraoperative and long-term measurements. American journal of kidney diseases : the official journal of the National Kidney Foundation. 2004 Dec;44(6):Io9o-6.

54. MacRae JM, Pandeya S, Humen DP, Krivitski N, Lindsay RM. Arteriovenous fistula-associated high-output cardiac failure: a review of mechanisms. American journal of kidney diseases : the official journal of the National Kidney Foundation. 2004 May;43(5):er7-22.

55. Vaes RH, Wouda R, van Loon M, van Hoek F, Tordoir JH, Scheltinga MR. Effectiveness of surgical banding for high flow in brachial artery-based hemodialysis vascular access. Journal of vascular surgery : official publication, the Society for Vascular Surgery [and] International Society for Cardiovascular Surgery, North American Chapter. 20I5 Mar;6r(3):762-6.

56. Hamed S, Brenner B, Roguin A. Nitric oxide: a key factor behind the dysfunctionality of endothelial progenitor cells in diabetes mellitus type-2. Cardiovasc Res. 20II Jul I;9I(I):9-I5.

57. Vaes RH, van Loon M, Vaes SM, Cuypers P, Tordoir JH, Scheltinga MR. One-year efficacy of the RUDI technique for flow reduction in high-flow autologous brachial artery-based hemodialysis vascular access. J Vasc Access. 2015;16 Suppl 9:S96-Ior.

58. Brunet P, Gondouin B, Duval-Sabatier A, Dou L, Cerini C, Dignat-George F, et al. Does uremia cause vascular dysfunction? Kidney \& blood pressure research. 2011;34(4):284-90.

59. Engelberts I, Tordoir JH, Boon ES, Schreij G. High-output cardiac failure due to excessive shunting in a hemodialysis access fistula: an easily overlooked diagnosis. American journal of nephrology. 1995;15(4):323-6

6o. Behlouli H, Feldman DE, Ducharme A, Frenette M, Giannetti N, Grondin F, et al. Identifying relative cutoff scores with neural networks for interpretation of the Minnesota Living with Heart Failure questionnaire. Conf Proc IEEE Eng Med Biol Soc. 2009;2009:6242-6.

6r. Vaes RHD, Beerenhout CH, Tordoir J, Scheltinga MR. Hemodynamic effects of vascular access compression in haemodialysis patients Submitted. 2012.

62. Green D, Kalra PR, Kalra PA. Echocardiographic abnormalities in dialysis patients with normal ejection fraction. Nephrol Dial Transplant. 20I2 Dec;27(I2):4256-9.

63. Wang H, Liu J, Yao XD, Li J, Yang Y, Cao TS, et al. Multidirectional myocardial systolic function in hemodialysis patients with preserved left ventricular ejection fraction and different left ventricular geometry. Nephrol Dial Transplant. 20I2 Dec;27(I2):4422-9. 
64. Basile C, Lomonte C. When and how should an arterio-venous access be modified because of a high blood flow rate? Semin Dial. 20II Jul-Aug;24(4):396-8.

65. Tellioglu G, Berber I, Kilicoglu G, Seymen P, Kara M, Titiz I. Doppler ultrasonography-guided surgery for high-flow hemodialysis vascular access: preliminary results. Transplantation proceedings. 2008 JanFeb;40(I):87-9.

66. van Hoek F, Scheltinga MR, Luirink M, Raaymakers LC, van Pul C, Beerenhout CH. Access flow, venous saturation, and digital pressures in hemodialysis. Journal of vascular surgery : official publication, the Society for Vascular Surgery [and] International Society for Cardiovascular Surgery, North American Chapter. 2007 May;45(5):968-73.

67. Pascual J, Martins J, Bouarich H, Galeano C, Barrios V, Marcen R, et al. Sudden death after arteriovenous fistula ligation in a renal transplant patient. Annals of vascular surgery. $2008 \mathrm{Jan} ; 22(\mathrm{I}): \mathrm{I} 34-5$.

68. Kariya S, Tanigawa N, Kojima H, Komemushi A, Shomura Y, Shiraishi T, et al. Transcatheter coil embolization for steal syndrome in patients with hemodialysis access. Acta radiologica (Stockholm, Sweden : 1987). 2009 Jan;50(I):28-33.

69. Vaes RH, Scheltinga MR. Side branch ligation for haemodialysis-access-induced distal ischaemia. European journal of vascular and endovascular surgery : the official journal of the European Society for Vascular Surgery. 2OI2 Oct;44(4):452-6.

70. Scheltinga MR, Van Hoek F, Bruyninckx CM. Surgical banding for refractory hemodialysis access-induced distal ischemia (HAIDI). J Vasc Access. 2009 Jan-Mar;Io(I):43-9.

7I. Tuka V, Malik J, Chytilova E, Kudlicka J, Slavikova M, Wijnen E, et al. Long-term arterial adaptation to high blood flow in the feeding artery of vascular access for hemodialysis. J Vasc Access. 20I2 Jan I6:O.

72. Parmar CD, Chieng G, Abraham KA, Kumar S, Torella F. Revision using distal inflow for treatment of heart failure secondary to arteriovenous fistula for hemodialysis. J Vasc Access. 2009 Jan-Mar;ro(I):62-3.

73. Bourquelot P, Gaudric J, Turmel-Rodrigues L, Franco G, Van Laere O, Raynaud A. Transposition of radial artery for reduction of excessive high-flow in autogenous arm accesses for hemodialysis. Journal of vascular surgery : official publication, the Society for Vascular Surgery [and] International Society for Cardiovascular Surgery, North American Chapter. 2009 Feb;49(2):424-8, 8 er.

74. Bourquelot P, Gaudric J, Turmel-Rodrigues L, Franco G, Van Laere O, Raynaud A. Proximal radial artery ligation (PRAL) for reduction of flow in autogenous radial cephalic accesses for haemodialysis. European journal of vascular and endovascular surgery : the official journal of the European Society for Vascular Surgery. 20Iо Jul;40(I):94-9.

75. Young PR, Jr., Rohr MS, Marterre WF, Jr. High-output cardiac failure secondary to a brachiocephalic arteriovenous hemodialysis fistula: two cases. Am Surg. I998 Mar;64(3):239-4I.

76. Meeus F, Kourilsky O, Guerin AP, Gaudry C, Marchais SJ, London GM. Pathophysiology of cardiovascular disease in hemodialysis patients. Kidney Int Suppl. 2000 Aug;76:Si40-7.

77. De Lima JJ, Vieira ML, Molnar LJ, Medeiros CJ, Ianhez LE, Krieger EM. Cardiac effects of persistent hemodialysis arteriovenous access in recipients of renal allograft. Cardiology. 1999;92(4):236-9.

78. De Palma JR, Vannix R, Bahuth J, Abukurah A. "Steal” syndrome, ischemia, congestive failure and periperhal neuropathy. Proc Clin Dial Transplant Forum. I973;3:9-II.

79. Anderson CB, Groce MA. Banding of arteriovenous dialysis fistulas to correct high-output cardiac failure. Surgery. 1975 Nov;78(5):552-4.

8o. Isoda S, Kajiwara H, Kondo J, Matsumoto A. Banding a hemodialysis arteriovenous fistula to decrease blood flow and resolve high output cardiac failure: report of a case. Surgery today. 1994;24(8):734-6.

8I. Tzanakis I, Hatziathanassiou A, Kagia S, Papadaki A, Karephyllakis N, Kallivretakis N. Banding of an overfunctioning fistula with a prosthetic graft segment. Nephron. I999;8I(3):35I-2.

82. Bednarek-Skublewska A, Jozwiak L, Przywara S, Baranowicz-Gaszczyk I, Wronski J, Ksiazek A. [Acute cardiac failure secondary to brachiocephalic arteriovenous fistula in patient on chronic haemodialysis]. Pol Arch Med Wewn. 2004 Oct;ir2(4):I22I-7.

83. Schneider CG, Gawad KA, Strate T, Pfalzer B, Izbicki JR. T-banding: a technique for flow reduction of a hyperfunctioning arteriovenous fistula. Journal of vascular surgery : official publication, the Society for Vascular Surgery [and] International Society for Cardiovascular Surgery, North American Chapter. 2006 Feb;43(2):402-5. 




\section{Chapter - VIII}

\section{Effectiveness of surgical banding for high flow in brachial artery based haemodialysis vascular access}

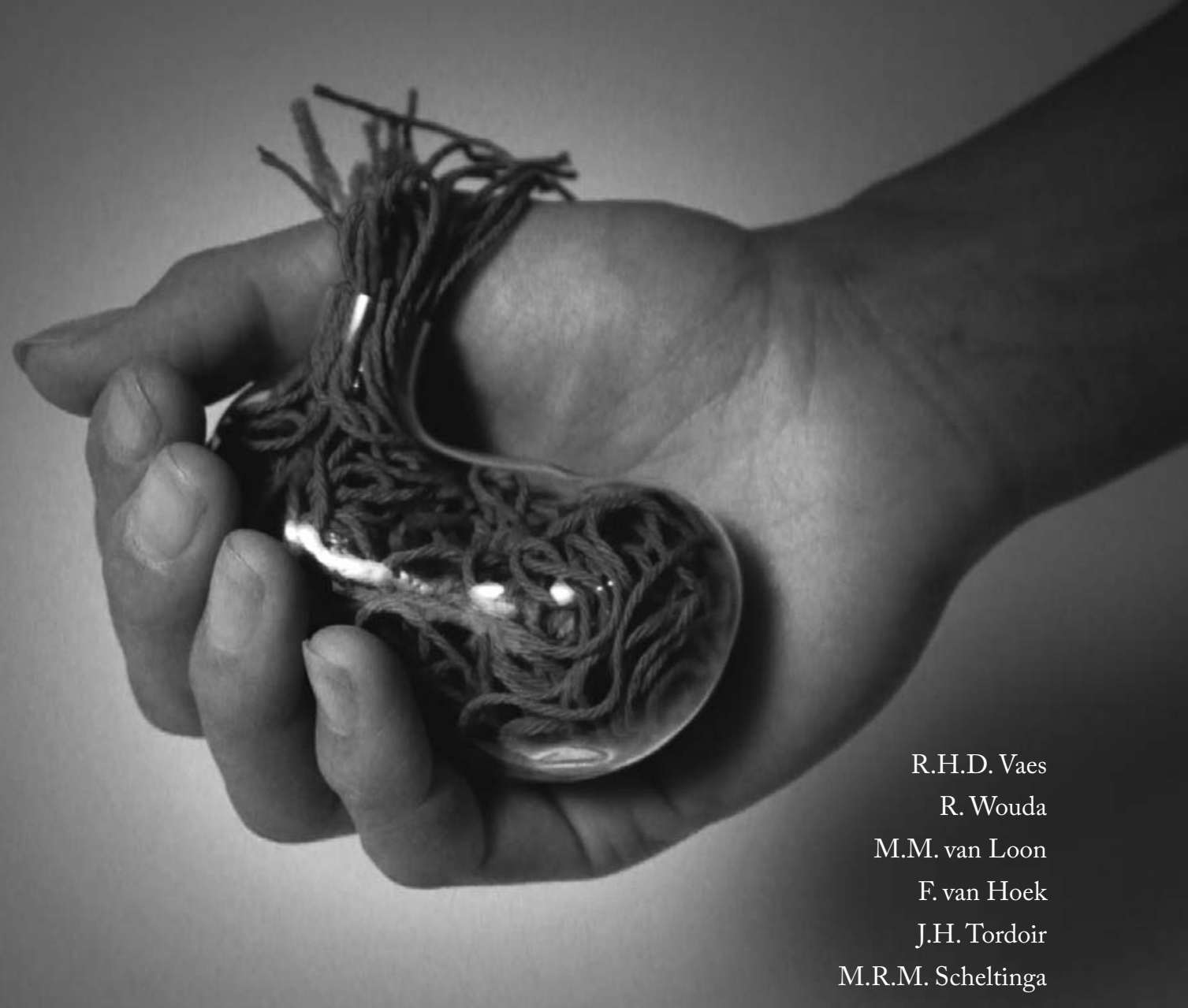

J Vasc Surg 2015 Mar;6r(3):762-6 


\section{Abstract}

\section{Objective}

Autogenous arteriovenous haemodialysis (AV) access may develop high flow (>2 L/min) over time. Reducing flow volume of high flow access (HFA) using a surgical banding technique has been reported to be successful on the short term. The aim of this study was to evaluate the efficacy of banding in HFAs in terms of freedom from recurrence of high flow during a one year follow up.

\section{Design of study}

All haemodialysis (HD) patients undergoing surgical banding of a high flow access during a 8 year time period in three hospitals were retrospectively studied. Access flow data, freedom of recurrent high flow and complications were analysed during a I2 month postoperative observation period.

\section{Results}

A total of 50 patients were available for analysis ( 30 males, age $5^{\mathrm{I}} \pm 2 \mathrm{yr}$ ). Banding was performed $30 \pm 6$ months following AV access construction. The majority of HFA patients suffered from hypertension requiring medication $(56 \%)$ but diabetes mellitus and peripheral arterial obstructive disease were seldomly observed (6\% and I2\%, respectively). Most HFA's (96\%) were brachial artery based fistulas (brachiocephalic: $56 \%$, basilic vein transposition: $40 \%$, radiocephalic $4 \%$ ). Banding initially reduced access flow by more than $50 \%$ (3070 \pm 95 vs I $490 \pm 105 \mathrm{~mL} / \mathrm{min}, \mathrm{P}<\mathrm{O} .00 \mathrm{O})$. More than half $(52 \%)$ of the patients developed recurrent high flow $(>2 \mathrm{~L} / \mathrm{min})$ during the observation period. Young age ( $45 \pm 3$ vs $57 \pm 3 \mathrm{yr}, \mathrm{P}=0.02)$ and an access flow above $\mathrm{L} / \mathrm{min}$ immediately after banding $(\mathrm{P}=0.03)$ were risk factors for recurrent high flow.

\section{Conclusion}

An immediate postbanding access flow $>\mathrm{I} \mathrm{L} / \mathrm{min}$ and young age are risk factors for recurrent high flow in a banded brachial artery based haemodialysis access during a one year follow up. 


\section{Introduction}

An autogenous arteriovenous haemodialysis (AV) access may demonstrate high flow over time. A $>2 \mathrm{~L} / \mathrm{min}$ flow is used as a cut-off point for the treatment of high flow fistulas ( $\mathrm{I}-4)$. The etiology and risk factors for high flow access (HFA) development are largely unknown but ongoing arterial and venous remodelling, mediated by NO release, may play a role in the pathogenesis (5). One overview reported that an estimated $2-4 \%$ of the patients undergoing HD will have a HFA (4).

A HFA is often asymptomatic. However, not treating HD patients harbouring a HFA may possibly lead to an unproportionally high incidence of cardiovascular death in dialysis facilities $(2,6-9)$. Any HD patient demonstrating signs of volume overload combined with a progressive increase in access flow beyond the $2 \mathrm{~L} / \mathrm{min}$ may undergo cardiovascular evaluation (4). For instance, increased body weight, fatigue and shortness of breath during minimal exertion or rest may be reported in the presence of a HFA. Physical examination may reveal signs of dyspnoea, tachypnoea and peripheral edema as well as systolic bruits or a gallop rhythm (I, 7). If a HFA is thought to contribute to vascular overload in a HD patient, a multidisciplinary team including a nephrologist, radiologist, a vascular technician and a vascular surgeon may decide on a surgical treatment for the HFA. The simultaneous presence of haemodialysis access induced distal ischemia (HAIDI) may tip the balance towards access flow reduction as symptoms of hand hypoperfusion may be attenuated following HFA treatment (I).

Several surgical techniques are available for flow reduction in a $\mathrm{HFA}(\mathrm{I}, 3, \mathrm{IO})$. Flow guided banding appeared an effective treatment option for HFA (I, II). By wrapping a band around the access venous tract, overall $\mathrm{AV}$ access outflow resistance is increased while access flow is reduced and digital blood pressures increase (I). Although the direct postoperative results of banding on access flow volume reduction are favourable, the effects on the longer term are unknown.

Aim of this study was to evaluate the efficacy of banding HFAs in terms of freedom from recurrence of high flow (defined as access flow >2 1/min) during a I2 month follow up.

\section{Material and methods}

\section{Study populations}

This retrospective study was performed in all patients who had undergone a banding procedure for HFA in three dialysis facilities in the Netherlands (MMC Máxima Medical Center, Veldhoven; 
MUMC Maastricht University Medical Center; Radboud University Medical Center, Nijmegen). Each dialysis facility accommodates between Ioo-I50 chronic HD patients.

Access flow in these dialysis facilities is routinely measured every two months using ultrasound dilution technique (HDor, Transonic Systems Inc, New York, USA) as advised by vascular access guidelines (I2). Inclusion criteria for the present study were a stable (>3 months) HD treatment and $\mathrm{a}>2 \mathrm{~L} / \mathrm{min}$ access flow on at least two consecutive access flow measuring points. Patients having signs of cardiac failure and an access flow between I and $2 \mathrm{~L} / \mathrm{min}$ were also eligible for a banding procedure. Patients were discussed in a multidisciplinary team consisting of a nephrologist, a vascular technician, a radiologist and a vascular surgeon. Cardiologists were consulted if required. Decision making was based on consensus.

The banding technique was performed using a standard uniform operative technique (MMC, between March 2003 and October 20II; MUMC, between October 2005 and April 20Ir; Radboud UMC, between August 2009 and October 20II). However, alternative surgical techniques aimed at flow reduction were not offered.

All patients were informed on the nature of the study and consented to its specifics. The MMC Medical Ethics Committee judged that study approval was not necessary.

\section{Operative banding protocol}

Banding was performed as previously reported (I, I3). Patients were operated on as outpatients. Anaesthetic technique was left to the preference of the anaesthesiologist or vascular surgeon. The ipsilateral access hand was placed in a plastic bag allowing inspection of distal limb perfusion at any time during the procedure. Following desinfection, the venous portion of the AV access in proximity to the anastomosis was dissected. Downstream towards the axillar region, a two centimeter incision allowed intraoperative access flow measurement using an ultrasonic transit time technique (HT 313, Transonic Systems Inc, New York, USA). This monitoring technique was used in all patients. A five millimeter wide flat woven polyester band (Mersilene, Johnson and Johnson, Hamburg, Germany) was wrapped around the dissected venous portion of the HFA, usually two to four centimetres from the anastomosis. Once the desired tightness of the band was attained, the band was fixed using metal clips and sutures $\left(\mathrm{I}, \mathrm{I}_{3}\right)$. The decision to secure the band at a given diameter was guided by a sufficient reduction of access flow whereas a palpable thrill was maintained. Grade of desired flow reduction was beforehand calculated on the basis of a preoperative access flow as measured by the ultrasound dilution technique. In general, we strived to attain an postoperative access flow between $600-1000 \mathrm{~mL} / \mathrm{min}$. 


\section{Data collection, definitions and statistics}

Demographic factors, type of AV access and access flows were obtained from electronic files of all patients that had undergone banding procedures between January, 2005 and January, 2013. Immediate and long term complications following banding including postoperative access occlusion, recurrent high flow and possible other complications were also extracted from these files. Recurrent high flow was defined as a $>2 \mathrm{~L} / \mathrm{min}$ access flow during a twelve month postbanding observation period.

SPSS I7.o software version was used for statistical analysis (SPSS Inc., Chicago, IL, USA).Data were expressed as mean \pm standard error of mean (SEM). Differences between groups were determined using various statistical tests such as the Mann-Whitney $U$ test and Fisher-exact test when appropriate. Correlations between variables were calculated with the Pearson correlation test. A $\mathrm{P}<0.05$ was considered significant.

\section{Results}

Table I depicts demographic data of $50 \mathrm{HD}$ patients that received a banding procedure for HFA in the three hospitals (male $\mathrm{n}=3 \mathrm{O}$, age $5^{\mathrm{I}} \pm 2 \mathrm{yrs}$ ). Approximately $65 \%$ of the autogenous $\mathrm{AV}$ access in the three institutions are brachial artery based and $35 \%$ are radial artery based. Based on the present study population, $3 \%$ of all HD access surgery in the three hospitals was related to HFA surgery. Not one of the 50 study patients was in acute cardiac failure. Diabetes mellitus and PAOD were seldomly observed ( $6 \%$ and I $_{2} \%$ of patients, respectively). However, the majority of HFA patients suffered from other comorbidities such as hypertension requiring medication $(n=28,56 \%)$.

Table I. Demographics of haemodialysis patients with a high flow access (HFA) undergoing banding

\begin{tabular}{lllll}
\hline & $\begin{array}{l}\text { HFA }^{\mathbf{a}} \\
(\mathbf{n = 5 0 )}\end{array}$ & $\begin{array}{l}\text { Recurrent HFA }^{\mathbf{b}} \\
(\mathbf{n = 2 6})\end{array}$ & $\begin{array}{l}\text { No recurrence } \\
(\mathbf{n = 2 4 )}\end{array}$ & $\mathbf{p}^{\mathbf{2 4}}$ \\
\hline Sex (male/female) & $30 / 20$ & $17 / 9$ & $13 / 11$ & 0.3 \\
\hline Age (years) & $51 \pm 2$ & $45 \pm 3$ & $57 \pm 3$ & 0.02 \\
\hline Diabetes mellitus (\%) & $3(6)$ & $2(4)$ & $1(4)$ & 0.5 \\
\hline PAOD d (\%) & $6(12)$ & $3(12)$ & $3(13)$ & 0.67 \\
\hline Hypertension (\%) & $28(56)$ & $13(50)$ & $15(63)$ & 0.67 \\
\hline Time to development of HFA (months) & $30 \pm 6$ & $38 \pm 12$ & $23 \pm 4$ & 0.80 \\
\hline
\end{tabular}

${ }^{a}$ HFA, total population who underwent banding

${ }^{\mathrm{b}}$ Recurrent HFA, subpopulation developing recurrent high flow ( $>2 \mathrm{~L} / \mathrm{min}$ ) after banding

${ }^{c}$ No recurrence, subpopulation with stable access flows $(<2 \mathrm{~L} / \mathrm{min})$ after banding

d PAOD, peripheral arterial occlusive disease 
Most HFAs were brachial artery-based (96\%) including autogenous brachial-cephalic upper arm direct access (56\%) and autogenous brachial-basilic upper arm transposition (40\%). Two autogenous radio-cephalic direct wrist access developed high flow (4\%). Demographics of the three hospital cohorts were not different regarding these parameters (data not shown). Banding was performed $30 \pm 6$ months following AV access construction. Alternative flow reductive procedures such as RUDI (revision using distal inflow) or access ligation were not performed during the study period (3).

Twenty-seven patients (54\%) of all patients received general anaesthesia, twenty two (44\%) local and one (2\%) regional anaesthesia. Preoperative access flows of all HFA patients are depicted in Table 2.

Prior to operation, access flow was $3070 \pm 95 \mathrm{ml} / \mathrm{min}$ (Table $2, \mathrm{n}=50$ ). Immediately following banding, flow dropped to $1490 \pm 105 \mathrm{ml} / \mathrm{min}(\mathrm{n}=47, \mathrm{P}<0.00 \mathrm{r}$; data of 3 patients missing). Access flow increased in most patients during the $\mathrm{I} 2$ month observation period (Figure I). More than half ( $\mathrm{n}=26,52 \%$ ) developed recurrent high flow $(>2 \mathrm{~L} / \mathrm{min}$ ) during this time period, on average approximately $5 \pm \mathrm{I}$ month after banding. In contrast, access flow remained below $2 \mathrm{~L} / \mathrm{min}$ in the remaining 24 patients. Type of anaesthesia was not associated with an increased risk of recurrent HFA. Differences in outcome between the three hospitals were not present. Young age and high immediate postoperative access flow were the only factors that were related to the onset of recurrence. Patients with recurrent HFA were on average I2 years younger compared to patients who maintained a stable postbanding access flow volume ( $45 \pm 3$ vs $57 \pm 3 \mathrm{yrs}, \mathrm{P}=0.02$ ). Moreover, a postoperative access flow above $1000 \mathrm{~mL} / \mathrm{min}$ was associated with recurrent HFA within one year (Figure 2). All patients with an immediate postbanding access flow $>1600 \mathrm{~mL} / \mathrm{min}$ developed a recurrent HFA. The magnitude in drop of access flow immediately following banding did not predict a recurrent HFA.

Table II. Access flows in HFA patients before and immediately after banding

\begin{tabular}{|c|c|c|c|c|}
\hline & $\begin{array}{l}\text { HFA }^{a} \\
(n=50)\end{array}$ & $\begin{array}{l}\text { Recurrent } \mathrm{HFA}^{\mathrm{b}} \\
(\mathrm{n}=26)\end{array}$ & $\begin{array}{l}\text { No Recurrence } \\
(n=24)\end{array}$ & $\mathbf{P}$ \\
\hline Preoperative flow & $3070 \pm 95$ & $3390 \pm 120$ & $2890 \pm 150$ & 0.16 \\
\hline Postoperative & $\begin{array}{l}1490 \pm \\
105\end{array}$ & $1785 \pm 165$ & $1090 \pm 60$ & 0.001 \\
\hline
\end{tabular}

${ }^{\text {a }}$ HFA, total population who underwent banding

${ }^{\mathrm{b}}$ Recurrent HFA, subpopulation developing recurrent high flow (> $2000 \mathrm{~mL} / \mathrm{min}$ ) after banding

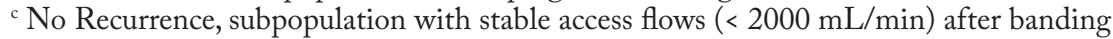




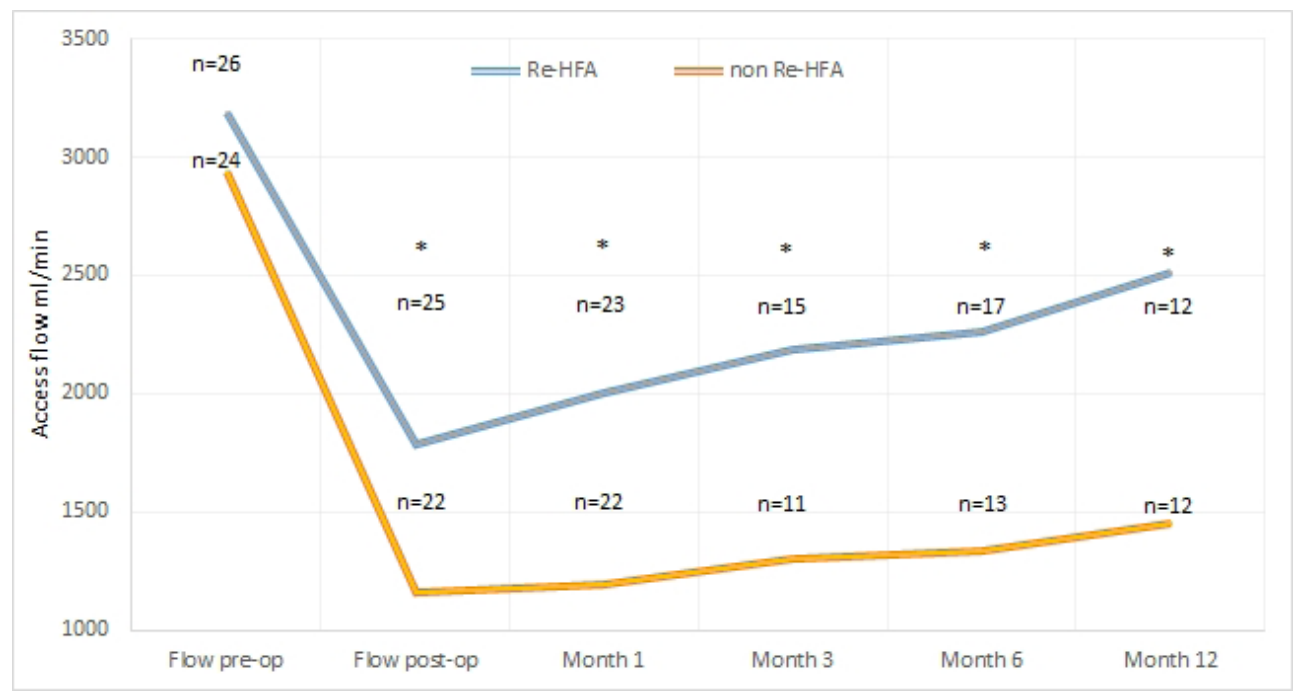

Figure 1. Access flow $(\mathrm{ml} / \mathrm{min})$ after banding. The upper curve reflects patients developing recurrent high flow $(>2000 \mathrm{~mL} / \mathrm{min})$. The lower curve illustrates patients with access flow that remained below $2000 \mathrm{~mL} / \mathrm{min} .{ }^{*} \mathrm{P}<0.05$

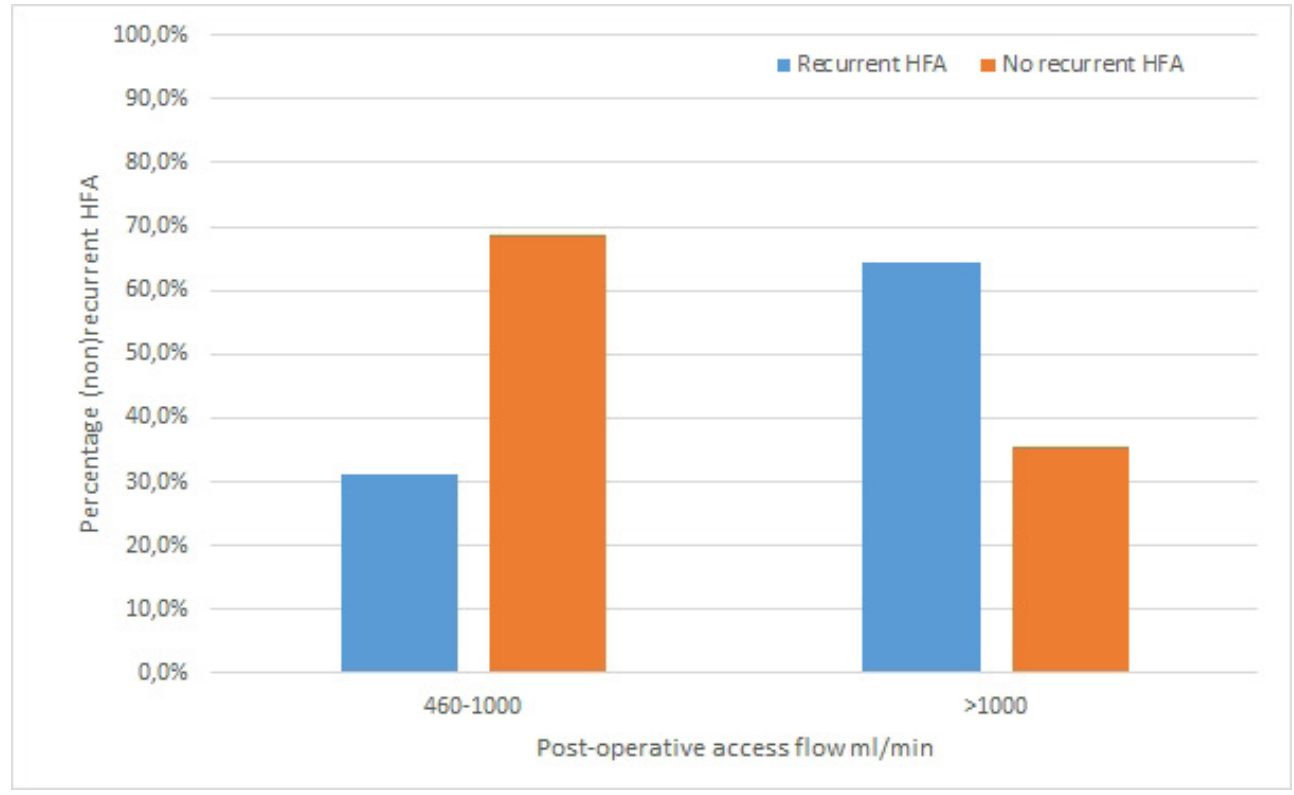

Figure 2. Postoperative access flow $>1000 \mathrm{ml} / \mathrm{min}$ was significantly associated with an increased risk on recurrent HFA $(\mathrm{P}=0.03)$ 
Access occlusion immediately following banding requiring (successful) revision was observed in one patient. Eight of the 26 patients with recurrent HFA underwent a surgical revision (rebanding $\mathrm{n}=6$, revision using distal inflow (RUDI, $\mathrm{n}=2$ ), on average $8 \pm 3$ months following the initial banding procedure. Rebanding was successful in 3 patients whereas the other 3 patients again developed high access flows. Infection necessitating band removal occurred once.

During the twelve months follow up period, three patients died because of cessation of HD treatment whereas four patients were successfully transplanted. All other patients remained on HD. Eight patients were transplanted in the period beyond the twelve months follow up period. No HD patient died of a cardiac event during this observation period.

\section{Discussion}

Previous studies have demonstrated that banding effectively reduces AV access flow on the short term but data on efficacy at 12 month follow up are unknown. The aim of the present study was to evaluate the longevity of flow reduction in banded HFAs during a one year observation period. More than half of the banded population developed recurrent high flows (>2 L/min) during this observation period, usually already during the first few months. Young age and immediate postoperative access flow $>1000 \mathrm{ml} / \mathrm{min}$ were risk factors for recurrent high flow.

It is unclear why some HD patients go on to develop high access flow whereas others do not. Triggers for up regulation of these events are unknown. Connecting vascular systems with different pressures leads to augmented blood flows along the anastomotic area. The consequent increased wall shear stress stimulates production of nitric oxide (NO) and metalloproteinases (MMP) and associated smooth muscle cell (SMC) relaxation ( $\left.14,{ }_{5}\right)$. MMP's are known to promote disintegration of medial vascular wall layers leading to arterial dilatation (I4-I6). A similar physiologic response is seen in portions of the venous outflow tract (I7). Interestingly, the present study demonstrated that just 3 of 5 o patients (6\%) suffered from diabetes mellitus (DM). It may well be that DM protects HD patients from developing high flow as arterial remodelling is hampered due to progressively calcification of arterial vessels

Although immediate flow reduction following banding approximated an average $2 \mathrm{~L} / \mathrm{min}$ in a previous study, the present report demonstrates that flow reduction was short lived in most banded patients (I). An important factor determining lack of success after I2 months was young age. Age as a risk factor for HFA development and recurrent high flow after banding is likely related to age related functioning of the vascular endothelium (I8). Conversely, older age is probably associated 
with exhaustion of endothelial function impeding HFA development. Another factor contributing to unsuccessful banding was insufficient access flow reduction as demonstrated at the immediate postoperative flow control. Although the aim was to push the access flow below the $\mathrm{I} / \mathrm{min}$ threshold, this success was only attained in fifteen of 50 patients. By cautiously narrowing the band while not pushing the limits, the risk on an immediate postbanding access occlusion was reduced to $2 \%(\mathrm{n}=\mathrm{I})$. However, the down side of a low occlusion rate was an insufficient grade of banding as reflected by relatively high postbanding flow volumes.

An important factor potentially complicating accurate flow reduction is probably related to the anaesthetic technique. General anaesthesia is found to reduce systemic blood pressure as also reflected by a decrease in the dialysis arm's locoregional blood flow. Conversely, regional techniques including axillary blocks may lead to augmented flow volumes in an arm. Banding under these circumstances may lead to unpredictable access flows once the anaesthetic effects wear off. In theory therefore, banding is ideally performed using locally injected anaesthetic agents. However, results were not superior when patients were banded using a local technique ( $44 \%$ of the banded population) suggesting that the effects of these locally administered substances on locoregional flow dynamics may also be unpredictable. Standardly monitoring intraoperative access flow volume also did not contribute to success. However, banding using a free hand technique was not performed.

Is there still a place for banding as a preferred technique for AV access flow reduction? Several reports were published on effective access flow reduction following banding for HFA. However, most publications report on few patients (IO, I9-2I). Only two studies reporting on nine and twenty two patients identified two recurrences during a three months follow up (I, 22). Based on the present study, banding for a brachial artery based HFA in young patients may not be the first choice technique. This is particularly true as current intraoperatively used tools such as flow meters guiding grade of banding may perform suboptimal. Conversely, alternative procedures such as 'revision using distal inflow' (RUDI), 'proximal radial artery ligation' (PRAL) or 'radial artery transposition' may be more appropriate for an elbow artery-based HFA in these young patients $(3,23-25)$. Long term data following these alternative approaches must be awaited. However, banding may still be considered in elderly comorbid patients who are poor candidates for a flow reducing technique that requires general anaesthesia. Banding may be long term successful in these patients, particularly if the immediate postoperative access flow is $<\mathrm{I} \mathrm{L} / \mathrm{min}$. 
There are several flaws in this study that should be addressed. The retrospective design of the study has its limitations concerning the assumed positive effect of banding on cardiac function. Although no cardiac deaths were reported, an objective evaluation of cardiac functioning (for instance, using echocardiography) was not standardly performed during the $\mathrm{I} 2$ months observation period. HFA patients refusing banding were also not registered. Therefore, the present study does not address the natural course of a HFA. Differences between the three institutions may have influenced study results. However, consensus on preferred anaesthetic and surgical technique was attained prior to study initiation. Moreover, outcome was not different in the three institutions. In conclusion, an immediate postbanding access flow $>\mathrm{I} \mathrm{L} / \mathrm{min}$ and young age are risk factors for recurrent high flow in a high flow access in haemodialysis patients during a one year follow up. 


\section{References}

I. van Hoek F, Scheltinga M, Luirink M, Pasmans H, Beerenhout C. Banding of hemodialysis access to treat hand ischemia or cardiac overload. Semin Dial. 2009 Mar-Apr;22(2):204-8. PubMed PMID: 19426430. Epub 2009/05/12. eng.

2. Basile C, Lomonte C, Vernaglione L, Casucci F, Antonelli M, Losurdo N. The relationship between the flow of arteriovenous fistula and cardiac output in haemodialysis patients. Nephrol Dial Transplant. 2008 Jan;23(I):282-7. PubMed PMID: 17942475. Epub 2007/ro/r9. eng.

3. Chemla ES, Morsy M, Anderson L, Whitemore A. Inflow reduction by distalization of anastomosis treats efficiently high-inflow high-cardiac output vascular access for hemodialysis. Semin Dial. 2007 JanFeb;20(I):68-72. PubMed PMID: 17244I25. Epub 2007/oI/25. eng.

4. Scheltinga M, Hoek van F. Banding for high flow hemodialysis access. J Tordoir: Vascular access. Turino: Edizione Minverva Medica; 2009. p. I4I-50.

5. Zakrzewicz A, Secomb TW, Pries AR. Angioadaptation: keeping the vascular system in shape. News Physiol Sci. 2002 Oct;17:197-201. PubMed PMID: 12270956. Epub 2002/o9/25. eng.

6. United States Renal Data System. 2orr USRDS Annual Data Report. Chapter 5: mortality. Available at: http://www.usrds.org/20II/view/v2_05.asp. Accessed June 2I, 2014.

7. Schier T, Gobel G, Bosmuller C, Gruber I, Tiefenthaler M. Incidence of arteriovenous fistula closure due to high-output cardiac failure in kidney-transplanted patients. Clin Transplant. 2013 Nov-Dec;27(6):858-65 PubMed PMID: 24II825r. Epub 2013/ro/r5. eng.

8. Unger P, Velez-Roa S, Wissing KM, Hoang AD, van de Borne P. Regression of left ventricular hypertrophy after arteriovenous fistula closure in renal transplant recipients: a long-term follow-up. Am J Transplant. 2004 Dec;4(I2):2038-44. PubMed PMID: 15575907. Epub 2004/I2/o4. eng.

9. van Duijnhoven EC, Cheriex EC, Tordoir JH, Kooman JP, van Hooff JP. Effect of closure of the arteriovenous fistula on left ventricular dimensions in renal transplant patients. Nephrol Dial Transplant. 200I Feb;16(2):36872. PubMed PMID: III58414. Epub 2001/02/o7. eng.

Io. Murray BM, Rajczak S, Herman A, Leary D. Effect of surgical banding of a high-flow fistula on access flow and cardiac output: intraoperative and long-term measurements. Am J Kidney Dis. 2004 Dec;44(6):Io90-6. PubMed PMID: 15558531. Epub 2004/II/24. eng.

II. Zanow J, Petzold K, Petzold M, Krueger U, Scholz H. Flow reduction in high-flow arteriovenous access using intraoperative flow monitoring. J Vasc Surg. 2006 Dec;44(6):I273-8. PubMed PMID: I7I45429. Epub 2006/12/o6. eng.

I2. K/DOQI clinical practice guidelines for cardiovascular disease in dialysis patients. Am J Kidney Dis. 2005 Apr;45(4 Suppl 3):Si-I53. PubMed PMID: 15806502. Epub 2005/04/05. eng.

I3. Scheltinga MR, Van Hoek F, Bruyninckx CM. Surgical banding for refractory hemodialysis access-induced distal ischemia (HAIDI). J Vasc Access. 2009 Jan-Mar;io(I):43-9. PubMed PMID: I9340799. Epub 2009/04/o3. eng.

I4. Achneck HE, Sileshi B, Li M, Partington EJ, Peterson DA, Lawson JH. Surgical aspects and biological considerations of arteriovenous fistula placement. Semin Dial. 20Io Jan-Feb;23(I):25-33. PubMed PMID: 20331815. Epub 2010/03/25. eng.

I5. Ben Driss A, Benessiano J, Poitevin P, Levy BI, Michel JB. Arterial expansive remodeling induced by high flow rates. Am J Physiol. I997 Feb;272(2 Pt 2):H851-8. PubMed PMID: 9124448. Epub 1997/o2/or. eng.

16. Tronc F, Mallat Z, Lehoux S, Wassef M, Esposito B, Tedgui A. Role of matrix metalloproteinases in blood flow-induced arterial enlargement: interaction with NO. Arterioscler Thromb Vasc Biol. 2000 Dec;20(ı2):Eı20-6. PubMed PMID: imi6o76. Epub 2000/ı2/ı6. eng.

I7. Dammers R, Tordoir JH, Kooman JP, Welten RJ, Hameleers JM, Kitslaar PJ, et al. The effect of flow changes on the arterial system proximal to an arteriovenous fistula for hemodialysis. Ultrasound Med Biol. 2005 Oct;3I(Io):I327-33. PubMed PMID: 16223635. Epub 2005/Io/I5. eng.

I8. van Golde JM, Ruiter MS, Schaper NC, Voo S, Waltenberger J, Backes WH, et al. Impaired collateral recruitment and outward remodeling in experimental diabetes. Diabetes. 2008 Oct;57(Io):2818-23. PubMed PMID: I8633II4. Pubmed Central PMCID: 2551694. Epub 2008/o7/r8. eng.

I9. Anderson CB, Groce MA. Banding of arteriovenous dialysis fistulas to correct high-output cardiac failure. Surgery. 1975 Nov;78(5):552-4. PubMed PMID: 1188596. Epub r975/rI/or. eng.

20. Isoda S, Kajiwara H, Kondo J, Matsumoto A. Banding a hemodialysis arteriovenous fistula to decrease blood flow and resolve high output cardiac failure: report of a case. Surg Today. 1994;24(8):734-6. PubMed PMID: 7981545. Epub i994/or/or. eng. 
2I. Tzanakis I, Hatziathanassiou A, Kagia S, Papadaki A, Karephyllakis N, Kallivretakis N. Banding of an overfunctioning fistula with a prosthetic graft segment. Nephron. I999;8I(3):35I-2. PubMed PMID: 10050094. Epub i999/o3/o2. eng.

22. Schneider CG, Gawad KA, Strate T, Pfalzer B, Izbicki JR. T-banding: a technique for flow reduction of a hyperfunctioning arteriovenous fistula. J Vasc Surg. 2006 Feb;43(2):402-5. PubMed PMID: I6476625. Epub 2006/o2/16. eng.

23. Bourquelot P, Gaudric J, Turmel-Rodrigues L, Franco G, Van Laere O, Raynaud A. Transposition of radial artery for reduction of excessive high-flow in autogenous arm accesses for hemodialysis. J Vasc Surg. 2009 Feb;49(2):424-8, 8 er. PubMed PMID: 19028066. Epub 2008/ri/26. eng.

24. Parmar CD, Chieng G, Abraham KA, Kumar S, Torella F. Revision using distal inflow for treatment of heart failure secondary to arteriovenous fistula for hemodialysis. J Vasc Access. 2009 Jan-Mar;Io(I):62-3. PubMed PMID: 19340803. Epub 2009/o4/o3. eng.

25. Minion DJ, Moore E, Endean E. Revision using distal inflow: a novel approach to dialysis-associated steal syndrome. Ann Vasc Surg. 2005 Sep;19(5):625-8. PubMed PMID: 16052391. Epub 2005/07/30. eng. 




\section{Chapter - IX}

\section{One year efficacy of the RUDI technique for flow reduction in high flow autologous brachial artery-based haemodialysis vascular access}

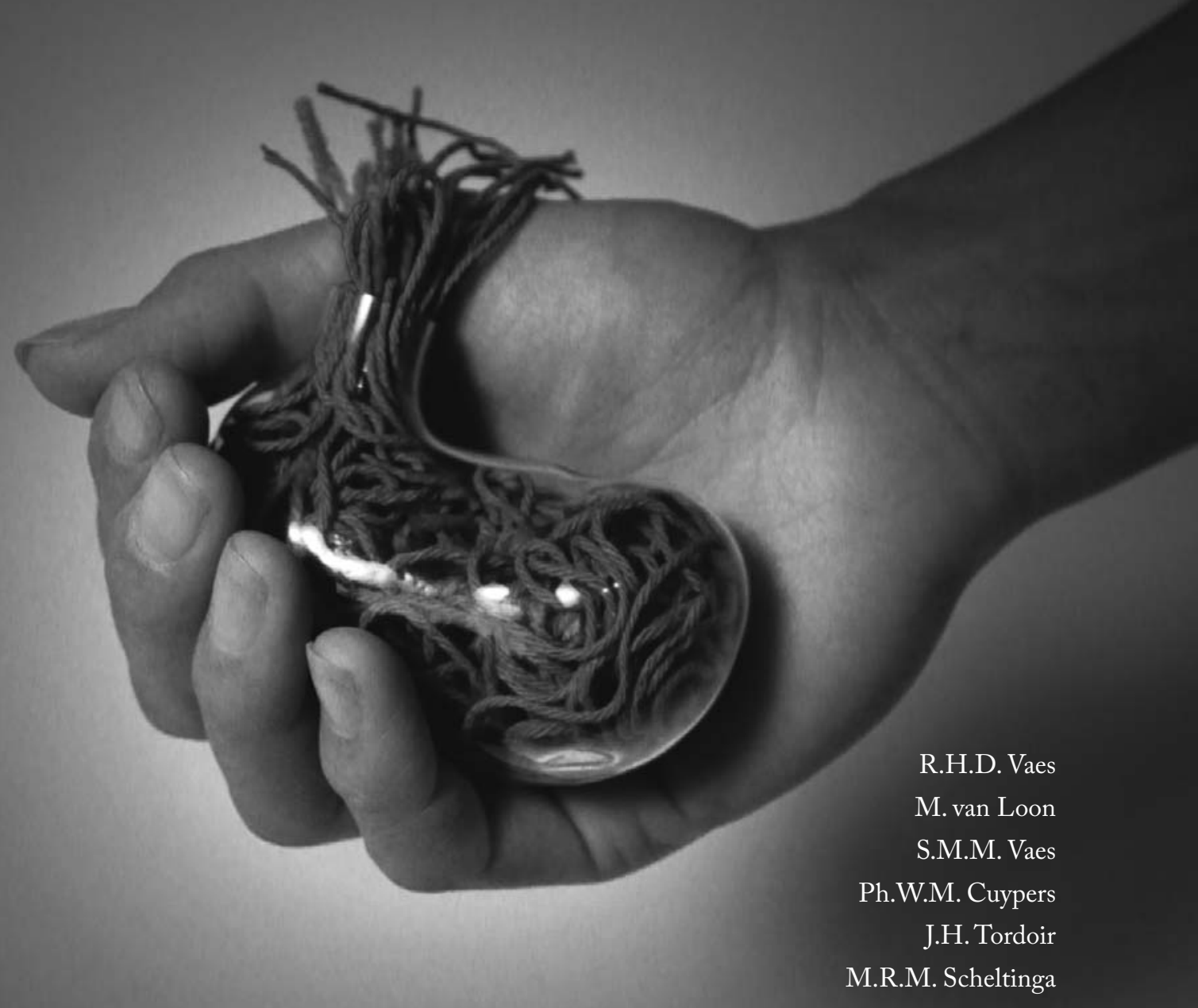

J Vasc Access. 20I5;16 Suppl 9:S96-IoI 


\section{Abstract}

\section{Purpose}

Flow reduction is advised in haemodialysis patients with a high flow $(>2 \mathrm{~L} / \mathrm{min})$ arteriovenous fistula (AVF). The revision using distal inflow technique (RUDI) is based on the premise that access flow is attenuated once inflow is provided by a smaller calibre forearm artery. Aim of the study was to evaluate the efficacy of RUDI during a one year follow up.

\section{Methods}

All haemodialysis (HD) patients undergoing a RUDI operation using a greater saphenous vein (GSV) or a basilic vein $(\mathrm{BaV})$ interposition for a high flow access (HFA, >2 L/min) during a 3.5 year time period were included. Serial access flow, percentage of freedom from recurrent high flow and complications were determined.

\section{Results}

A total of 19 HFA patients were studied (Ir males, age $55 \pm 3$ years). All AVFs were brachial arterybased (brachiocephalic, $\mathrm{n}=\mathrm{I} 4$; brachiobasilic, $\mathrm{n}=5$ ). RUDI immediately reduced access flow by more than $65 \%(3080 \pm 200 \mathrm{ml} / \mathrm{min}$ to II $70 \pm \mathrm{I} 60 \mathrm{~mL} / \mathrm{min}(\mathrm{P}=0.00 \mathrm{I}))$. Access flows at $\mathrm{I}, 6$ and $\mathrm{I} 2 \mathrm{months}$ were $1150 \pm 160,1460 \pm 200$ and $1580 \pm 260 \mathrm{~mL} / \mathrm{min}$, respectively. Postoperative complications included insufficient flow reduction $(\mathrm{n}=\mathrm{I}, \mathrm{BaV})$ and occlusion requiring revision ( $\mathrm{n}=\mathrm{I}, \mathrm{GSV})$. Recurrent HFA occurred three times $(\mathrm{n}=2 \mathrm{BaV}, \mathrm{n}=\mathrm{I}$ GSV). Access flows were significantly ( $\mathrm{p}<0.05$ ) higher in the $\mathrm{BaV}$ group compared to the GSV group.

\section{Conclusions}

RUDI effectively reduces access flow in a brachial artery-based high flow haemodialysis vascular access. A flow reducing effect is sustained at one year follow up in most patients. The GSV is preferred as an interposition graft compared to a $\mathrm{BaV}$. 


\section{Introduction}

Some $2-4 \%$ of the haemodialysis (HD) population with an autologous arteriovenous fistula (AVF) will develop a high flow access (HFA, >2 L/min) (I). High flow preferentially occurs in an AVF that originates from a large calibre artery such as the brachial artery compared to a small calibre radial artery (2-4). Two long-term complications are associated with the presence of a HFA, cardiac overload and hand ischemia (5-7). If patients with a HFA are found to suffer from these complications, one may decide to reduce access flow.

Several flow-reducing operative techniques are currently available. Venous outflow banding appears an effective short-term tool $(\mathrm{I}, 7,8)$. However, more than half of the banded patients develops recurrent high flow during an one year observation period (9). Young age and insufficient post banding access flow reduction are risk factors for recurrence (9). Others prefer access inflow reduction by distalisation of the anastomosis or by using a revision using distal inflow (RUDI) technique (4, IO, II). The fate of access flow following a RUDI operation is largely unknown (II). Aim of the present report was to serially study access flow following a RUDI operation for a brachial artery-based HFA during a one year follow up.

\section{Material and methods}

\section{Study populations}

This prospective study was performed between March 20II and September 2014 in patients undergoing a RUDI procedure for HFA in three dialysis facilities. The senior authors (PC, JT, MS) have ample experience in dialysis surgery. Access flow is measured at least once every two months using an ultrasound dilution technique (HDor, Transonic Systems Inc, New York, USA) (I2). Inclusion criteria were stable haemodialysis (> 3 months) using an AVF, a >2 L/min access flow on at least two consecutive measuring points, or a $>\mathrm{I} .5 \mathrm{~L} / \mathrm{min}$ access flow combined with overt signs of cardiac failure or venous congestion. Patients were discussed in a multidisciplinary team (nephrologist, vascular technician, radiologist, vascular surgeon) whereas cardiologists were consulted if required.

The RUDI technique was essentially performed as suggested (II). A Io $\mathrm{cm}$ segment of the thigh greater saphenous vein (GSV) was preferentially used as an interposition graft rather than a cephalic vein or brachial vein side branch as originally suggested (Io). A basilic vein ( $\mathrm{BaV}$ ) was used in a limited number of patients as determined by the surgeon's preference. Alternative flow-reducing surgical techniques were not performed during the study period. As patients were 
subjected to a standard follow up evaluation and were not randomized, study approval was not necessary.

\section{Operative protocol}

All patients were informed on the nature and specifics of the operative procedure. Duplex analysis determined GSV or BaV suitability (diameter $>3 \mathrm{~mm}$ ). Patients were operated in day care using a general anaesthetic technique. The venous portion of the AVF close to the anastomosis was dissected. Towards the axillar region, a separate two centimetre incision was used for intraoperative access flow measurement using an ultrasonic transit time technique (Optimax flow probes, HT 3I3, Transonic Systems Inc, New York, USA). This monitoring technique was used in $75 \%$ of patients while no monitoring technique was used in the remaining $25 \%$ of the patients. A portion of the mid forearm radial artery (or occasionally, proximal ulnar artery) was identified via a $5 \mathrm{~cm}$ longitudinal incision using a standard approach (Figure I). A 5-10 $\mathrm{cm}$ vein segment (GSV or $\mathrm{BaV}$ ) was harvested. The AVF some $2 \mathrm{~cm}$ downstream from the anastomosis with the brachial artery was transsected. The venous stump on the brachial artery's side was truncated and ligated using 5.0 Prolene. The vein was subsequently used as an interposition graft between the radial artery (end-to-side, 6.0 or 7.0 Prolene) and to the access vein (end-to-end or end-to-side, 5.0 Prolene, Figure 2-3).

\section{Data collection, definitions and statistics}

Demographic factors, type of AVF and serial access flows were obtained from electronic files of patients that had undergone a RUDI procedure between January, 2oII and June, 20I4. Complications including access thrombosis, recurrent high flow (defined as an access flow >2 L/ min) and other adverse events during a one year follow up were also extracted from these files.

SPSS I7.0 software version was used for statistical analysis (SPSS Inc., Chicago, IL, USA). Data were expressed as mean \pm standard error of mean (SEM). Differences between groups were determined using the Mann-Whitney $\mathrm{U}$ test or Fisher-exact test as appropriate. A $\mathrm{P}<0.05$ was considered significant. 

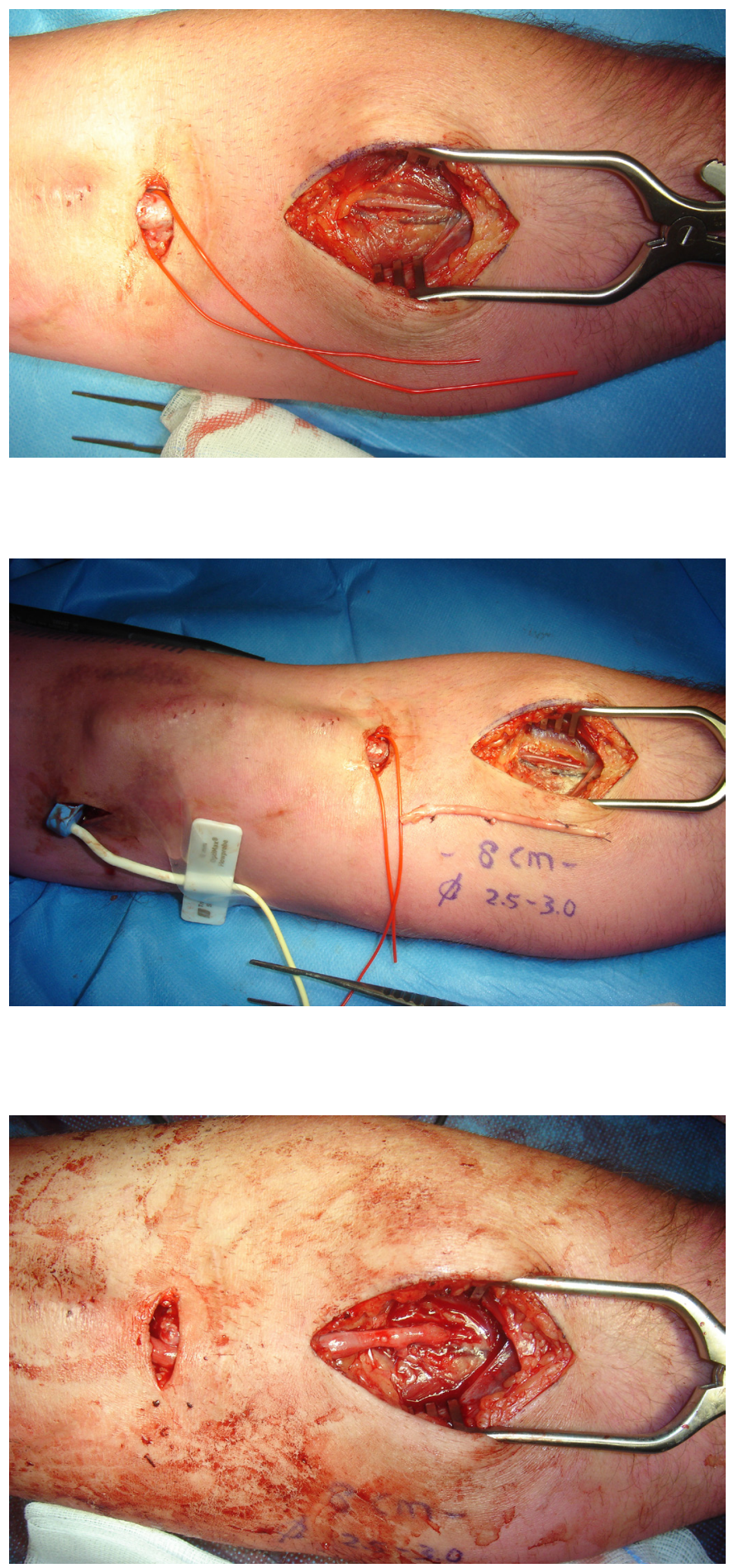

Figure 1. Surgical technique of inflow reduction in patients undergoing RUDI for a HFA (> $2 \mathrm{~L} / \mathrm{min}$ ). A vessel loop is around the venous outflow tract of a brachiocephalic AVF. A portion of the proximal radial artery is dissected.

Figure 2. Access flow is measured downstream using an ultrasonic transit time technique. An $8 \mathrm{~cm}$ portion of greater saphenous vein is used as an interposition graft.

Figure 3. The AVF some 5-7 $\mathrm{cm}$ downstream from the anastomosis with the brachial artery is transsected. The venous stump on the brachial artery's side is truncated and ligated using 5.0 Prolene. The GSV is used as a graft between the radial artery (end-to-side, 6.0 or 7.0 Prolene) and to the stump of the access (end-to-end or end-to-side, 5.0 Prolene). At the end of the procedure, access flow has dropped but a thrill is still present. 


\section{Results}

Table I depicts demographic data of study patients ( $n=I 9$, male $n=I I$, age $55 \pm 3$ years). Diabetes mellitus and PAOD were seldomly observed (5\% and o\% of patients, respectively). However, most patients demonstrated hypertension requiring medication $(74 \%, \mathrm{n}=\mathrm{I} 4)$.

RUDI was performed $20 \pm 4$ months following AVF construction. AVFs were brachial arterybased including brachial-cephalic upper arm direct access $(\mathrm{n}=\mathrm{I} 4)$ and brachio-basilic upper arm transposition $(n=5)$. All patients but one demonstrated an asymptomatic $>2 \mathrm{~L} / \mathrm{min}$ access flow and had a preventive RUDI. One patient underwent a RUDI for a venous congestion of the AVF arm in the presence of a r.6 L/min access flow. The new feeding artery were radial artery $(n=I 4)$, ulnar artery $(n=4)$ or brachial artery $(n=I)$. The GSV was used as an interposition graft in fifteen patients (GSV group) whereas the basilic vein was used in four ( $\mathrm{BaV}$ group).

Table 1. Demographic data of patients undergoing RUDI for a HFA ( $>2 \mathrm{~L} / \mathrm{min}$ )

\begin{tabular}{ll} 
& RUDI (n=19) \\
\hline Gender; male/female & $11 / 8$ \\
Age & $55 \pm 3$ \\
Diabetes mellitus (\%) & $1(5.3)$ \\
PAOD (\%) & $0(0.0)$ \\
Hypertension (\%) & $14(73.7)$ \\
Time to RUDI (months) & $20 \pm 4$ \\
AVF (brachiocephalic/brachiobasilic) & $15 / 4$ \\
\hline
\end{tabular}

Serial access flows are shown in figure 4. Immediately after the procedure, access flows dropped from $3080 \pm 200 \mathrm{ml} / \mathrm{min}$ to $1170 \pm 160 \mathrm{~mL} / \mathrm{min}$ ( $\mathrm{P}=0.00 \mathrm{I}$ ). One RUDI (using $\mathrm{BaV}$ ) was unsuccessful as the postoperative flow remained $>2 \mathrm{~L} / \mathrm{min}$. Immediate postoperative access flows were significantly lower ( $\mathrm{p}<0.05$ ) in the GSV group compared to the $\mathrm{BaV}$ group (990 $\pm \mathrm{I} 20 \mathrm{ml} /$ $\mathrm{min}$ vs $1790 \pm 480 \mathrm{ml} / \mathrm{min}$ ). This difference in access flow remained significantly lower in de GSV group until nine months postoperatively. Access flow remained well below $2 \mathrm{~L} / \mathrm{min}$ during the $\mathrm{I} 2$ month observation period in $\mathrm{I}_{4}$ of $\mathrm{I}_{5} \mathrm{GSV}$ patients. However, three patients developed recurrent high flow (>2 L/min, GSV n=r; $\mathrm{BaV}$ n=2). Use of a BaV was significantly associated with a HFA recurrence $\left(\mathrm{BaV}_{3}\right.$ of 4 vs GSV I out of $\left.\mathrm{r}_{5}, \mathrm{p}=0.02\right)$.

Complications such as wound infection and skin necrosis were not observed. Access thrombosis occurred once in a patient with a GSV interposition graft three days postoperatively. A possibly too small calibre GSV interposition $(2.5 \mathrm{~mm}$ ) was successfully replaced by a $3.5 \mathrm{~mm}$ 
GSV interposition. Eight months following RUDI, one GSV patient underwent a successful endovascular intervention for a stenosis in the vein graft as the AVF was deemed at risk (access flow of $390 \mathrm{ml} / \mathrm{min}$ ). No patient died of a cardiac event during the $\mathrm{I} 2$ months observation period.

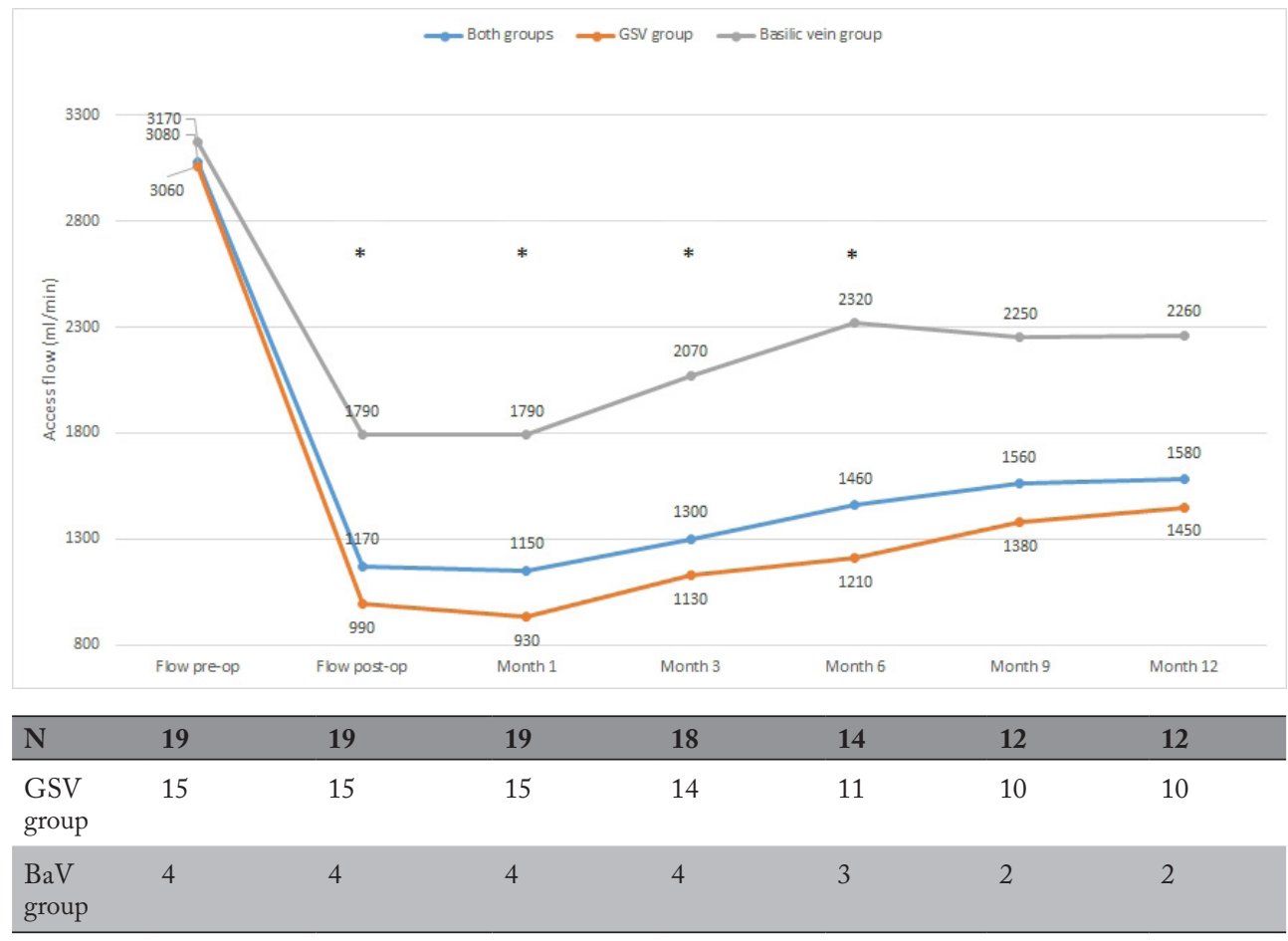

Figure 4. Access flow after RUDI. The upper curve reflects patients following a basilic vein interposition $(\mathrm{BaV}, \mathrm{n}=4)$, the lower curve reflects patients after a greater saphenous vein interposition (GSV, $\mathrm{n}=15)$. All patients $(n=19)$ are reflected by the middle curve. Significant differences $(p<0.05)$ between the GSV and basilic vein group are depicted with *.

\section{Discussion}

The ratio of autologous brachiocephalic to radiocephalic direct AVFs is increasing due to population related factors. As a consequence, rates of complications such as haemodialysis access induced distal ischemia (HAIDI) and high flow (HFA, access flow >2 L/min) associated with these larger upper arm arteries based AVFs will rise as well (13). The current tendency of favouring a brachial artery-based AVF has urged researchers to develop and optimize remedial techniques for HAIDI including banding ( 7, I4), distal revascularization interval ligation (DRIL, (I5), proximalization of arterial inflow (PAI, (I6), endoluminal banding (MILLER, (I7), transposition of the radial artery (TRA, (I8) and proximal radial artery ligation (PRAL, (I9). Some of these techniques 
may also prove useful for HFA treatment. Specifics and indications were recently discussed in an extensive overview (20).

A decade ago, an approach termed revision using distal inflow (RUDI) was added to the spectrum of therapies for HAIDI and HFA (Io, II). However, how should this novel surgical technique be rated? The expanding number of surgical options may be confusing for vascular surgeons. Which patient and AVF related factors will objectively guide a choice for the most appropriate treatment tool? An essential first step is to determine whether symptoms or signs associated with HAIDI (pain, coldness, cramps) are found in the presence or absence of a HFA. If high flow is present, one utilizes a flow reduction technique as lowered access flows mirror increasing finger pressures (20). For a brachial- artery based HFA, frequently used flow reducing techniques are banding, RUDI (and its variants) and TRA (Table 2) (4, IO, II, I8, 2I-25).

Banding is the oldest available access flow reducing technique. It was often utilized when surgery was required for high-output heart failure in the presence of a HFA (7). Introduced by de Palma et.al., the diameter of the AVF's venous outflow tract is reduced by means of a $5 \mathrm{~mm}$ wide band (I4). Although banding may seem successful on the short term, a recent study demonstrated that more than half $(n=26)$ of a banded population $(n=50)$ developed recurrent high flow during a I2 month observation period $(7,9)$. These disappointing results were a prompt for us to explore alternative flow reducing strategies. Literature on RUDI for high flow in a brachial artery- based AVF is limited (Table 2). As depicted in the table, some RUDI studies that were performed for hand ischemia did not report on drops in access flow (II, 22, 24, 25). Chemla et al. studied patients with high-output heart failure undergoing a variant of a RUDI procedure (4). In contrast to the 'original' RUDI technique as introduced by Andrade and Minion, he used distal (rather than proximal) portions of a radial artery as inflow source and a $6 \mathrm{~mm}$ prosthesis as an interposition graft (II, 2I). Access flow (-2.I L/min) and cardiac output $(-2.4 \mathrm{~L} / \mathrm{min})$ were greatly attenuated following this inflow revision. A point of concern was the $24 \% \mathrm{AVF}$ failure rate after a mean follow up of $\mathrm{r} 6$ months. Access flows preceding the occlusion were not provided so the reason for failure is unknown. Immediate flow reduction following RUDI (or a variant) as depicted in table 2 is promising. As information on durability of lowered levels of access following RUDI is currently lacking, we studied whether flow reduction was sustained during a one year observation period. The results indicate that the majority ( 15 of $19,79 \%$ ) of patients demonstrated acceptably lower levels of access flow during these twelve months. Three patients (I6\%) developed recurrent high flow (>2 L/min), two with an (inferiorly performing) type basilic vein interposition. A surgery related complication such as access occlusion was observed just once. 


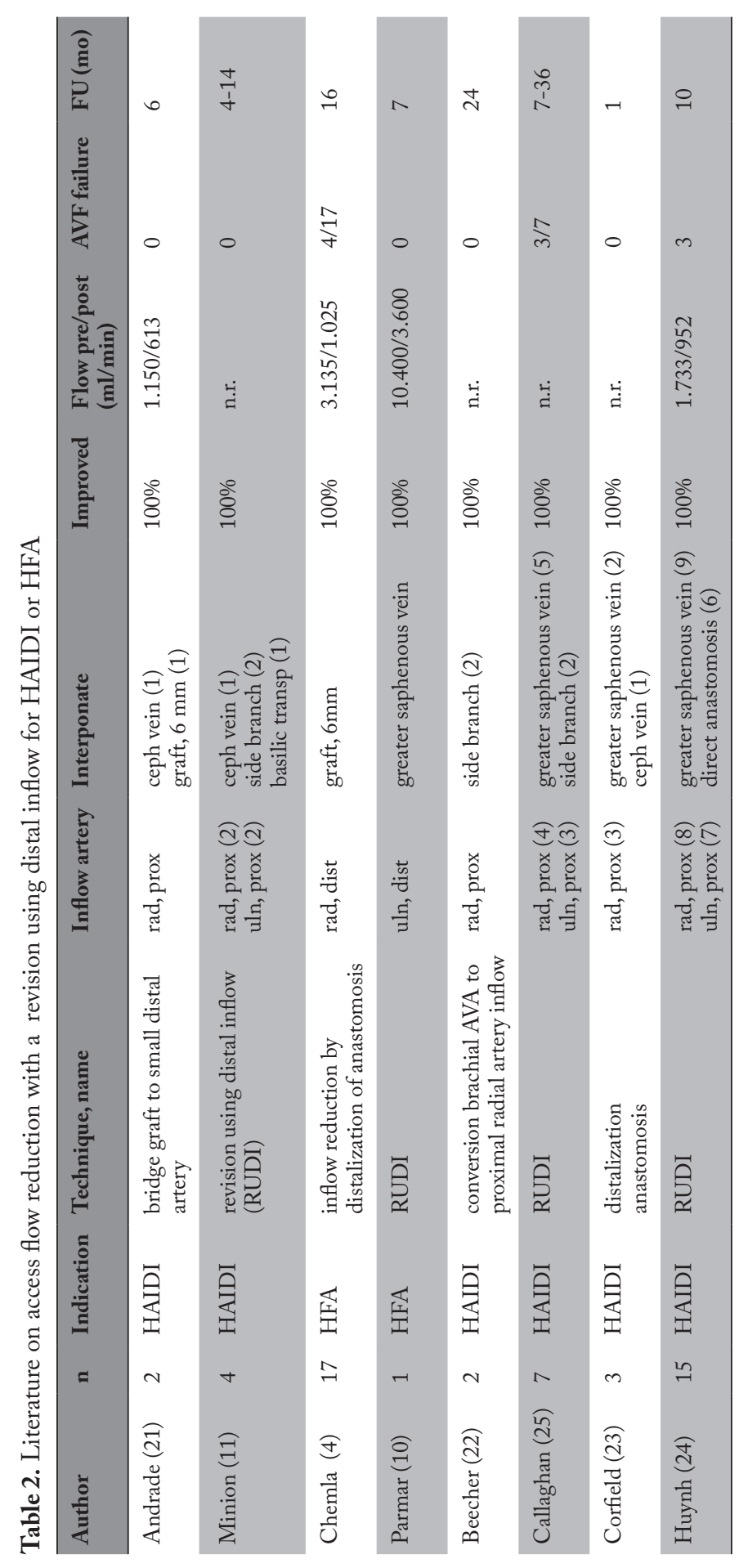


Each vascular surgeon reporting on RUDI proposes his/her own modification of the technique (Table 2). The present authors preferentially used a GSV graft as suggested (Io). Interestingly, postoperative success was limited in patients receiving a basilic vein graft. Moreover, the chance on a recurrent HFA was increased in this small group of 4 patients. An additional advantage of the current approach is the use of a relative short segment of autologous material $(5-8 \mathrm{~cm})$ compared to a longer graft ( $>\mathrm{I}_{5} \mathrm{~cm}$ ) as suggested by others $(4)$. A relative disadvantage is the slightly more difficult exposure of the proximal radial artery compared to a standard distal artery identification at the wrist. However, the proximal radial (or ulnar) artery is more easily found once intraoperative AVF clamping results in more prominent arterial pulsations. However, choice of inflow artery should primarily be dictated by its quality as evaluated using a preoperative Duplex analysis.

One may question the value of intraoperative flow measurements as an adjunctive tool during a RUDI procedure. Several studies suggested beneficial effects of this support (7, 26-28). These flow measurements are standard protocol in patients undergoing surgery for HAIDI or HFA in our institutions. The current study found that flow immediately decreased following revascularization when compared to preoperative levels. However, it must be appreciated that the value of this finding is relative. In our experience, maintenance of thrill albeit less prominent towards the end of the procedure is essential.

In conclusion, RUDI effectively reduces high flow in a brachial artery-based high flow haemodialysis access. The use of a greater saphenous vein as an interposition graft is preferred. The flow reducing effect is sustained at the one year follow up time point in most patients. 


\section{References}

I. Scheltinga M, Hoek van F. Banding for high flow hemodialysis access. J Tordoir: Vascular access. Turino: Edizione Minverva Medica; 2009. p. I4I-50.

2. Stern AB, Klemmer PJ. High-output heart failure secondary to arteriovenous fistula. Hemodial Int. 20II Jan I2.

3. Wasse H, Singapuri MS. High-output heart failure: how to define it, when to treat it, and how to treat it. Semin Nephrol. 2012 Nov;32(6):55I-7.

4. Chemla ES, Morsy M, Anderson L, Whitemore A. Inflow reduction by distalization of anastomosis treats efficiently high-inflow high-cardiac output vascular access for hemodialysis. Semin Dial. 2007 JanFeb;20(I):68-72.

5. Basile C, Lomonte C, Vernaglione L, Casucci F, Antonelli M, Losurdo N. The relationship between the flow of arteriovenous fistula and cardiac output in haemodialysis patients. Nephrol Dial Transplant. 2008 Jan;23(I):282-7.

6. Dikow R, Schwenger V, Zeier M, Ritz E. Do AV fistulas contribute to cardiac mortality in hemodialysis patients? Semin Dial. 2002 Jan-Feb;15(I):I4-7.

7. van Hoek F, Scheltinga M, Luirink M, Pasmans H, Beerenhout C. Banding of hemodialysis access to treat hand ischemia or cardiac overload. Semin Dial. 2009 Mar-Apr;22(2):204-8.

8. Murray BM, Rajczak S, Herman A, Leary D. Effect of surgical banding of a high-flow fistula on access flow and cardiac output: intraoperative and long-term measurements. Am J Kidney Dis. 2004 Dec;44(6):Io9o-6.

9. Vaes RHD, Wouda R, Van Loon M, Van Hoek F, Tordoir JH, Scheltinga MR. Effectiveness of surgical banding for high flow in brachial artery based haemodialysis vascular access Journal of vascular surgery. 20I4; In Press.

Io. Parmar CD, Chieng G, Abraham KA, Kumar S, Torella F. Revision using distal inflow for treatment of heart failure secondary to arteriovenous fistula for hemodialysis. J Vasc Access. 2009 Jan-Mar;10(I):62-3.

II. Minion DJ, Moore E, Endean E. Revision using distal inflow: a novel approach to dialysis-associated steal syndrome. Ann Vasc Surg. 2005 Sep;19(5):625-8.

I2. K/DOQI clinical practice guidelines for cardiovascular disease in dialysis patients. Am J Kidney Dis. 2005 Apr;45(4 Suppl 3):SI-I53.

I3. van Hoek F, Scheltinga MR, Kouwenberg I, Moret KE, Beerenhout CH, Tordoir JH. Steal in hemodialysis patients depends on type of vascular access. Eur J Vasc Endovasc Surg. 2006 Dec;32(6):710-7.

I4. De Palma JR, Vannix R, Bahuth J, Abukurah A. "Steal” syndrome, ischemia, congestive failure and periperhal neuropathy. Proc Clin Dial Transplant Forum. I973;3:9-II.

I5. Schanzer H, Schwartz M, Harrington E, Haimov M. Treatment of ischemia due to "steal" by arteriovenous fistula with distal artery ligation and revascularization. J Vasc Surg. 1988 Jun;7(6):770-3.

16. Zanow J, Kruger U, Scholz H. Proximalization of the arterial inflow: a new technique to treat access-related ischemia. J Vasc Surg. 2006 Jun;43(6):I2I6-2I; discussion 2I.

I7. Goel N, Miller GA, Jotwani MC, Licht J, Schur I, Arnold WP. Minimally Invasive Limited Ligation Endoluminal-assisted Revision (MILLER) for treatment of dialysis access-associated steal syndrome. Kidney Int. 2006 Aug;70(4):765-70.

I8. Bourquelot P, Gaudric J, Turmel-Rodrigues L, Franco G, Van Laere O, Raynaud A. Transposition of radial artery for reduction of excessive high-flow in autogenous arm accesses for hemodialysis. J Vasc Surg. 2009 Feb;49(2):424-8, 8 eI.

I9. Bourquelot P, Gaudric J, Turmel-Rodrigues L, Franco G, Van Laere O, Raynaud A. Proximal radial artery ligation (PRAL) for reduction of flow in autogenous radial cephalic accesses for haemodialysis. Eur J Vasc Endovasc Surg. 2010 Jul;40(I):94-9.

20. Beathard GA, Spergel LM. Hand ischemia associated with dialysis vascular access: an individualized access flow-based approach to therapy. Semin Dial. 20I3 May-Jun;26(3):287-3I4.

2I. Andrade JL, Paschoa AF, van Bellen B. Bridge graft to a small distal artery after fistula ligation for angioaccessinduced ischemia: report of two cases. J Vasc Access. 2004 Jan-Mar;5(I):33-5.

22. Beecher BA, Taubman KE, Jennings WC. Simple and durable resolution of steal syndrome by conversion of brachial artery arteriovenous fistulas to proximal radial artery inflow.J Vasc Access. 2010 Oct-Dec;II(4):352-5.

23. Corfield L, Muller J, Ryan J, Bond R. Distalization of the anastomosis: an effective treatment for dialysis access-associated steal syndrome. Ann Vasc Surg. 20I2 May;26(4):572 eII-3. 
24. Huynh TT, Peden EK, Anaya-Ayala JE, Davies MG, Naoum JJ. Volume Flow Reduction Using Distal Inflow Provides Excellent Intermediate Outcome for Patients with Functioning Autogenous AV Fistula and Dialysis Access Steal Syndrome. Soc for Clin Vasc Surg. 20I4.

25. Callaghan CJ, Mallik M, Sivaprakasam R, Iype S, Pettigrew GJ. Treatment of dialysis access-associated steal syndrome with the "revision using distal inflow" technique. J Vasc Access. 20II Jan-Mar;12(I):52-6.

26. Chemla ES, Tang VC, Eyman SA. Intraoperative flow measurements are helpful in the treatment of highinflow steal syndrome on a predialysis patient with a brachiocephalic fistula: a case report. Ann Vasc Surg. 2007 Sep;2I $(5): 645^{-7}$.

27. Scheltinga MR, Van Hoek F, Bruyninckx CM. Surgical banding for refractory hemodialysis access-induced distal ischemia (HAIDI). J Vasc Access. 2009 Jan-Mar;Io(I):43-9.

28. Zanow J, Petzold K, Petzold M, Krueger U, Scholz H. Flow reduction in high-flow arteriovenous access using intraoperative flow monitoring. J Vasc Surg. 2006 Dec;44(6):1273-8. 




\section{Chapter - X}

\section{Summarizing discussion, conclusions and future perspectives}




\section{Summarizing discussion, conclusions and future perspectives}

A worldwide changing population with end stage renal disease (ESRD) creates challenges in the standard management of haemodialysis (HD) issues in the upcoming years. Daily dialysis care is optimalised by realising regular multidisciplinary meetings as advised by the Dutch and KDOQI guidelines ( $\mathrm{I}-3)$. Unfortunately, only $60 \%$ of all Dutch dialysis facilities engage in these meetings with all responsible caretakers (3). Nevertheless, the additional value of a regular multidisciplinary vascular access (VA) meeting is beyond doubt (I, 2). Its tasks, among others, are to monitor adequate arteriovenous fistula (AVF) maturation and a timely recognition of VA failure in patients on chronic $\mathrm{HD}(4)$. A third task is to early recognize the development of potential complications including haemodialysis access induced ischaemia (HAIDI) and high flow access (HFA). The present thesis is aimed to provide more insight in these two, largely underrecognized long-term complications. In chapter one, detailed descriptions of aetiology, diagnosis and treatment of HAIDI and HFA are provided.

A prominent and often occurring problem in research is the issue of 'inappropriate comparison'. Results of two studies cannot be compared because patient or population characteristics are dissimilar. As a consequence, researchers should be encouraged to adhere to standard evaluation tools. For instance, studies on HAIDI used a variety of nonstandardized and largely subjective terms to describe intensity of hand ischaemia ('severe', 'unacceptable', etc). We have previously introduced a 'hand ischaemic questionnaire'(HIQ) that allows for a quantification of symptoms associated with HAIDI. Frequency and severity of pain, coldness, sensibility loss, loss of strength and cramps are scored on a o to 500 point scale (5). HD patients requiring treatment for HAIDI typically demonstrate scores between $150-250$ points. Conversely, successful surgery leads to a normalized $40-60$ points HIQ score $(6,7)$. A HIQ may serve as an excellent screening tool in the hands of dialysis nurses as well as of physicians (5). Although cut-off points have not been validated yet, changing HIQ scores reflected detoriation as well as a successful response following treatment $(6,7)$. Severity of hand ischaemia was standardly scored using the HIQ in studies of the present thesis.

The term HAIDI is coined as it properly describes the aetiology of ischaemia of peripheral portions of the upper limb induced by the presence of a VA. Hand pain due to other causes such as carpal tunnel syndrome, uremic arteriopathy or peripheral arterial occlusive disease is not uncommon in HD patients. In contrast, HAIDI is caused by a diminished lower arm and hand flow due to blood pressure loss along the arterial inflow tract and at the AVF anastomosis. 
Steal, a reversal of arterial flow distal to the AVF anastomosis, was formerly accepted as the most important contributor of hand ischaemia in a HD patient. However, steal was recently hypothesized as a non-contributor of HAIDI (8). It may well be that the confusion on proper terms is a matter of semantics. In American literature, steal is possibly considered as synonymous to hand ischaemia and is not used to describe the pathophysiological phenomenon responsible for hand ischaemia $(9$, Io).

This thesis starts with a case control study in an attempt to improve insight into the pathophysiological changes of lower arm arterial flow in HD patients in general, and in HAIDI patients in particular. In Chapter two, we describe a study in HAIDI patients with a brachiobasilic or brachiocephalic AVF (BB-AVF/BC-AVF) who were scheduled to undergo a surgical revision because of unacceptable symptomatic hand ischaemia (mean $25^{8} \pm 30$ HIQ scores). Matched HD patients without hand ischaemia served as controls (mean $3 \mathrm{I} \pm \mathrm{I} 6 \mathrm{HIQ}$ scores). Although radial artery flow was similarly reduced in both groups, ulnar artery flow appeared significantly lower in HAIDI patients ( $38 \pm 4$ vs $56 \pm 3 \mathrm{~cm} / \mathrm{s}, \mathrm{P}<$.or). Interestingly, ulnar artery flow was significantly correlated to hand digital pressure $(r=0.87)$. These data suggest that ulnar arterial flow may dominate hand perfusion in HAIDI. Conversely, ischemic symptoms may intensify once compensatory ulnar flow fails. Additionally, digital pressures in HAIDI patients only partially improved after AVF compression whereas the digital brachial index (DBI) rose from o to just 0.57 , still below the 0.6 ischaemic threshold.

It is concluded that the aetiology of HAIDI is multifactorial, and loss of blood pressure around the anastomosis only partially contributes to diminished hand perfusion pressures. Other factors such as atherosclerosis and arterial stiffness due to diabetes, ESRD and uraemia are also major contributors impairing distal perfusion $\left(8, \mathrm{II}-\mathrm{II}_{5}\right)$. Therefore, an appropriate preoperative work up of a HAIDI patient should always include imaging of the entire arterial inflow tract.

As reported in chapter two, loss of blood pressure in proximity to the AVF anastomosis can significantly contribute to digital hypoperfusion $(5,8)$. Turbulent blood flow due to (arterial and venous) diameter and elasticity mismatch as well as shunting of blood towards a low pressure, low resistance venous outflow tract both contribute to this perfusion pressure loss. Shunting of blood in the presence of a brachial artery based AVF may be aggravated by open venous side branches (SB). In chapter three, the immediate results of a novel treatment technique termed side branch ligation (SBL) in a group of HAIDI patients are presented. Five HAIDI patients underwent ligation of SB's that were not used for cannulation whereas seven patients underwent 
SBL and an additional AVF revision by banding or DRIL. Mean DBI increased from 0.49 to o.6I while ischemic symptoms improved as reflected by lower HIQ scores (HIQ $73 \pm 26$ vs 2I6 $\pm 39, \mathrm{P}=0.04)$. Although surgical SBL was hitherto mainly used for stimulating AVF maturation, its ameliorating effect on HAIDI symptoms was not previously reported in objective details (I6).

Two rules apply when surgical AVF revision is needed in patients with HAIDI. First, symptoms and signs of hand ischaemia (digital pressure, Pdig or digital brachial index, DBI) require preoperative evaluation and peroperative monitoring. Second, an appropriate access flow $(>400$ $\mathrm{ml} / \mathrm{min}$ ) must be maintained ensuring effective postoperative HD. In most studies on revisional surgery for HAIDI, effects on symptoms, AVF function and access flow are unknown after one year follow up or longer. If knowledge on these issues would increase, vascular surgeons would be more certain regarding their preferred technique. In chapter four, follow up data on patients undergoing SBL are presented. Between January 2005 and December $2013,55 \%$ of all HD patients in Máxima Medical Center presenting with a minimal HAIDI ${ }_{2} \mathrm{~B}$ stage were treated with a first step SBL approach. Half of this $55 \%$ underwent SBL as a single treatment option whereas the other half additionally underwent flow reducing surgery. After one year of follow up, $94 \%$ was still without complaints of hand ischaemia. Primary and secondary AVF patency rates were $67 \%$ and $89 \%$, respectively. Access flow remained adequate (mean, $700 \mathrm{~mL} / \mathrm{min}$ ). If possible, a SBL first approach is advised in BC-AVF prior to surgically modifying the AVF itself. Peroperative access flow and Pdig measurement allow for the real-time evaluation of the effect of SBL on HAIDI symptoms. Such intraoperative techniques may determine whether an additional AVF revision using a banding or a Distal Revascularization and Interval Ligation (DRIL) is mandatory for a sufficient enhancement of digital perfusion.

Several surgical options have been described in the current literature for the surgical treatment of hand ischaemia in HD patients with an AVF. Chapter five shows that a vascular surgeon must be able to think 'out of the box' when treating a HAIDI patient. A unique case is described on an highly unusual solution in a patient with a HAIDI stage 4a. As regular endovascular and surgical options were depleted in the presence of bilateral subclavian artery disease, a femoral-to-axillary artery bypass graft was constructed that effectively cured his thumb ulcer, alleviated ischemic symptoms (HIQ 300 to 5) whereas access flow improved from 300 to $750 \mathrm{ml} / \mathrm{min}$.

A HFA is an AVF having an access flow $>2 \mathrm{~L} / \mathrm{min}$. In contrast to HAIDI, high flow is seldomly recognized as a long term complication in HD patients, probably because it is often asymptomatic, or latently symptomatic ( $\mathrm{I} 7, \mathrm{I} 8)$. If symptoms do occur in the presence of a HFA, signs of cardiac 
overload and failure may be found ( $17-\mathrm{I} 9$ ). Whether a symptomatic HFA required treatment is under debate, let alone an asymptomatic HFA patient (20). Increased systemic blood pressure (BP) and a compensatory decrease in heart rate (HR) after temporary AVF clamping may reflect the cardiovascular strain of the AVF (I9, 2I-24). In chapter six, the effect of perioperative access clamping on $\mathrm{HR}$ and $(\mathrm{BP})$ in patients with a $\mathrm{HFA}(>2 \mathrm{~L} / \mathrm{min}$ ) undergoing flow reduction is reported. HFA patients showed a significant increase in systolic and diastolic BP in contrast to control patients having a normal access flow (I L/min, or less). A compensatory drop in HR was similar in both groups. However, patients with an access flow $>2.5 \mathrm{~L} / \mathrm{min}$ demonstrated attenuated $\mathrm{BP}$ responses possibly suggesting loss of 'normal' adaptive mechanism due to impaired autonomic function. This study provides indirect evidence on the potential detrimental cardiovascular effects of ongoing systemic overload due to the presence of an asymptomatic HFA.

In Chapter seven, the potential deleterious effects of a combination of ESRD, HD, AVF and especially HFA on cardiac function are reviewed.

A surgical correction of HFA in order to decrease the cardiovascular burden of ongoing high flow is advised by some. If so, banding was proposed as an effective and safe surgical option for access flow reduction $(7,25)$. Banding entails the surgical wrapping of a flat woven polyester band around the venous outflow just distal to the anastomosis, preferably under guidance of real-time access flow measurements to reduce the risk of access occlusion or early thrombosis $(7,26)$. In chapter eight, an observational study reports on the one year results of banding in 50 HFA patients with flows $>2 \mathrm{~L} / \mathrm{min}$ in three hospitals. The results indicate that patients with a brachial artery based AVF rather than a radial artery based access are prone to develop a HFA. Indeed, $96 \%$ of all HFA's in this study were brachial artery based. Some $56 \%$ of patients required medical treatment for high blood pressure while only $6 \%$ suffered from diabetes suggesting its protective effect regarding AVF over maturation. A $50 \%$ one year post banding recurrence rate (again flows $>2 \mathrm{~L} / \mathrm{min}$ ) was found indicating that surgical banding is a suboptimal long term access flow reducing technique.

In anticipation of a limited long term efficacy of banding for HFA, a 'revision using distal inflow' (RUDI) procedure was implemented as the first step surgical treatment option. In chapter nine, the immediate postoperative and one year results of this technique for treatment of HFA are presented. Between March 20II and September 20I4, nineteen HFA patients with a brachial artery based AVF underwent a RUDI in three different dialysis facilities. The majority of patients received a greater saphenous vein (GSV) bypass, and four a basilic vein (BaV) bypass. Mean access flows dropped from $3.080 \mathrm{~mL} / \mathrm{min}$ to $1.170 \mathrm{~mL} / \mathrm{min}$. A GSV bypass was preferred when 
compared to the $\mathrm{BaV}$ bypass (access flow, $990 \mathrm{ml} / \mathrm{min}$ vs $1790 \mathrm{ml} / \mathrm{min}$ ). A recurrence developed in three patients ( $16 \%$ ) at one year follow up, twice in $\mathrm{BaV}$ patients. In one HFA patient RUDI using a $\mathrm{BaV}$ was unsuccessful. At present, a RUDI technique using a GSV is the preferred long term surgical technique to reduce access flow in HFA patients.

\section{Conclusions of this thesis}

I. Patients with haemodialysis access induced distal ischaemia (HAIDI) in the presence of a brachial artery based arteriovenous fistula (AVF) demonstrate decreased ulnar artery blood flow. A phenomenon of 'steal' (reversal of blood flow) is not causing HAIDI.

2. Venous side branch ligation (SBL) is effective in over half of HAIDI patients, either as a single technique or preceding an additional flow reductive technique. SBL must always be considered in HAIDI prior to embarking on more invasive flow reducing procedures.

3. Patients with a high access flow $(\mathrm{HFA},>2 \mathrm{~L} / \mathrm{min})$ demonstrate a more profound increase in blood pressure following temporary AVF occlusion compared to controls with low flows. The response in some patients with a HFA may reflect autonomic dysfunction due to a long lasting cardiovascular overload.

4. One year after a banding procedure, high access flow had recurred in half of the HFA patients. An immediate >I 1/min post banding access flow and young age were risk factors for a recurrence.

5. After one year, $84 \%$ of HFA patients undergoing a revision using distal inflow (RUDI) technique still benefitted from flow reduction.

\section{Future perspectives}

Aim of this thesis was to attain a further insight in the pathophysiology and treatment of hand ischaemia (HAIDI) and high flow (HFA) in HD patients harbouring a brachial artery based AVF. The sequence of steps in the treatment of HAIDI is increasingly becoming clear and should also be based on its classification as discussed in chapter 2, 3 and 4. A patient with minor symptoms (HAIDI type I and II a) should receive a conservative treatment approach including correction of anemia, gloves and antiplatelet medication. If suffering from a HAIDI type IIb or beyond, imaging is required and inflow stenosis (if present) mandates percutaneous angioplasty. If absent or unresponsive, the surgical treatment is based on preference of the multidisciplinary team (8). Studies from the present thesis have unveiled that the presence of the AVF's open venous sidebranches require Duplex analysis. If side branch flow is substantial, ligation may be beneficial in over half of the patients and should always be performed prior to more invasive 
techniques such as DRIL (distal revascularization interval ligation), proximalization of arterial inflow (PAI) , RUDI or banding. Based on the knowledge achieved in our studies we propose a treatment algorithm for HAIDI as depicted in figure I. Future research should focus on conducting prospective observational trials that standardly encompasses the use of a HIQ as a means of objectively determining the burden of ischaemia. Only then efficacies of surgical techniques may be compared. It may also be worthwhile to investigate whether the different stages of HAIDI are associated with HIQ cut off points.

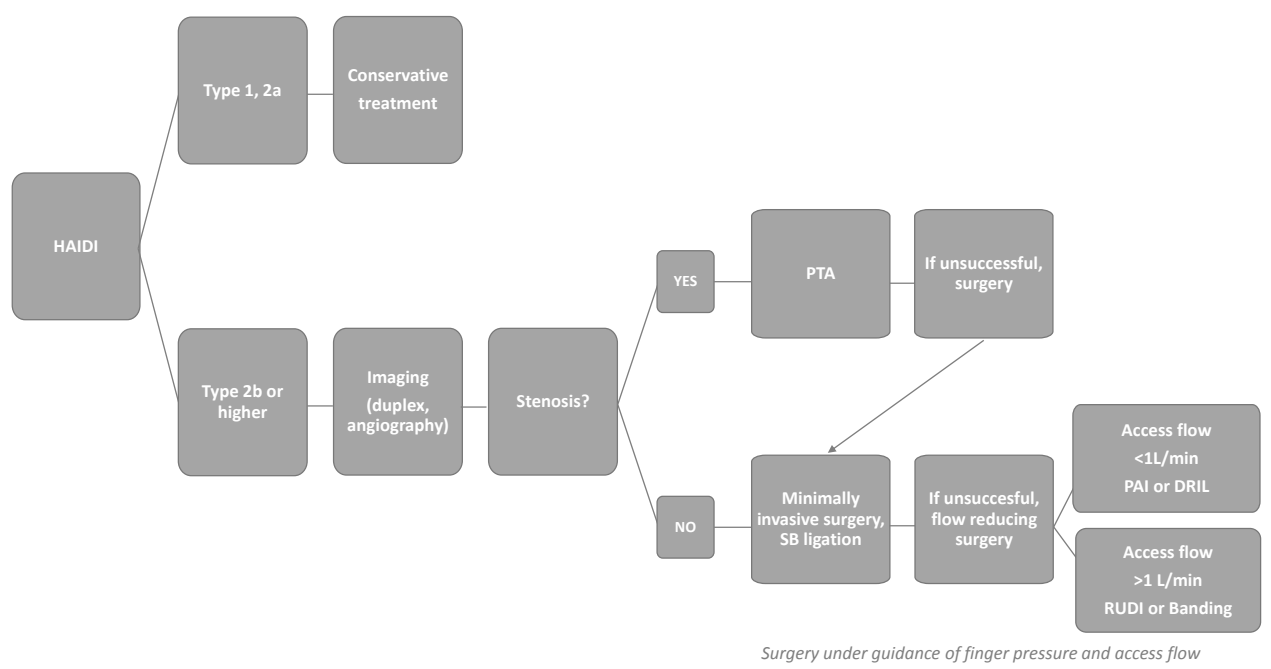

Figure 1. Treatment algorithm for HAIDI.

There is currently no consensus on whether an asymptomatic HFA patient requires treatment, let alone timing and type of treatment. Specialized clinics may advise an aggressive treatment of any HD patient with a persistent $>21 /$ min access flow. Both the Dutch vascular access guideline and the KDOQI guideline only minimally discuss HFA as a complication risk after brachial artery based AVF creation. Clear indications and treatment options for HFA are not provided (I, 2). A survey among physicians responsible for dialysis care in the Netherlands could provide insight in current opinions regarding the treatment of HFA.

The 'Fistula First Initiative' has raised several questions about the standard creation of an AVF in each ERSD patient as advocated by national and international guidelines ( $\mathrm{I}, 2,27,28)$. The question is not the surgical creation of an AVF itself. However, the challenge is to identify favourable patient characteristics that are associated with appropriate maturation leading to a well-functioning AVF once HD is imminent (29). In contrast to an arteriovenous graft (AVG), an 
AVF has an up to 40 to $60 \%$ primary failure rate although interventions to maintain patency are fewer in the long term $(27,29)$. Therefore, multidisciplinary teams should discuss whether creation of an AVF is always in the patient's best interest (30). This is particularly true when considered that compelling evidence that a BC-AVF or BB-AVF is better than an AVG is lacking (29). Future randomized studies may shed some light on these issues.

Adequate preoperative AVF planning will become key in ESRD patients as patient demographics continue to change worldwide with increasing numbers of elderly patients with comorbidities such as arteriosclerosis, hypertension and diabetes resulting in suboptimal lower arm arteries and veins. These unfavourable characteristics will negatively influence AVF maturation and functional patency and will be associated with higher long term complication rates. Physicians are not able to influence patient outcome by improving the patient's characteristics. On the other hand, efforts to improve a pre-emptive surgical planning will likely be beneficial. In most dialysis centers, the current pre-operative AVF planning is based on clinical observations and sonographic mapping of arterial and venous structures of the intended dialysis arm (3). However, evidence suggests that policies based on these static Duplex reports are ineffective in reducing primary access failure rates or insufficient maturation after AVF creation (27, 29). Therefore, vascular surgeons should search for tools that objectively aid in deciding on the ideal type of AVF. For instance, the 'ARCH' study developed a computer model that accurately predicted access flows in various types of AVF on the basis of Duplex parameters (3I). Another option is an algorithm that was derived from the REDUCE trial suggesting that patient characteristics determined whether an AVF or an AVG should be created (29,32). Future computer models and algorithms are expected to lead to improved AVF maturation rates $(29,30,32)$. 


\section{References}

I. Clinical practice guidelines for vascular access. Am J Kidney Dis. 2006 Jul;48 Suppl r:S248-73.

2. Betjes MGH, Hoogeveen EK. Richtlijn Vaattoegang. 2009.

3. Tordoir JH, van Loon MM, ter Meer M, van Laanen J, Bode AS, Weijmer MC, et al. Hemodialysis vascular access management in the Netherlands. J Vasc Access. 2015;16 Suppl 9:Sir-5.

4. Flu H, Breslau PJ, Krol-van Straaten JM, Hamming JF, Lardenoye JW. The effect of implementation of an optimized care protocol on the outcome of arteriovenous hemodialysis access surgery. J Vasc Surg. 2008 Sep;48(3):659-68.

5. van Hoek F, Scheltinga MR, Kouwenberg I, Moret KE, Beerenhout CH, Tordoir JH. Steal in hemodialysis patients depends on type of vascular access. Eur J Vasc Endovasc Surg. 2006 Dec;32(6):710-7.

6. Vaes RH, Scheltinga MR. Side branch ligation for haemodialysis-access-induced distal ischaemia. Eur J Vasc Endovasc Surg. 20I2 Oct;44(4):452-6.

7. van Hoek F, Scheltinga M, Luirink M, Pasmans $H$, Beerenhout C. Banding of hemodialysis access to treat hand ischemia or cardiac overload. Semin Dial. 2009 Mar-Apr;22(2):204-8.

8. Scheltinga MR, Bruijninckx CM. Haemodialysis access-induced distal ischaemia (HAIDI) is caused by loco-regional hypotension but not by steal. Eur J Vasc Endovasc Surg. 20I2 Feb;43(2):218-23.

9. Goff CD, Sato DT, Bloch PH, DeMasi RJ, Gregory RT, Gayle RG, et al. Steal syndrome complicating hemodialysis access procedures: can it be predicted? Ann Vasc Surg. 2000 Mar;I4(2):I38-44.

Io. Knox RC, Berman SS, Hughes JD, Gentile AT, Mills JL. Distal revascularization-interval ligation: a durable and effective treatment for ischemic steal syndrome after hemodialysis access. J Vasc Surg. 2002 Aug;36(2):250-5; discussion 6.

II. Aitken E, Jackson A, Kong C, Coats P, Kingsmore D. Renal function, uraemia and early arteriovenous fistula failure. BMC nephrology. 20I4;15:I79.

I2. Georgiadis GS, Georgakarakos EI, Antoniou GA, Panagoutsos S, Argyriou C, Mourvati E, et al. Correlation of pre-existing radial artery macrocalcifications with late patency of primary radiocephalic fistulas in diabetic hemodialysis patients. J Vasc Surg. 20I4 Aug;6o(2):462-70.

I3. Gunthner T, Jankowski V, Kretschmer A, Nierhaus M, van der Giet M, Zidek W, et al. Endothelium and vascular smooth muscle cells in the context of uremia. Semin Dial. 2009 Jul-Aug;22(4):428-32.

14. Prenner SB, Chirinos JA. Arterial stiffness in diabetes mellitus. Atherosclerosis. 2015 Feb;238(2):370-9.

15. van Golde JM, Ruiter MS, Schaper NC, Voo S, Waltenberger J, Backes WH, et al. Impaired collateral recruitment and outward remodeling in experimental diabetes. Diabetes. 2008 Oct;57(Iо):2818-23.

I6. Falk A. Optimizing hemodialysis arteriovenous fistula maturation. J Vasc Access. 20II Jan-Mar;I2(I):I-3.

17. Basile C, Lomonte C, Vernaglione L, Casucci F, Antonelli M, Losurdo N. The relationship between the flow of arteriovenous fistula and cardiac output in haemodialysis patients. Nephrol Dial Transplant. 2008 Jan;23(I):282-7.

18. Schier T, Gobel G, Bosmuller C, Gruber I, Tiefenthaler M. Incidence of arteriovenous fistula closure due to high-output cardiac failure in kidney-transplanted patients. Clinical transplantation. 20I3 NovDec;27(6):858-65.

19. Dikow R, Schwenger V, Zeier M, Ritz E. Do AV fistulas contribute to cardiac mortality in hemodialysis patients? Semin Dial. 2002 Jan-Feb;15(I):I4-7.

20. Basile C, Lomonte C. When and how should an arterio-venous access be modified because of a high blood flow rate? Semin Dial. 2oII Jul-Aug;24(4):396-8.

2I. Ahearn DJ, Maher JF. Heart failure as a complication of hemodialysis arteriovenous fistula. Ann Intern Med. I972 Aug;77(2):20I-4.

22. Nickerson JL, Elkin DC, Warren JV. The effect of temporary occlusion of arteriovenous fistulas on heart rate, stroke volume, and cardiac output. J Clin Invest. I95I Feb;30(2):215-9.

23. Nicoladoni C. Phlebarteriectasie der rechten oberen Extremität. Arch Kleinische Chirurgie. 1875;18:252-74.

24. Chemla ES, Morsy M, Anderson L, Whitemore A. Inflow reduction by distalization of anastomosis treats efficiently high-inflow high-cardiac output vascular access for hemodialysis. Semin Dial. 2007 JanFeb;20(I):68-72.

25. Scheltinga M, Hoek van F. Banding for high flow hemodialysis access. J Tordoir: Vascular access. Turino: Edizione Minverva Medica; 2009. p. I4I-50.

26. Zanow J, Petzold K, Petzold M, Krueger U, Scholz H. Flow reduction in high-flow arteriovenous access using intraoperative flow monitoring. J Vasc Surg. 2006 Dec;44(6):I273-8. 
27. Allon M, Lockhart ME, Lilly RZ, Gallichio MH, Young CJ, Barker J, et al. Effect of preoperative sonographic mapping on vascular access outcomes in hemodialysis patients. Kidney Int. 200I Nov;60(5):2013-20.

28. Schinstock CA, Albright RC, Williams AW, Dillon JJ, Bergstralh EJ, Jenson BM, et al. Outcomes of arteriovenous fistula creation after the Fistula First Initiative. Clin J Am Soc Nephrol. 20Ir Aug;6(8):I9962002.

29. Allon M, Lok CE. Dialysis fistula or graft: the role for randomized clinical trials. Clin J Am Soc Nephrol. 20I0 Dec;5(I2):2348-54.

30. Tordoir JH, Bode AS, van Loon MM. Preferred strategy for hemodialysis access creation in elderly patients. Eur J Vasc Endovasc Surg. 2015 Jun;49(6):738-43.

3r. Caroli A, Manini S, Antiga L, Passera K, Ene-Iordache B, Rota S, et al. Validation of a patient-specific hemodynamic computational model for surgical planning of vascular access in hemodialysis patients. Kidney Int. 2013 Dec;84(6):1237-45.

32. Lok CE, Allon M, Moist L, Oliver MJ, Shah H, Zimmerman D. Risk equation determining unsuccessful cannulation events and failure to maturation in arteriovenous fistulas (REDUCE FTM I). J Am Soc Nephrol. 2006 Nov;I7(II):3204-I2. 




\section{Chapter - XI}

Valorisation

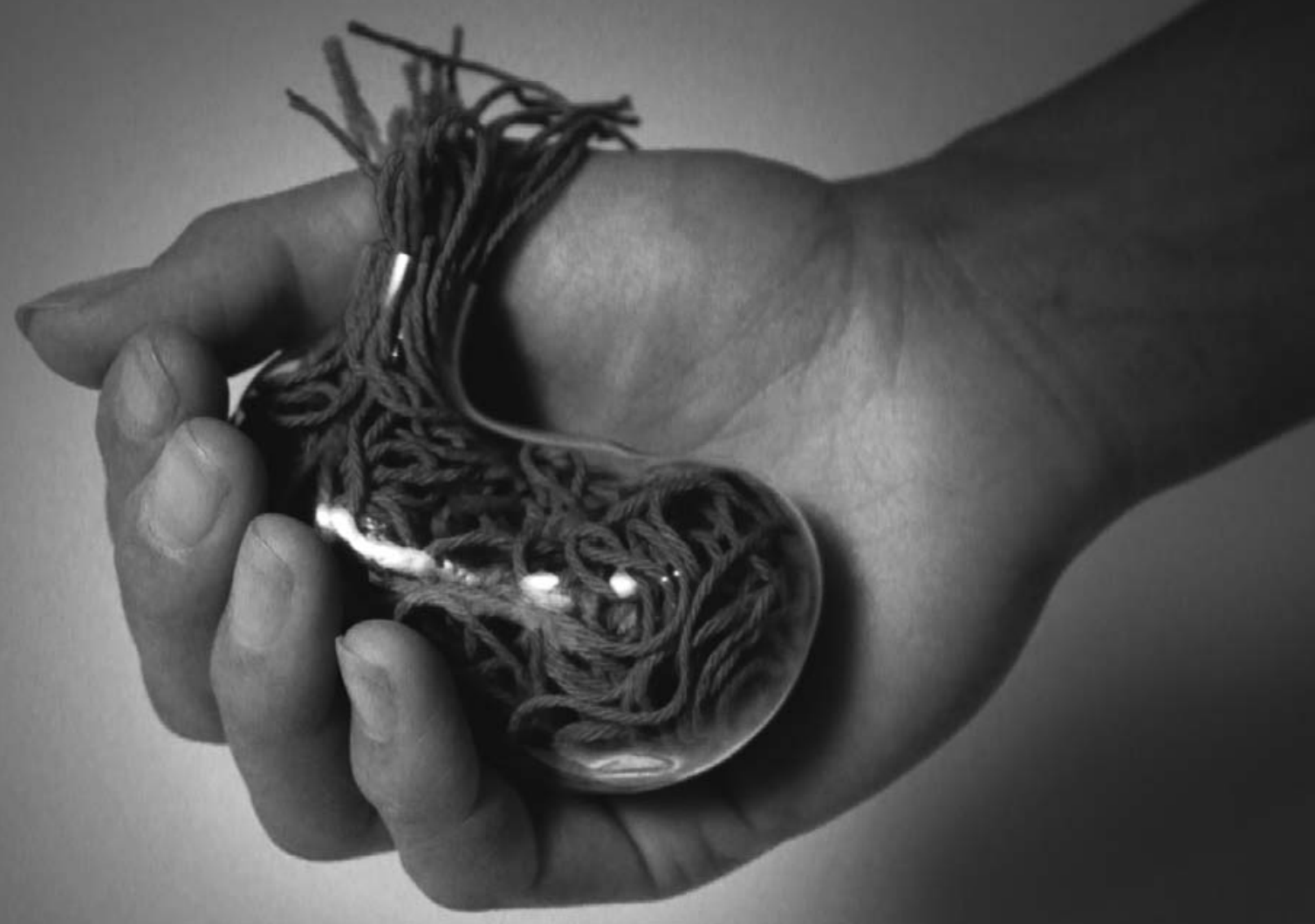




\section{Introduction}

Currently, approximately one million Dutch patients suffer from chronic kidney disease (CKD). Although the majority of CKD patients are treated conservatively, some I6.0oo patients with end stage renal disease (ESRD) are in the need of renal replacement therapy (RRT). The incidence of ESRD in the Netherlands is about 2.000 patients per year. Both increasing numbers of ESRD patients undergo successful kidney transplantation as well as patient survival on renal replacement therapy has been improved.

Nonetheless, some 6.500 patients require a form of RRT by means of chronic intermittent haemodialysis (HD) or peritoneal dialysis (PD). HD is increasingly preferred over PD, however the creation of a well-functioning vascular access (VA) has become more challenging in the usually elderly, comorbid population. International guidelines dictate an autologous arteriovenous fistula (AVF) as the primary choice of VA. Such an AVF is preferred over a prosthetic arteriovenous graft $(A V G)$ or a central venous catheter (CVC). However, several patient related factors determine the chance on successful maturation and long- term function of an AVF. Due to changing patient demographics (older patient, more comorbidity etc.), the use of the brachial artery for AVF inflow is often preferred over a radial artery based AVF. The down side of an accelerated maturation following a brachial artery connection with high access flow, is an increased chance on access related complications such as haemodialysis access induced distal ischaemia (HAIDI) or cardiac failure due to a high flow access (HFA, >2 L/min). At present, some 5-10\% of the HD patients with a brachial artery based AVF will develop HAIDI and $2-4 \% \mathrm{HFA}$ at a certain time period in their lives.

International guidelines and quality improvement programs such as the 'fistula-first initiative', promote creation of an autologous AVF. As a consequence, most scientific research and funding concentrate on surgical decision- making in VA surgery. In other words, 'when to create which type of VA' and 'how to improve successful AVF maturation, decrease AVF thrombosis and improve outcome'. Unfortunately, the chances on the onset of long- term complications such as HAIDI and HFA are not considered in this equation. Nonetheless, quality of life is highly influenced by these complications. In the current thesis, we sought to improve our insight concerning these complications. Consequently, daily dialysis care and quality of life will be improved. 


\section{Socio-economic relevance}

When focusing on HAIDI, a hypothesis was tested that was formulated earlier on by our research group. It was previously hypothesized that hand ischaemia in the presence of an AVF is caused by a combination of peripheral blood pressure decreasing phenomena:

- $\quad$ Progressive arterial stiffness due to patient characteristics, such as diabetes, long-term uraemia and atherosclerosis, thereby hampering arterial remodelling capacity.

- A possible significant arterial stenosis along the arterial inflow tract.

- Turbulent blood flow at the anastomosis due to an arterial and venous vessel wall mismatch.

- Excessive shunting of arterial blood into a low resistance outflow vein and its venous side branches.

Subsequently, a novel minimal invasive surgical approach in the treatment of HAIDI was studied: The side branch ligation (SBL), in which venous side branches of the VA are ligated leading to a reduced loss of peripheral blood pressure, has provided the vascular surgeon with a new technique for HAIDI treatment. SBL appeared effective in selected cases of HD patients suffering from HAIDI while effective dialysis is maintained. Two important criteria in VA surgery for hand ischemia were thus sustained:

I. Maintain a functional VA to continue successful $\mathrm{HD}$ at all times, and

2. decrease the physical and psychological burden associated with ongoing hand ischaemia and improve hand function and quality of life.

Another issue, is the novel step-by-step approach that was proposed in the treatment of HAIDI. Several treatment algorithms for hand ischaemia in HD patients are available in current literature. However, the treatment of choice for HAIDI is often based on the preference of the vascular surgeon as comparative studies are lacking. In our approach towards an uniform treatment algorithm, all HAIDI patients received a standard set of diagnostics and followed a step-by-step treatment protocol. Using this protocol, dialysis nurses and nephrologists responsible for daily dialysis care are familiar with questionnaires and imaging that are needed for a proper diagnostic pathway of HAIDI. Although the exact effect on the quality of care is difficult to measure as this protocol has developed itself over the years, its utility is beyond doubt as all patients are examined and treated uniformly. As a consequence, individuals are treated with a minimal number of different treatments improving patient care and reducing medical costs. 
Cornerstone in our diagnostic regime for HAIDI is a hand ischaemia questionnaire (HIQ). Although other research groups have not validated this questionnaire, its extensive use at our dialysis center in daily practice and for research purposes has given us a wealth of hands-on experience. The HIQ is a practical and useful tool for the assessment of severity of ischemic complaints in HAIDI patients and allows for an objective evaluation of the effect of treatment. Widespread use of this questionnaire would improve comparability of outcome in future studies by different/other research institutions.

In our studies concerning HD patients harbouring HFA we aimed to emphasize any potential devastating consequences of a high flow AVF on cardiac function. Cardiac dysfunction is 'endemic' in HD patients. Several factors contribute to a state of enhanced cardiac stress in HD patients, including left ventricular hypertrophy, interdialytic fluid changes, hypertension, anaemia, HD itself, and possibly the AVF. However, a HFA even puts an extra strain to the heart. Unfortunately, physicians and especially vascular surgeons are hesitant when it comes to perform an AVF revision for HFA as these HD patients are often asymptomatic. In this thesis we discuss the diagnostic pathway that patients are subjected to in order to achieve convincing reasons to reduce access flow. Nonetheless it is strongly advised to surgically revise the AVF with a high flow even if it is seemingly asymptomatic and access flow persists above $2 \mathrm{~L} /$ min during a 6 month follow-up.

As in HAIDI surgery, the scientific evidence on the optimal surgical option for HFA is limited. Most techniques are expert-based and solely depend on the surgeon's preference. In this thesis we demonstrate that a frequently used flow reduction technique ('banding') is less effective on the long-term than previously assumed. More favourable results are achieved with a technique called revision using distal inflow (RUDI). This RUDI technique is presently considered as a first treatment option for HFA patients.

\section{Target groups}

Findings in this thesis are useful for HD patients and all healthcare workers who are responsible for daily dialysis care (nurses, vascular surgeons, nephrologists, interventional radiologists, cardiologists).

\section{How can further valorisation in the future be achieved?}

A future challenge to improve valorisation is to convert the HIQ to an online questionnaire or even mobile (E-health) application. Furthermore, an online service may allow free access to 
our step-by-step treatment protocol. Research in VA surgery is in a clear need of high standard comparative studies. Unfortunately, current knowledge is mainly based on small studies, in particular when it comes to revision surgery. Expert opinion (level IV evidence) is setting the current standard. A potential future valorisation of our studies is to create a national database in the Netherlands in which all HD patients and their VA are registered and followed creating useful datasets and a platform to facilitate future research on HAIDI and HFA. 



\section{Chapter - XII \\ Samenvatting \\ (Dutch summary)}




\section{Samenvatting}

Dit proefschrift behandelt twee langetermijncomplicaties van een arterioveneuze fistel (AVF) voor haemodialyse (HD). In het eerste deel staat handischemie centraal, ook wel haemodialysis access induced distal ischaemia (HAIDI) genoemd. Deze aandoening wordt in 5 -10\% van de HD patiënten beschreven en kan ernstige gevolgen hebben voor de functie van de dialysehand en daarmee de kwaliteit van leven. Voornamelijk HD patiënten met diabetes mellitus en perifeer vaatlijden hebben een extra risico op het ontwikkelen van HAIDI. Vroegtijdige herkenning en tijdige behandeling voorkomt irreversibele schade. Net als bij claudicatio intermittens wordt HAIDI veroorzaakt door bloeddrukverlies in het verloop van een voedende slagader. Indien conservatieve behandeling (medicatie, handschoenen) onvoldoende effect heeft, wordt beeldvorming uitgevoerd gericht op identificatie van een vernauwing in de armslagader. Indien aanwezig, bestaat de voorkeursbehandeling uit een minimaal invasieve radiologische aanpak. Indien dit te weinig effect heeft, wordt uitgeweken naar een chirurgische aanpak. In de hoofdstukken 2-5 worden enige aspecten van etiologie en behandeling bij HAIDI verder belicht.

Een tweede langetermijncomplicatie dat belicht wordt in dit proefschrift is high flow access (HFA). Normaal is een AVF flow tussen de $400-800 \mathrm{~mL}$ ruim voldoende om goed te kunnen dialyseren. Echter, soms neemt de flow over de jaren geleidelijk aan toe. Men spreekt van een HFA indien de AVF flow $>2000 \mathrm{ml} / \mathrm{min}$ is. Een HFA is waarschijnlijk een sterk onderschat probleem, ook al omdat deze zelden symptomatisch is. Hartfalen door cardiale uitputting kan echter voorkomen. Sterker nog, HD patiënten met een HFA lijken een duidelijk verhoogd risico op cardiaal falen te hebben. Immers, het hart moet, bovenop de $4-5 \mathrm{~L} / \mathrm{min}$ voor een normale lichaamsfunctie, continu $2 \mathrm{~L} / \mathrm{min}$ extra flow 'genereren' dat eigenlijk alleen nodig is voor HD. Enkele studies betreffende cardiovasculaire effecten en risico's van een HFA in dialysepatiënten worden in hoofdstuk 6-8 besproken.

Hoofdstuk twee betreft een studie waarin meer inzicht wordt verkregen in de fysiologische veranderingen van de onderarmarteriën bij $\mathrm{HD}$ patiënten in het algemeen, en bij HAIDI patiënten met een brachiobasilica (BB-AVF) of brachiocephalica AVF (BC-AVF) in het bijzonder. Twee gematchte groepen worden vergeleken, patiënten met handischemie en patiënten zonder. Handischemie wordt gekwantificeerd met een door ons eerder geïntroduceerde vragenlijst (HIQ, hand ischemie questionnaire). Allen ondergingen vingerdrukmetingen en duplexanalyse van de arterie ulnaris en radialis van de onderarm. Opvallend blijkt de arterie radialis flow in beide HD groepen lager dan normaal. Tevens is de flow in de a. ulnaris significant lager bij HAIDI patiënten 
( $38 \pm 4$ vs $56 \pm 3 \mathrm{~cm} / \mathrm{s}, \mathrm{P}<$.or). Bovendien blijkt de a. ulnaris flow significant gecorreleerd aan de vingerdruk $(\mathrm{r}=0.87)$. Deze bevindingen suggereren dat de kwaliteit van de a. ulnaris de uiteindelijke handperfusie in HAIDI patiënten bepaalt. Met andere woorden, ischemische symptomen zullen mogelijk verergeren op het moment dat ulnaire flow afneemt. Ook blijkt dat vingerdrukken in HAIDI patiënten slechts deels verbeteren na AVF compressie (DBI, ratio vingerbloeddruk vs. bovenarmbloeddruk; o naar 0.57 ; 0.6 is ondergrens voor handischemie). Concluderend wordt bevestigd dat de etiologie van HAIDI multifactorieel is. Verlies van bloeddruk nabij de anastomose draagt slechts deels bij aan de verminderde hand perfusie. Andere factoren zoals gegeneraliseerde atherosclerose, arteriële stijfheid door diabetes, nierfalen en uremie bepalen ook de verminderde handperfusie.

Zoals bekend kan bloeddrukverlies rondom de arterioveneuze anastomose significant bijdragen aan hypoperfusie van de vingers bij HD patiënten. Turbulente flow door verschillen in diameter en elasticiteit tussen arterie en vene met daarbij het wegstromen van bloed in de richting van een grote bovenarmader met een lage druk en lage weerstand dragen bij aan verminderde doorbloeding van de hand. Het weglekken van bloed bij een bovenarm-AVF kan in theorie verergerd worden door andere openstaande veneuze zijtakken. In hoofdstuk drie worden de resultaten van een nieuwe techniek ('side branch ligation', SBL), in een groep HAIDI patiënten gepresenteerd. Twaalf patiënten met HAIDI worden bestudeerd. Vijf hebben alleen een onderbinding van deze patente veneuze zijtakken ondergaan terwijl zeven na SBL aansluitend nog 'banding' of een 'distale revascularizatie met interval ligatie (DRIL) ondergingen. Gemiddeld steeg de DBI van 0.49 naar $0.6 \mathrm{I}$, terwijl subjectieve symptomen van ischemie verbeterden ( $\mathrm{HIQ}_{2} 73 \pm 26$ vs $216 \pm 49$, $\mathrm{P}=0.04$ ). Alhoewel het positieve effect van SBL bij andere indicaties al wel bekend is (stimulering van rijping van de AVF), is het vingerbloedruk verhogende effect van SBL bij patiënten met HAIDI nog niet eerder beschreven.

Hierop voortbordurend worden in hoofdstuk vier de I jaarresultaten na SBL bestudeerd. Zoals bij elke vorm van shuntchirurgie is het relevant om te weten wat de effecten van een nieuwe operatietechniek op de wat langere termijn zijn. Is het effect op handischemie bestendig, of treden er allerlei complicaties op zoals afsluitingen of steeds lagere AVF doorbloeding waardoor dialyse gaandeweg steeds lastiger wordt (flow $>400 \mathrm{ml} / \mathrm{min}$ ). In de periode tussen januari 2005 en december 2013 werden 55\% van alle HAIDI patiënten in Máxima Medisch Centrum met veneuze zijtak ligatie (SBL) behandeld. Ongeveer de helft heeft alleen een SBL ontvangen, terwijl de andere helft een additionele flow reducerende ingreep heeft ondergaan. $\mathrm{Na}$ een jaar is $94 \%$ nog altijd klachtenvrij. Primaire en secondaire patency percentages zijn respectievelijk $67 \%$ 
en $89 \%$. Access flow bleek gedurende deze periode voldoende (gemiddeld $700 \mathrm{ml} / \mathrm{min}$ ). De 'SBL' benadering wordt, mits mogelijk, derhalve als eerste maatregel geadviseerd bij BC en BB AVFs voordat de AVF aanvullend met een bestaande, meer invasieve vorm van chirurgie moet worden gereviseerd. Peroperatief gemeten access flow en digitale bloeddruk (Pdig) maken continue beoordeling van het effect van SBL op hand perfusie mogelijk. Dergelijke intra-operatieve technieken bepalen vervolgens dan ook of AVF revisie middels banding of DRIL aanvullend nog noodzakelijk is.

Hoofdstuk vijf laat zien dat een vaatchirurg 'out of the box' moet kunnen denken tijdens de behandeling van HAIDI. Een unieke casus wordt gepresenteerd waarbij een patiënt met stadium 4a HAIDI een onorthodoxe chirurgische behandeling krijgt. Aangezien normale endovasculaire en chirurgische opties ter verbetering van de arteriële inflow niet mogelijk zijn door bilaterale atherosclerose van de a. subclavia, wordt een femoro-axillaire arteriële bypass naar de shuntarm aangelegd. Hiermee nemen anamnestische de klachten van HAIDI af (HIQ,300 naar 5), genezen chronische ulcera op de duim en neemt de access flow toe van 300 naar $750 \mathrm{ml} / \mathrm{min}$.

De behandeling van asymptomatische HFA patiënten is een punt van discussie. In Hoofdstuk zes is onderzocht of de mate van cardiale overbelasting geschat kan worden door middel van het bestuderen van de effecten van het afklemmen van een HFA. Bij patiënten die een AVF revisie moeten ondergaan in verband met een HFA wordt de AVF's outflow geblokkeerd waarna het effect op de hartfrequentie (HF) en de bloeddruk (RR) wordt gemeten. Deze HFA patiënten laten een significante stijging van systolische en diastolische RR zien in tegenstelling tot controlepatiënten met een normale access flow ( $\leq \mathrm{I} \mathrm{L} / \mathrm{min})$. Een compensatoire daling in hartfrequentie blijkt in beide groepen vergelijkbaar. Echter, patiënten met een access flow $>2.5$ $\mathrm{L} / \mathrm{min}$ laten een afgenomen bloeddrukreactie zien. Mogelijk moet dit laatste worden gezien als een verlies van normale aanpassingsmechanismen door uitputting van de autonome functie. Deze studie levert indirect bewijs over de schadelijke cardiovasculaire effecten van persisterende overbelasting door de aanwezigheid van een asymptomatische HFA.

Hoofdstuk zeven bevat een review waarin de schadelijke effecten van nierfalen, HD, AVF en voornamelijk HFA op het cardiale functioneren worden besproken. Alhoewel er duidelijke aanwijzingen zijn dat HD patiënten met een HFA een verhoogd risico op cardiaal falen hebben, zijn er meerder factoren die hieraan bijdragen. Patiënten met eindstadium nierfalen lopen namelijk al een risico op cardiaal falen door linker ventrikel hypertrofie, anemie, volume overbelasting tussen dialysesessies in, en door HD zelf. Tevens is het bekend dat het chirurgisch aanleggen van een 
AVF een extra cardiale inspanning vergt. Logischerwijs zorgt een hoge flow voor een additionele belasting. Daarentegen, flowvermindering of zelfs opheffen van de AVF zijn effectief gebleken in vermindering van cardiale overbelasting in HFA patiënten. Preventieve flowvermindering in asymptomatische HFA patiënten lijkt dan ook verstandig om cardiale uitputting op de lange termijn te voorkomen.

Door sommigen wordt te allen tijde een chirurgische revisie van een HFA geadviseerd. Echter, de termijngevolgen betreffende de flow in deze gecorrigeerde HFA's zijn niet onderzocht. In hoofdstuk acht wordt in een observationele studie de I-jaarsresultaten van banding bij 50 HFA patiënten gerapporteerd. Een banding procedure bestaat uit het beperken van de fistelflow door een AVF door de diameter van het afvoerende vat te verkleinen met behulp van een polyester bandje. De resultaten van deze studie in drie ziekenhuizen laten zien dat patiënten met een $\mathrm{BC}$ AVF of BB-AVF, vergeleken met patiënten met een RC-AVF, een grotere kans hebben op het ontwikkelen van een HFA (96\% vs 4\%). Meer dan de helft (56\%) van de HFA patiënten wordt medicamenteus behandeld voor hypertensie. Slechts 6\% lijdt aan diabetes hetgeen suggereert dat diabetes beschermt voor het ontwikkelen van een HFA. Na een jaar blijkt de helft van de gebande HFA patiënten weer een flow > $2 \mathrm{~L} / \mathrm{min}$ te hebben. Banding leidt bij de meeste patiënten dus slechts tot een kortdurende flowvermindering en is dus ongeschikt als langetermijntherapie.

Anticiperend op een (niet geheel onverwachte) beperkte efficiënte van de banding voor HFA is de 'revision using distal inflow' (RUDI) techniek in onze kliniek geïmplementeerd als de voorkeursbehandeling van een HFA. In hoofdstuk 9 worden de direct postoperatieve en de I-jaarsresultaten van deze techniek gepresenteerd. Tussen maart $201 \mathrm{I}$ en september $20{ }_{4}$ hebben negentien HFA patiënten met een BB-AVF of BC-AVF in drie verschillende ziekenhuizen een RUDI ondergaan. Vijftien hiervan hebben een bypass vanaf de a. radialis met een stuk vena saphena magna (VSM) gekregen, en vier een bypass van een stukje vena basilica (VB). Gemiddeld blijkt de access flow van $3080 \mathrm{ml} / \mathrm{min}$ naar II70 $\pm 160 \mathrm{ml} / \mathrm{min}$ gedaald. Een VSM bypass heeft de voorkeur vergeleken met een VB bypass (postoperatieve access flow $990 \mathrm{ml} / \mathrm{min}$ versus $\mathrm{I} 790 \mathrm{ml}$ / min, respectievelijk). Drie patiënten (I6\%) hadden binnen één jaar opnieuw een HFA waarvan twee patiënten een bypass met een VB. Op dit moment verdient de RUDI techniek met een VSM interponaat de voorkeur in de behandeling van HFA. 



\section{Dankwoord}

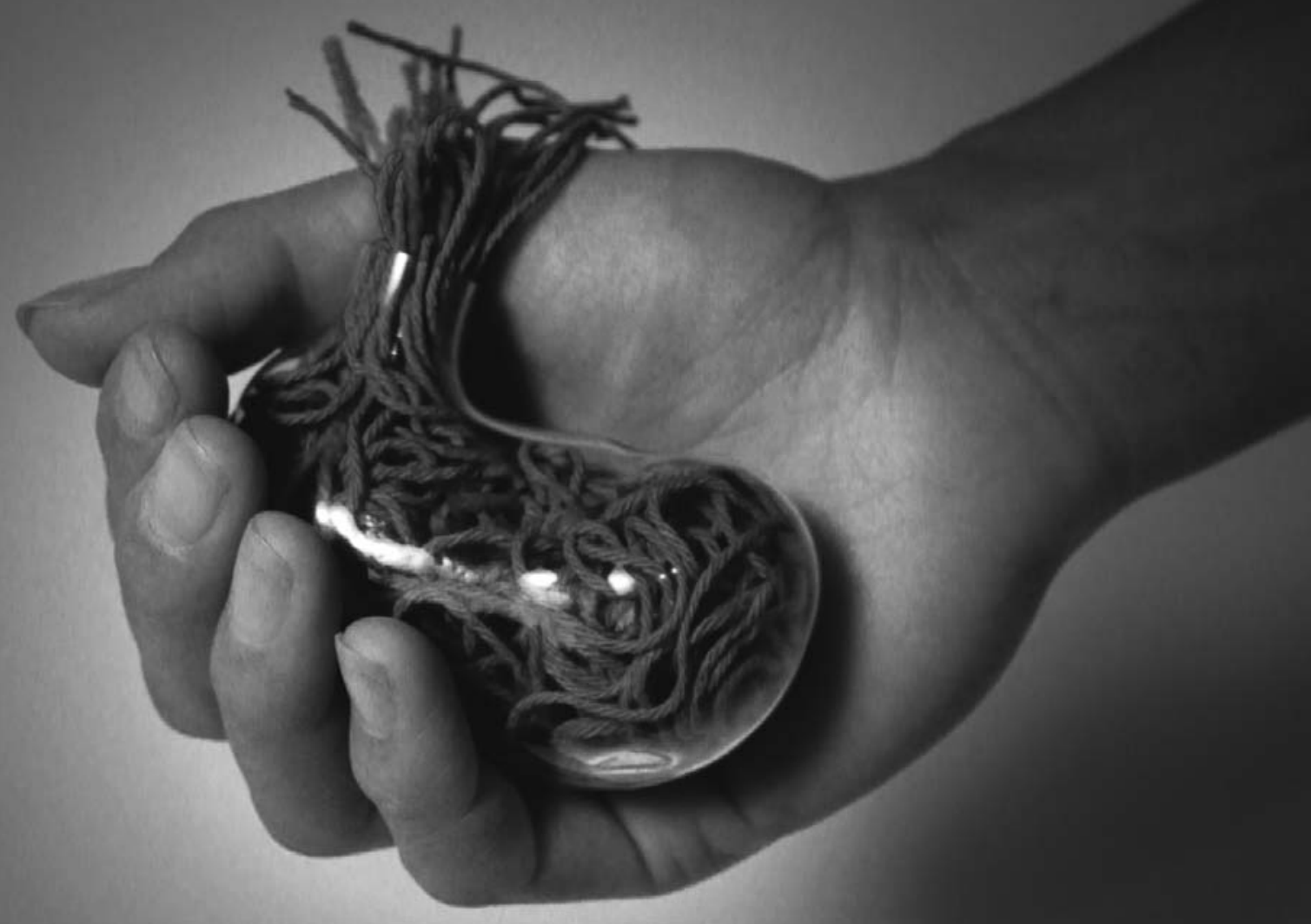


Met de eindstreep in zicht tot slot een woord van dank aan eenieder die op welke manier dan ook heeft bijgedragen aan dit prachtwerk.

In het bijzonder ben ik de haemodialyse patiënten van de verschillende ziekenhuizen die belangeloos hebben deelgenomen aan mijn onderzoek veel dank verschuldigd.

Prof J. Teijink, beste Joep.

Een jaar geleden pas bij ons team aangesloten als promotor maar je kwam op het perfecte moment. Je hulp heeft een enorme boost gegeven aan het voltooien van dit proefschrift. Ik heb je in deze korte periode leren kennen als begenadigd onderzoeker en energiek man. Razendsnelle revisies van artikelen en je weet als geen ander hoe je onderzoek weg moet zetten. Ik ben je dankbaar voor je hulp in deze eindfase.

Dr Scheltinga, beste Marc.

Trots op je kindjes, je promovendi. Vol passie over je onderzoekslijnen. Enorm enthousiast wanneer je positieve aandacht krijgt vanuit binnen en buitenland voor je onderzoek. Samen met Rudi richtte je de Solvimax poli op en creëerden daarmee's werelds grootste chirurgische kliniek voor buikwand- en liespijn. Daarnaast bezit je de grootste onderzoekspopulatie chronische compartimentsyndroom binnen Nederland met nu zelfs drie aanstaande promovendi. Het feit dat dit nou niet de meest sexy onderwerpen binnen de chirurgie zijn deert je helemaal niets. Want waar jou het uiteindelijk om te doen is, is mensen beter maken en goed wetenschappelijk onderzoek verrichten. Je motto 'science races on and waits for no one' zet je kracht bij door altijd in een furieus tempo artikelen te lezen en reviseren. Je bent de drijvende kracht achter mijn promotie geweest en ik ben je enorm dankbaar voor deze kans die je mij gegeven hebt. Dank voor je steun tijdens mijn opleiding, voor je interesse in mijn gezin en je oog voor belangrijke zaken buiten het werk. Met veel plezier kijk ik uit naar mijn vaatdifferentiatie in het Máxima waarbij we onze gezamenlijke wetenschappelijke interesse zeker zullen voortzetten.

Dr Tordoir, beste Jan.

Toen Marc en ik dit promotietraject startten, was er één ding duidelijk. Tordoir moest en zou co-promotor zijn en dus zaten we gezamenlijk op jouw werkkamer een plan te smeden. Je bent een buitengewoon kundig vaatchirurg, een grootheid als het om dialyse chirurgie gaat en een zeer sterk wetenschapper. Je revisies van artikelen waren kort en krachtig maar altijd spot-on. Met soms een (terechte) kritische nood behoedde je mij van teveel tunnelvisie in discussies. Ik ben bevoorrecht dat ik nog een jaar de tijd heb om me bij jou in Maastricht de fijne kneepjes van het vak eigen te maken. 
Leden van de beoordelingscommissie, prof Kooman, prof de Haan, prof Zeebregts , dr Rotmans. Dank voor het lezen en beoordelen van mijn manuscript.

Maatschap chirurgie MMC.

Hartelijk dank voor jullie steun tijdens mijn opleiding en voor jullie interesse in mijn onderzoek. Goed om te zien dat wetenschap door de maatschap zo ondersteund wordt.

Verpleegkundigen dialyse MMC.

Wat een heerlijk relaxte maar professionele groep verpleegkundigen zijn jullie. Typerend voor het MMC. Nooit een probleem om extra vragenlijsten af te nemen, afspraken te maken of nog meer 'access flow'-metingen te doen. Ik ben jullie veel dank verschuldigd voor jullie hulp.

Dames en heer van het vaatlab.

Veel van mijn onderzoeken vallen en staan bij gedegen Duplex- en vingerdrukmetingen. Daarvoor ben ik bij jullie aan het juiste adres. Dank voor alle metingen en dank voor het meedenken bij het opstellen van nieuwe (onderzoek)protocollen.

\section{Collega ANIOS en AIOS MMC en MUMC.}

Beste collega's dank voor een mooie opleidingstijd. Dank voor jullie interesse in mijn onderzoek en voor jullie hulp bij het overnemen van taken tijdens de afrondende fase van mijn proefschrift.

Victor, Thomas, Thijn; a.k.a. de bruno's.

Al vroeg in jaar I van geneeskunde troffen we elkaar en werden we een hechte club. Alhoewel we ondertussen allemaal ons eigen gezin gesticht hebben en ieders opleiding ook zijn tijd vergt ben ik blij dat ons contact nog altijd goed is en met name ongedwongen. Ik koester mooie herinneringen uit onze vriendschap die ik maar al te graag met jullie ophaal.

Victor, mijn Maastrichtse stapmaat van het eerste uur die mijn kleptomane dronk stimuleerde met een kratje bier. Grotendeels onze hele studietijd hebben wij vertoefd in jouw appartement, pokeren, feesten, mini-snacks en saté met friet voor elke stapavond. Echte Maastrichtse gastvrijheid. Mooi dat wij samen chirurgisch Maastricht onveilig mogen maken nu we directe collega's zijn. Thomas, Maastrichtenaar met Hongaarse roots, kern voor je multilingualiteit. Nederlands, Spaans, Maastrichts, Brabants, je kan het allemaal. Je Mercedes heeft ons de hele studietijd en daarna bijgestaan in onze avonturen. Mannenweekend in Kalkar, skiën in Oostenrijk, door de drive-thru omdat koken te veel werk is of naar Coldplay in Nijmegen. Als eerste Bruno trotseerde jij de corona en dat deed je met verve, zoiets geeft mij als opvolger moed. 
Thijn, goedlachse ras-Brabander met een VonDutch pet en een ketchup dispenser in de koelkast. Zo leerde ik je kennen. Nooit heb je getwijfeld aan je ambitie om orthopeed te worden en in die weg daar naartoe koos je, heel kenmerkend, geheel je eigen weg, wat ik altijd enorm in je heb gewaardeerd. Deze keuze legt jou geen windeieren en zowel je snijdend als wetenschappelijk talent is niet onopgemerkt gebleven.

Paranimfen.

Mathieu, tijdens onze coschappen startte onze vriendschap maar in jaar 6 werden we pas echte maatjes en haakte je als 5 e Bruno aan. Menig uur verbeterden we onze skills met gamen soms tot frustratie van onze wederhelft. Samen discussiëren over vrouwen, relaties en het leven. Je hielp me door mindere tijden en was mijn vaste 'wingman' in onze beste tijden. Ik ben trots dat je nu nogmaals als mijn wingman wil fungeren.

Mark, als oudste broer ben je altijd een voorbeeld voor mij geweest en alhoewel we totaal verschillend zijn, is gedrevenheid en ambitie ons raakvlak. Met interesse volg ik je werk aan's werelds beste metaal $3 \mathrm{D}$ printer voor industrieel gebruik. Dank voor je hulp bij alle acute (klus) technische problemen en dank dat je altijd voor mij klaarstaat. Jarenlang ben je mijn aanvoerder bij heren I geweest en ik ben verheugd en trots dat jij ditmaal achter mij staat.

Guido, Patrick, Selma en Dominic.

Wat een heerlijke jeugd hebben we gehad. Met veel plezier denk ik aan onze potjes hockey achter het huis. Altijd tot en over het randje van het toelaatbare. Meestal was ik het want jullie hadden meer talent om dat niet nodig te hebben. Nog altijd is het goed om te zien dat eenieder van ons altijd bereid is om de ander te helpen wanneer dat nodig is.

Guido en Patrick onze jaren in heren I samen met Mark waren geweldig. Met trots volg ik jullie (hockey)carrière nu wat meer op afstand maar het afronden van mijn promotie biedt kansen om elkaar vaker te zien.

Selma, enige meisje tussen 5 jongens. Iedereen die je niet kent vindt je zielig maar dat ben je allesbehalve. Talentvol, gedreven en enorm gedisciplineerd. Ik ben blij dat je ook arts wordt want dan zal je de eerste zijn in de familie Vaes die echt begrijpt waarom ons vak zo mooi is.

Dominic, de jongste Vaes telg. Wat ben je toch een fijne vent en wat is het mooi om jou je eigen weg in het leven te zien gaan! Je bent absoluut niet verstoken van talent maar nu nog het maximale eruit halen. Ik kom gauw weer eens naar een wedstrijd van je kijken. 
Yori, Nadine en Pascalle.

De een al wat langer onderdeel van de familie Vaes dan de ander maar desalniettemin allen zeer dierbaar voor mij, Tirza en de kids. Dank voor jullie interesse in mijn onderzoek en dank dat jullie altijd bereid zijn om ons gezin te helpen.

Christa en Hans.

Ik ben jullie enorm dankbaar dat jullie altijd voor ons gezin klaarstaan. Wat een geluk en voorecht, want zonder jullie zou ons leven nooit zo geordend verlopen als we zouden willen. Julian en Rogier kunnen zich geen liefdevollere grootouders wensen.

Mama en Papa.

'Meten is weten' en 'leren is repeteren'. Verschrikkelijk irritante dooddoeners die jullie mij gedurende mijn middelbare schooljaren regelmatig ingepeperd hebben. Ondertussen moet ik constateren dat deze twee opmerkingen nog dagelijks voor mij van toepassing zijn als wetenschapper en aanstaand chirurg en dat zal waarschijnlijk ook nooit meer veranderen. Uiteindelijk hebben jullie dus een goede vooruitziende blik gehad, of in andere woorden, een juiste opvoedstrategie. En daarvoor ben ik jullie zeer dankbaar. Ik ben jullie dankbaar voor alle liefde en aandacht die jullie mij hebben gegeven ook al moet dat soms lastig zijn geweest met zo'n groot gezin. Alhoewel jullie geen geneeskundige achtergrond hebben, zijn jullie altijd geïnteresseerd geweest in mijn werk en toekomstplannen maar ook kritisch wanneer het tempo uit mijn onderzoek dreigde te raken. Mama en papa dank dat jullie altijd voor ons klaarstaan.

Julian en Rogier

Wat zijn jullie toch heerlijke mannetjes. Nu nog zo klein maar al snel zo groot. Ik ben blij dat deze promotie op zijn einde loopt en ik meer tijd voor jullie vrij kan maken.

\section{Lieve Tirza.}

Vlak voordat ik 5,5 jaar geleden uit Maastricht zou vertrekken, leerde ik je kennen en ik prijs me daar nog iedere dag gelukkig mee. Je vrolijkheid en optimisme zijn aanstekelijk. Ik bewonder je om je zorgzaamheid en enorme liefde voor eenieder die je dierbaar is. Je bent een sterkere vrouw dan jij soms doet geloven en ik ben me er dan ook van bewust dat jij uiteindelijk de stille kracht achter deze promotie bent. Zonder jou had ik dit nooit gekund en niemand verdient dan ook meer lof! Dank je voor je zorgzaamheid, liefde en interesse. Dank je dat we zo'n prachtig gezin hebben en dat het leven samen zo heerlijk is. Ik houd van je! 



\section{Curriculum Vitae}

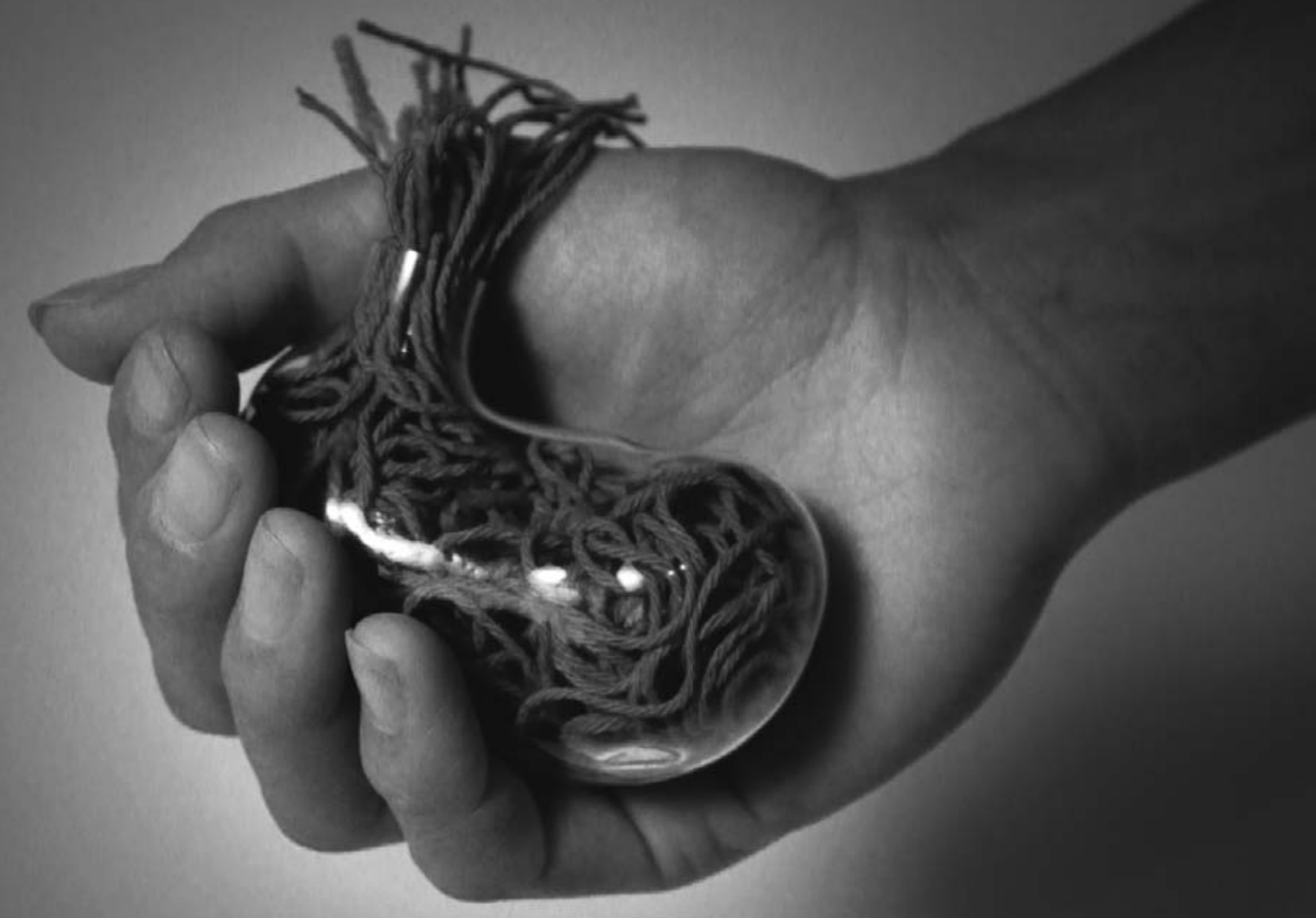


Roel Vaes is geboren op 4 juli 1986 te Nijmegen. Hij behaalde zijn VWO diploma aan het Bouwens van der Boije College te Panningen in 2004 waarna werd gestart met Geneeskunde aan de Universiteit te Maastricht. In het vierde studiejaar werd zijn keuze-co-schap doorgebracht op de afdeling chirurgie in Maxima Medisch Centrum (MMC) te Veldhoven waardoor zijn interesse voor de chirurgie bevestigd werd. Zowel het klinische als wetenschappelijke deel van zijn semiartsstage liep hij op de Intensive Care van Mastrichts Universitair Medisch Centrum (MUMC+). Direct na zijn afstuderen in 2010 begon Roel als arts niet-in-opleiding-tot-specialist (ANIOS) in MMC en werd de basis gelegd voor dit proefschrift onder leiding van eerste co-promotor dr. Marc Scheltinga. Roel is in 2013 begonnen met zijn specialisatie tot chirurg, het eerste en tweede jaar van zijn opleiding heeft hij gevolgd in het MMC. Momenteel is hij werkzaam in het MUMC+ waar hij onder meer de fijne kneepjes op dialysegebied onderwezen krijgt van zijn tweede co-promotor dr.Jan Tordoir. Vanaf januari 2oI7 zal hij terugkeren naar MMC en starten met zijn laatste twee differentiatiejaren tot vaatchirurg.

Roel woont samen met Tirza Wagenvoort in Eindhoven. Samen hebben ze twee zoons, Julian (2013) en Rogier (2015).

Roel Vaes was born on July, 4th 1986 in Nijmegen, the Netherlands. He graduated from high school (Bouwens van der Boije College in Panningen) and started medical school of the University of Maastricht in 2004. In his fourth study year he fullfilled an extra-curricular surgical internship in Maxima Medial Center (MMC) in Veldhoven, after which his special interest in surgery was confirmed. An additional clinical and scientific internship was followed at the Intensive Care department of the Maastricht University Medical Center (MUMC+). In 2oro he obtained his MD degree and started working as a resident-not-in-training (ANIOS) at the department of surgery in MMC. At that point he he initiated studies on hand ischaemia and high flow in haemodialysis patients under supervision of dr. Marc Scheltinga, vascular surgeon. Roel started his surgical residency on January Ist 20I3 in MMC for the first two years of his training. At present, his third and fourth residential years are completed at the MUMC+. From January 2017 on, he will finish his two years of specialization in vascular surgery in MMC.

Roel lives together with Tirza Wagenvoort in Eindhoven. They have two sons, Julian (2013) and Rogier (2015).

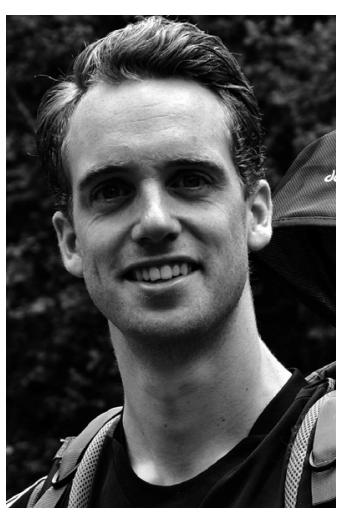

